UNIVERSIDADE DE SÃO PAULO

INSTITUTO DE GEOCIÊNCIAS

\title{
REAVALIAÇÃO GEOESTATÍSTICA DOS RECURSOS/RESERVAS DE FOSFATO DA MINA DE CAJATI, SP
}

\author{
GEORGE DE BARROS
}

Orientador: Dr. Jorge Kazuo Yamamoto

\author{
DISSERTAÇÃO DE MESTRADO
}

COMISSÃO JULGADORA

Nome

Presidente: Prof. Dr. Jorge Kazuo Yamamoto

Examinadores: Prof ${ }^{\mathrm{a} \cdot} \mathrm{Dr}^{\mathrm{a} \cdot}$ Lília Mascarenhas Sant'Agostino

Prof. Dr. Paulo Milton Barbosa Landim
Assinatura

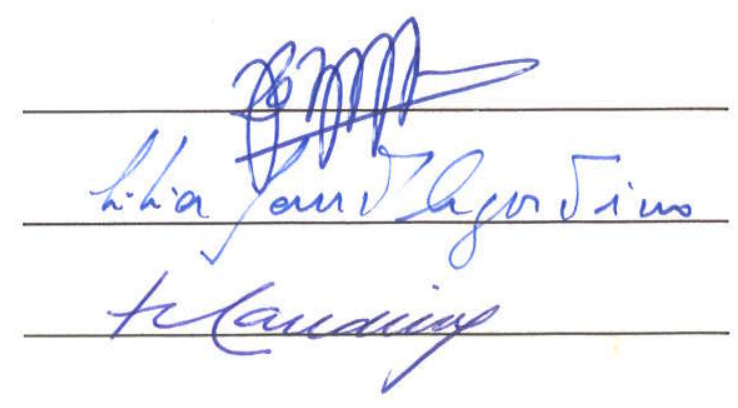

SÃO PAULO

2001 


\section{UNIVERSIDADE DE SÃO PAULO INSTITUTO DE GEOCIÊNCIAS}

\section{REAVALIAÇÃO GEOESTATÍSTICA DAS RESERVAS DE FOSFATO DA MINA DE CAJATI, SP}

George de Barros



Orientador: Prof. Dr. Jorge Kazuo Yamamoto

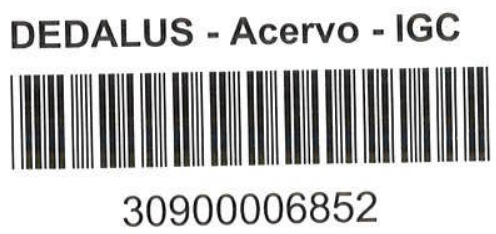

DISSERTAÇÃO DE MESTRADO

Programa de Pós-Graduação em Recursos Minerais e Hidrogeologia

SÃO PAULO

2001 
À Lúcia, Marcelo e Geraldo (in memorian), minha familia 
O Ontem é história,

o Amanhã ainda não existe, só temos o Hoje.

Vamos persistir somente Hoje, esquecer o Ontem que já morreu e o Amanhã que ainda não nasceu... 


\section{AGRADECIMENTOS}

Inúmeras foram as pessoas que contribuiram para esta dissertação. Deste modo, seguem os agradecimentos.

Em primeiro lugar ao Prof. Dr. Jorge Kazuo Yamamoto, pela sua orientação, além da segurança e paciência demonstrada durante toda a realização deste trabalho.

À FAPESP, Fundação de Amparo à Pesquisa do Estado de São Paulo (Processo 98/14202-2) pelo apoio financeiro.

À Bunge Fertilizantes S.A., pelo apoio oferecido durante todo o periodo desta pesquisa, e principalmente ao engenheiro Paulo Luz e à geóloga Paula Alves, sempre dispostos em ajudar no que se fizesse necessário.

Aos Profs. Drs. Jorge Silva Bettencourt e Lilia Mascarenhas Sant'Agostino, do Instituto de Geociências. Sem dúvida, o conhecimento de ambos sobre geologia e mineração, em especial sobre a Mina de Cajati, foi muito importante para este trabalho. Sou muito grato a ambos, além de muito admirá-los.

À geóloga, mestranda e amiga Márcia Mika Saito, pelo companheirismo, amizade e discussões (muitas vezes discussões mesmo!) a respeito de geologia, mineração, informática, assuntos acadêmicos, entre outros. Seus comentários sempre foram levados em consideração, mesmo quando não pertinentes.

Ao geólogo e amigo, Sergio Luis Fabris de Matos pelos comentários sempre construtivos sobre geologia e geoestatística. Sua amizade foi, e continua sendo, muito importante, estando sempre disposto a tentar solucionar alguns "probleminhas" enfrentados por mim, sejam eles de aspecto acadêmico ou automobilístico.

Ao geólogo e doutorando Marcelo Monteiro da Rocha, pela ajuda e iniciação na área de geoestatística. Seus conhecimentos nesta área e a sua disposição em sempre querer ajudar não podem ser esquecidos. Obrigado Marcelo!

Às minhas amigas do coração, Priscilla Antunes de Godoy, Cristiane Lorena Rodrigues e Silvia Cremonez do Nascimento, pelos grandes momentos que passamos juntos. Embora muitas vezes os assuntos discutidos não estavam relacionados à geologia, serviram para relaxar e deixar de lado os momentos difíceis do trabalho.

Aos meus colegas de graduação e de pós, a quem posso chamar de amigos, Alexandre Carnier (Thobias), Cláudia Nogueira (Mokoka), Guilherme Gualda (Kami), Ivo Trosdtorf Junior, Luciano Gobbo, Lucelene Martins (Wau), Rosely Teruiya e Valéria Guimarães. Todos eles foram e são muito importantes na minha vida. Valeu galera!!

Aos colegas da sala 106, ou que já passaram por ela, Erickson Zanon, Itamar (Lafon), Marcelo Ferreira Pedro (Lambidah), Sérgio Nobuo (Chicão), Sidney, e os geólogos e mestres Carlos César de Araújo e Sérgio Vicente Liotte. Todos eles se mostraram ótimos companheiros.

Aos demais colegas de pós-graduação, que são tantos: Gaston (Edir), Cláudio Genthner, Alexandre Tomio (Xokito), Leandro Donatti, Cláudia Varnier, Silvia Maria, Geani (Manah), e demais companheiros de luta na vida acadêmica. Agradeço por tudo!

À todos os professores, alunos e funcionários do Instituto de Geociências, que de alguma forma, me auxiliaram nesta jornada.

À minha mãe Lúcia e meu irmão Marcelo, que sempre me apoiaram, mesmo nos momentos de ausência. Tomara que eu consiga mostrar que valeu a pena!

Finalizando, não poderia deixar de destacar uma pessoa que se tornou muito importante na minha vida, e que sempre me recebia com um sorriso lindo ao final de um dia de trabalho! Para ela, só resta uma frase: Anisia eu te amo!! 


\section{RESUMO}

Este trabalho apresenta os resultados da avaliação geoestatística dos recursos/reservas minerais da Mina de Cajati, localizada no Sudoeste do Estado de São Paulo.

O corpo de minério, inserido no Complexo Ultramáfico Carbonatítico de Jacupiranga, constitui-se de rocha carbonatítica, sendo a apatita o principal mineral de minério.

A lavra iniciou-se nos anos 40 , inicialmente em rocha alterada pela empresa Bunge Fertilizantes S. A. (anteriormente Serrana de Mineração S. A.). Com a exaustão do minério residual, iniciou-se a lavra na rocha fresca, com conseqüentes de alterações dos processos tecnológicos de beneficiamento. O material atualmente lavrado é utilizado para a produção de fertilizantes para a agricultura, bem como o rejeito carbonático para a fabricação de cimento. Deste modo são obtidos dados analíticos de $\mathrm{P}_{2} \mathrm{O}_{5}$ e $\mathrm{MgO}$ no acompanhamento da lavra.

A construção de histogramas de distribuiçăo de freqüência para esta última variável revelou a presença de três populações geograficamente delimitáveis, denominadas Área Sul, Área Central e Área Norte, as quais foram estudadas separadamente. Estas populações foram associadas ao trabalho de Gaspar (1989), onde o referido autor concluiu que o corpo de carbonatito resultou de cinco eventos intrusivos, cada qual com características químicas e mineralógicas distintas. Com a análise das Áreas Central e Norte, verificou-se que estas áreas também apresentaram mais de uma população, indo ao encontro com as conclusões do trabalho de Gaspar (1989).

Este estudo mostra a importância das informações geológicas prévias sobre o depósito como um auxílio para a análise geoestatística, etapa chave no processo de quantificação de recursos/reservas. As duas variáveis apresentaram uma maior continuidade espacial na direção da intrusão. Além disso, a presença de zonas de xenólitos e zonas de reação do minério com a sua encaixante foram detectadas na alta variabilidade dos semivariogramas obtidos para as áreas onde ocorrem estas estruturas. 


\section{ABSTRACT}

This paper presents the results of a geostatistical evaluation of the mineral resources at Cajati Mine in the southwestern part of the state of São Paulo. The ore body is inserted into the Jacupiranga ultramafic carbonatite complex and apatite is the major ore mineral. Only weathered carbonatite was exploited in the past, but as it has exhausted, the Bunge Fertilizantes S. A. started to mine the fresh rock. The existence of small ore bodies in the region has always been known but they had never been studied in detail. The study of these ore bodies became necessary with the advance of mining and the increase of mining ratio.

As the ore is used to produce agriculture fertilizer, the two key variables are $\mathrm{P}_{2} \mathrm{O}_{5}$ and $\mathrm{MgO}$. The histogram for $\mathrm{MgO}$ revealed the presence of three geographically distinct sub-populations, which were studied separately. The statistical analysis also showed that the correlation between the two variables was very low so they were studied separately. Then the semivariograms were computed and modeled for the variables discussed above. Ordinary kriging was used to estimate the grades of both variables in mining blocks of $25 \mathrm{~m} \times 25 \mathrm{~m} \times 10 \mathrm{~m}$ and a three-dimensional model of the ore body was constructed. Re-evaluation of the mineral resources of Cajati Mine has been very important for planning mining activities for future years. It made possible to study the technical and economic feasibility of the new mine and to determine the annual production, the mineral dressing methods, financial investments, etc.

Finally, this research shows the importance of the geological information aiding the geostatistical analysis, which is the key stage for the process of mineral resources evaluation. In this sense, semivariograms computed along vertical direction presented greater spatial continuity than horizontal direction, confirming the geological model of the deposit, i. e., an intrusive body. Besides, the semivariograms also showed higher variability in areas where xenoliths and reaction zones occur. 


\section{SUMÁRIO}

CAPITULO 1 - INTRODUÇÃO E OBJETIVOS

1.1 - Introdução

1.2 - Objetivos

CAPITULO 2 - A MINA DE CAJATI

2.1 - Localização e Acessos

2.2 - Geologia Regional

2.3 - Geologia Local

2.4 - Histórico da Mina de Cajati

\section{CAPÍTULO 3 - MATERIAIS E MÉTODOS}

3.1 - Desenvolvimento do Trabalho

3.2 - Banco de Dados

\section{CAPÍTULO 4 ANÁLISE ESTATÍSTICA}

4.1 - Distribuição de Freqüências

4.2 - Estatística Descritiva

4.2.1 - Média ou Esperança Matemática $\quad 27$

4.2.2 - Variância

4.2.3 - Coeficiente da Variação 29

4.2.4 - Assimetria 30

4.2 .5 - Curtose 30

4.3 - Teste de Correlação 30

CAPITULO 5 - ANÁLISE GEOESTATÍSTICA

5.1 - Variáveis Regionalizadas 34

$\begin{array}{ll}5.2 \text { - Semivariograma } & 37\end{array}$

5.2.1 - Modelos Teóricos de Semivariogramas $\quad 42$

5.3 - Estimativas por Krigagem Ordinária 43

5.3.1 - Definição da vizinhança $\quad 45$

5.3.2 - Krigagem 46

5.3.2.1 - Variância de Interpolação

CAPITULO 6 - MODELAGEM TRIDIMENSIONAL DIGITAL 60

CAPÍTULO 7 - RESULTADOS OBTIDOS E DISCUSSÕES 66

7.1 - Análise Estatistica $\quad 66$

7.2 - Análise Geoestatistica $\quad 73$

7.3 - Estimativa de Teores por Krigagem Ordinária 82

7.4 - Cálculo dos Recursos/Reservas 93

7.5 - Modelagem Tridimensional do Corpo de Minério 95

CAPÍTULO 8 - CONSIDERAÇÕES FINAIS 100

REFERÊNCIAS BIBLIOGRÁFICAS 104 


\section{LISTA DE FIGURAS}

Figura 2.1 - Mapa de localização da área

Figura 2.2 - Mapa geológico do Complexo Alcalino de Jacupiranga (modificado de Germann et al. 1987)

Figura 2.3 - Comparação das ocorrências de corpos de carbonatitos no mundo (conforme Melcher, 1966)

Figura 2.4 - Mapa geológico da Mina de Cajati, modificado de Gaspar (1989) - Jac = jacupiranguito; $\mathrm{C} 1$ a $\mathrm{C} 5=$ intrusões carbonatíticas

Figura 2.5 - Visão panorâmica da cava da Mina de Cajati e do Complexo Industrial da Bunge Fertilizantes

Figura 2.6 -Visão sul da atual cava da Mina de Cajati

Figura 2.7 - Visão norte da atual cava da Mina de Cajati

Figura 2.5 - Processamento do minério da Mina de Cajati - Britagem e Homogeneização

Figura 2.6 - Processamento do minério da Mina de Cajati - Moagem e Condicionamento

Figura 2.7 - Processamento do minério da Mina de Cajati - Flotação e Produto Final

Figura 3.1 - Esquema da regularização dos teores de furos de sonda - A) Furo vertical; B) Furo Inclinado

Figura 3.2 - Gráficos mostrando a correlação entre os valores amostrais $(Z)$ e os valores estimados $\left(Z^{*}\right)$ onde o erro médio é igual a zero em $(A)$ e diferente de zero em (B), caracterizando, neste caso, o chamado efeito de suavização, segundo Olea \& Pawlowsky (1996)

Figura 3.3 --Variação dos comprimentos das amostras presentes no banco de dados

Figura 3.4 - Disposição dos furos de sonda na cava da Mina de Cajati

Figura 4.1 - Tipos de distribuição de freqüências: Distribuição normal ou gaussiana; Distribuição lognormal.

Figura 4.2 - Curvas de distribuição lognormal com $\alpha$ e $C$ iguais a zero e três valores de $\beta^{2}$, segundo Aitchison \& Brown (1957, apud Koch \& Link, 1971)

Figura 4.3 - Curva de freqüência acumulada destacando a mediana da distribuição

Figura 4.4 - Histograma destacando a moda, correspondendo ao ponto médio da classe de maior freqüência

Figura 4.5 - Curva de distribuição $t$ de Student $(n>30)$ com duas áreas criticas (cinza) limitando $5 \%$ da área sobre a curva, para o caso de testes de duas caudas. 
Figura 5.1 - Variância espacial em função dos intervalos de amostragem para as séries $\mathrm{A} e$ $\mathrm{B}$

Figura 5.2 - Desenho mostrando a direção do semivariograma, os passos, a tolerância angular, a largura máxima e a tolerância do passo (modificado de Pannatier, 1994 apud Yamamoto \& Rocha, 2000)

Figura 5.3-Semivariograma típico e seus elementos

Figura 5.4 - Tipos de anisotropias

Figura 5.5 - Comportamento do semivariograma na origem (segundo Bubenicek \& Haas, 1969

Figura 5.6 - Principais modelos de semivariogramas teóricos segundo Rocha (1999)

Figura 5.7 - Influência da dimensão de blocos de krigagem menores que a metade da malha de amostragem

Figura 5.8 - Critério de seleção de amostras por quadrante, com a escolha de duas amostras por setor

Figura 6.1 - Orientação de seções paralelas a partir da disposição de uma malha de furos de sondagem

Figura 6.2 - Seções geológicas interpretadas

Figura 6.3-Modelagem tridimensional utilizando o método das fatias seriais (modificado de Sameshima, 1995)

Figura 6.4 - Modelagem tridimensional utilizando o método das fatias interligadas (modificado de Sameshima, 1995)

Figura 6.5 - A) e B) Tipos de triangularização utilizando uma mesma malha de pontos; C) Triangularização da malha de pontos utilizando o Algoritmo de Delaunay (modificado de Popoff, 1966)

Figura 6.6 - Modelo triangularizado de uma unidade geológica

Figura 6.7 - Modelo geológico renderizado

Figura 7.1 - Histograma de distribuição de freqüencia e estatísticas das variáveis $P_{2} O_{5}(A)$ e $\mathrm{MgO}(\mathrm{B})$ dos dados não regularizados

Figura 7.2 - Histograma de distribuição de freqüenncia e estatísticas das variáveis $\mathrm{P}_{2} \mathrm{O}_{5}(A)$ e $\mathrm{MgO}(\mathrm{B})$ dos dados após a regularização

Figura 7.3 - Diagrama de dispersão entre as variáveis $\mathrm{P}_{2} \mathrm{O}_{5}$ e $\mathrm{MgO}$

Figura 7.4 - Curva de freqüência acumulada em escala logaritmica da variável MgO indicando três populações

Figura 7.5 - Mapa de localização das 3 populações observáveis no conjunto de dados

Figura 7.6 - Histograma de distribuição de freqüência e estatísticas das variáveis $\mathrm{P}_{2} \mathrm{O}_{5}(A)$ e MgO (B) da Área Sul 
Figura 7.7 - Histograma de distribuição de freqüência e estatísticas das variáveis $\mathrm{P}_{2} \mathrm{O}_{5}(A)$ e $\mathrm{MgO}(\mathrm{B})$ da Área Central

Figura 7.8 - Histograma de distribuiçäo de freqüencia e estatísticas das variáveis $\mathrm{P}_{2} \mathrm{O}_{5}(\mathrm{~A})$ e MgO (B) Área Norte

Figura 7.9 - Diagrama de dispersão entre as variáveis $\mathrm{P}_{2} \mathrm{O}_{5}$ e MgO (Área Sul)

Figura 7.10 - Diagrama de dispersão entre as variáveis $\mathrm{P}_{2} \mathrm{O}_{5}$ e $\mathrm{MgO}$ (Área Central)

Figura 7.11 - Diagrama de dispersão entre as variáveis $\mathrm{P}_{2} \mathrm{O}_{5}$ e $\mathrm{MgO}$ (Área Norte)

Figura 7.12 - Semivariograma experimental da variável $\mathrm{P}_{2} \mathrm{O}_{5}$ e seu respectivo modelo teórico ajustado (Área Sul)

Figura 7.13 - Semivariograma experimental da variável MgO e seu respectivo modelo teórico ajustado (Área Sul)

Figura 7.14 - Semivariograma experimental da variável $\mathrm{P}_{2} \mathrm{O}_{5}$ e seu respectivo modelo teórico ajustado (Área Central)

Figura 7.15-Semivariograma experimental da variável MgO e seu respectivo modelo teórico ajustado (Área Central)

Figura 7.16 - Semivariograma experimental da variável $\mathrm{P}_{2} \mathrm{O}_{5}$ e seu respectivo modelo teórico ajustado (Área Norte)

Figura 7.17 - Semivariograma experimental da variável MgO e seu respectivo modelo teórico ajustado (Area Norte)

Figura 7.18 - Diagrama de Dispersão para a variável $\mathrm{P}_{2} \mathrm{O}_{5}$ (Área Sul), obtido a partir da validação cruzada

Figura 7.19 - Diagrama de Dispersão para a variável Mgo (Área Sul), obtido a partir da validação cruzada

Figura 7.20 - Diagrama de Dispersão para a variável $\mathrm{P}_{2} \mathrm{O}_{5}$ (Área Central), obtido a partir da validação cruzada

Figura 7.21 - Diagrama de Dispersão para a variável Mgo (Área Central), obtido a partir da validação cruzada

Figura 7.22 - Diagrama de Dispersão para a variável $\mathrm{P}_{2} \mathrm{O}_{5}$ (Área Norte), obtido a partir da validação cruzada

Figura 7.23 - Diagrama de Dispersão para a variável MgO (Área Norte), obtido a partir da validação cruzada

Figura 7.24 - Modelos de blocos krigados para a variável P2O5 (Área Sul)

Figura 7.25 - Modelos de blocos krigados para a variável MgO (Área Sul)

Figura 7.26 - Modelos de blocos krigados para a variável P2O5 (Área Central)

Figura 7.27 - Modelos de blocos krigados para a variável MgO (Área Central) 
Figura 7.29 - Modelos de blocos krigados para a variável MgO (Área Norte)

Figura 7.30 - Teores estimados para a Área Sul - Nivel -40

Figura 7.31 - Teores estimados para a Area Central - Nivel +80

Figura 7.32 - Teores estimados para a Área Norte - Nivel +10

Figura 7.33 - Mapa do desvio de interpolação para a estimativa da Área Sul (Nível -40) A) $\mathrm{P} 2 \mathrm{O} 5-\mathrm{B}) \mathrm{MgO}$

Figura 7.34 - Mapa do desvio de interpolação para a estimativa da Área Central (Nivel + 80) A) $\mathrm{P} 2 \mathrm{O} 5$ - B) $\mathrm{MgO}$

Figura 7.35 - Mapa do desvio de interpolação para a estimativa da Área Norte (Nivel +10) A) $\mathrm{P} 2 \mathrm{O} 5-\mathrm{B}) \mathrm{MgO}$

Figura 7.36 - Diagrama de dispersão entre o teor estimado e o desvio de interpolação (MgO da Área Sul)

Figura 7.37 - Diagrama de dispersão entre o teor estimado e o desvio de interpolação (MgO da Área Central)

Figura 7.38 - Diagrama de dispersão entre o teor estimado e o desvio de interpolação (MgO da Área Norte)

Figura 7.39 - Modelo tridimensional do corpo carbonatítico visto em planta, juntamente com a topografia

Figura 7.40 - Modelo tridimensional do corpo carbonatítico com vista para o flanco oeste 96

Figura 7.41-Modelo tridimensional do corpo carbonatítico com vista para o flanco oeste

Figura 7.42 - Modelo tridimensional do corpo carbonatitico com vista para o flanco leste

Figura 7.43 - Modelo tridimensional do corpo carbonatítico, sem a topografia 


\section{LISTA DE TABELAS}

Tabela 2.1 - Mineralogia do Carbonatito da Mina de Cajati (Pereira \& Marguti, 1988 apud Alves, 1999)

Tabela 2.2 - Petrografia e mineralogia das intrusões carbonatíticas que compõem a Mina de Cajati (de acordo com Gaspar \& Wyllie, 1983)

Tabela 3.1 - Tipos Litológicos Adotados na Lavra da Mina de Cajati

Tabela 5.1 - Variância espacial para as duas seqüencias de números

Tabela 7.1 - Parâmetros dos modelos teóricos de semivariogramas

Tabela 7.2 - Resultado da validação cruzada para cada uma das variáveis

Tabela 7.3 - Quadro resumo da avaliação dos recursos minerais da Mina de Cajati

Tabela 7.4 - Quadro resumo da avaliação dos recursos de $\mathrm{P}_{2} \mathrm{O}_{5}$ considerando os blocos com teores acima de $3 \%$ 


\section{CAPÍTULO 1 \\ INTRODUÇÃO E OBJETIVOS}

\section{1 - Introdução}

Para uma avaliação adequada de recursos/reservas, deve-se considerar não somente dados de teor em sua forma bruta, mas sim de maneira integrada às informações sobre a geologia do depósito em estudo.

As principais técnicas de estimativa utilizadas para a avaliação de recursos/reservas minerais, dentre as quais a Krigagem Ordinária $(\mathrm{KO})$, não podem substituir ou descartar informações geológicas a respeito da mineralização. Entretanto, este fato não ocorre na prática, onde normalmente apenas os dados analíticos de amostragens são utilizados para a quantificação de recursos/reservas.

O modelo de avaliação de recursos minerais de um depósito deve ser elaborado de acordo com o modelo geológico da mineralização. Informações a respeito do tipo de mineralização, forma de ocorrência da substância de interesse na rocha, dados estruturais, litológicos e geoquímicos, além de associações com outros depósitos de mesma natureza constituem-se na base de informações necessárias para a elaboração do modelo conceitual da mineralização (modelo qualitativo). Estes dados não podem e não devem ser descartados quando do estudo para a elaboração do modelo de recursos/reservas (modelo quantitativo).

Neste trabalho, procedeu-se à reavaliação dos recursos de fosfato da Mina de Cajati, Estado de Săo Paulo, utilizando como técnica de estimativa a krigagem ordinária, mas utilizando-se da mesma forma informações a respeito da gênese do depósito.

A Mina de Cajati, que corresponde a uma clássica ocorrência brasileira de rochas carbonatíticas, começou a ser explorada em 1943. Trabalhos de pesquisa mineral tornaram-se necessários nos últimos anos visando definir a continuidade do corpo de minério em profundidade, pois a quantidade de informações em níveis mais inferiores era escassa. Visando estudos de otimização da cava final, planejamento de lavra e futuros trabalhos de caracterização tecnológica e tipológica, tornou-se necessária uma revisão do modelo das reservas atualmente adotado na lavra. 
Desta forma, este trabalho apresenta um estudo de reavaliação dos recursos/reservas minerais de fosfato da Mina de Cajati, empregando a krigagem ordinária como técnica de estimativa. Além disso, como forma de medir a incerteza associada a esta estimativa, utilizou-se do novo conceito da variância de interpolaçâo. A variância de interpolação, ao contrário da variância de krigagem, mede a dispersão local dos dados, além de levar em consideração a configuração espacial dos mesmos. Como se sabe, a variância de krigagem independe dos valores dos dados para o cálculo da estimativa e, portanto, é homoscedástica.

\section{2 - Objetivos}

Este trabalho teve por objetivo a reavaliação das reservas de fosfato na Mina de Cajati (SP), utilizando a krigagem ordinária, à luz do modelo conceitual adotado nesta jazida, por ocasião da elaboração desta dissertação. Além disso, neste trabalho procurou-se destacar a importância da avaliação geoestatística realizada de forma integrada com a geologia e gênese do depósito.

Para atingir estes objetivos, procurou-se executar o trabalho conforme as seguintes etapas:

- Revisão bibliográfica da geologia da Mina de Cajati;

- Revisão bibliográfica dos conceitos de estatística, geoestatística, avaliação de recursos/reservas minerais e modelagem geológica tridimensional;

- Inventário dos dados de pesquisa mineral;

- Análise estatística;

- Análise geoestatística;

- Avaliação dos recursos/reservas minerais da Mina de Cajati por krigagem ordinária;

- Elaboração do modelo geológico tridimensional do corpo de minério. 


\section{CAPÍTULO 2 \\ A MINA DE CAJATI}

\section{1 - Localização e Acessos}

A Mina de Cajati localiza-se na região do Vale do Ribeira, no Sudoeste do Estado de São Paulo (Figura 2.1). Situa-se a aproximadamente oito quilômetros do centro do município de Cajati, a 229 quilômetros da cidade de São Paulo. O acesso a este município se dá pelo km 488,5 da Rodovia Régis Bittencourt (BR-116), que liga a cidade de São Paulo ao sul do país.

A empresa Bunge Fertilizantes S.A. (antiga Fertilizantes Serrana S.A.) é a responsável pela operação do Complexo Industrial de Cajati, onde é lavrado e beneficiado o minério apatítico, proveniente da rocha carbonatítica.

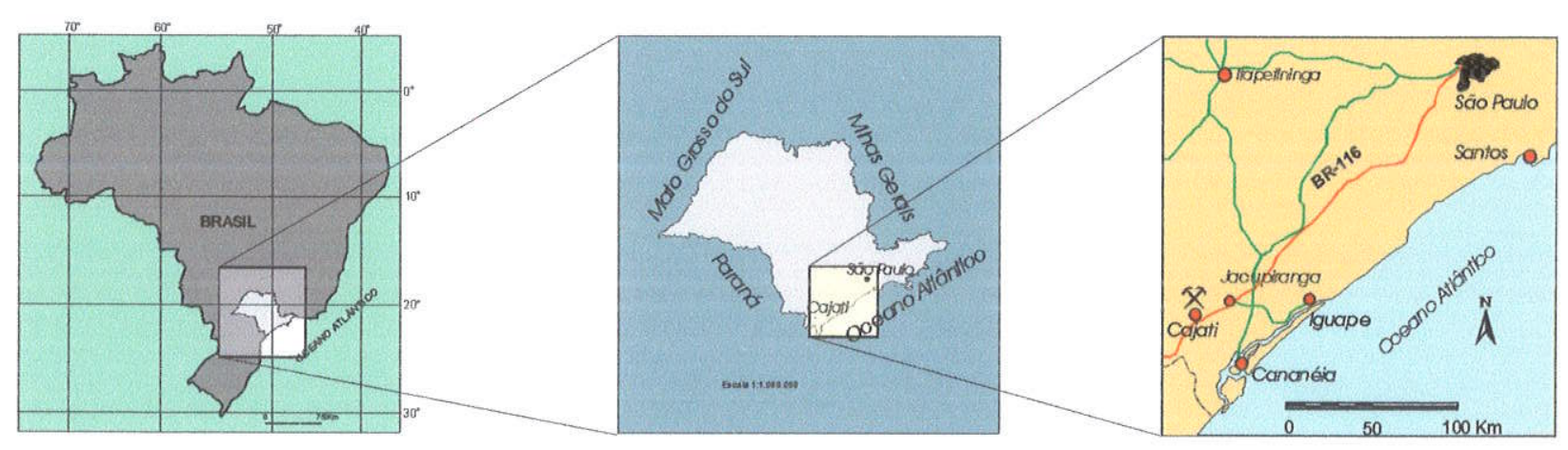

Figura 2.1 - Mapa de localização da área.

\section{2 - Geologia Regional}

A área onde se situa a Mina de Cajati é constituída por rochas alcalinas englobadas sob a designação genérica de "Complexo Ultramáfico-Carbonatítico de Jacupiranga", ocorrência brasileira clássica de rochas alcalinas.

A primeira referência a esta estrutura foi feita 1877 por Bauer que em seu artigo "As Minas de Ferro de Jacupiranga". Derby (1891) publicou as primeiras descrições do Complexo, definindo o termo jacupiranguito, que corresponde, basicamente, às rochas encaixantes do carbonatito. Os jacupiranguitos são rochas alcalinas constituídas essencialmente por titano-augita, tendo como minerais acessórios magnetita, biotita, 
nefelina e olivina. O Complexo está situado próximo às bordas da Bacia do Paraná, em uma região de intensa atividade magmática alcalina terciária e que inclui diversas ocorrências de material carbonatítico. Determinações radiométricas $\mathrm{K} / \mathrm{Ar}$ e $\mathrm{Rb} / \mathrm{Sr}$ (Amaral, 1978, Roden et. al., 1985) indicam uma idade aproximada de $131 \pm 3 \mathrm{Ma}$, interpretada por Herz (1977) como correspondendo a um local de um difuso hot spot em uma série de juntas tríplices, formadas quando da abertura inicial do Atlântico Sul.

Vários autores (Almeida, 1977; Algarte, 1972; entre outros) admitem que o Complexo está condicionado ao Arco de Ponta Grossa, uma estrutura de direção NWSE e ativa desde o Paleozóico. Ferreira \& Algarte (1979) propuseram sua associação ao lineamento de Guapiara, um dos quatro lineamentos relacionados a esta estrutura.

O Complexo de Jacupiranga exibe forma ovalada, com 10,5 x 6,7 Km, orientada segundo NNW. Acha-se encaixado em rochas pré-Cambrianas do Grupo Açungui, com granodioritos a norte e mica xistos ao centro e sul. Gaspar (1989) descreve biotita gnaisses ao norte e centro e biotita quartzo xistos ao sul. O mapa geológico do complexo, segundo Germann et al. (1987), pode ser observado na Figura 2.2.

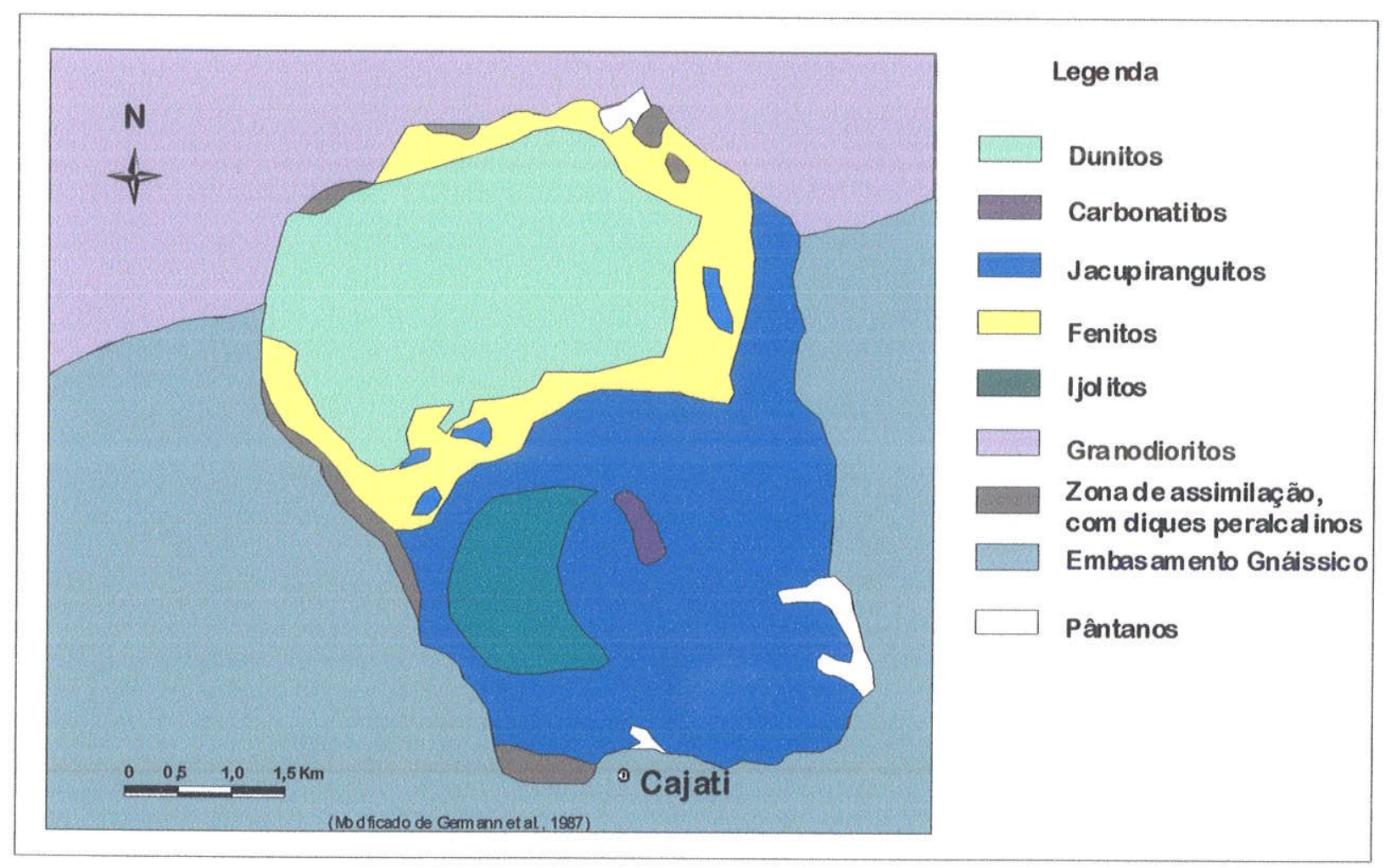

Figura 2.2 - Mapa geológico do Complexo Alcalino de Jacupiranga (modificado de Germann et al., 1987). 
A estrutura apresenta dois corpos intrusivos principais, constituídos por dunitos na região setentrional e jacupiranguitos na meridional. Dentro deste último corpo, na porção SW ocorrem ijolitos, sob a forma de meia-lua e, mais ao centro, os carbonatitos, objeto deste trabalho, na forma de um corpo alongado segundo NNW. Segundo o mesmo autor, rochas de natureza gabróide, incluindo desde gabros alcalinos e melagabros a quartzo monzonitos e quartzo sienitos, afloram na parte ocidental do complexo, enquanto que um enxame de diques (essexítos e teralitos) é encontrado junto à zona de transição entre dunitos e jacupiranguitos, que também são cortados por diques sieníticos. Veios pegmatíticos de nefelina sienito aparecem dispersos nas margens do complexo. Além destas variedades, Melcher (1966) menciona a existência de diques ijolíticos, monchiquíticos e tinguaíticos, assim como a presença de material proveniente de processos de fenitização nas encaixantes regionais próximo às bordas da intrusão. Segundo Gaspar (1989), muitos tipos de rochas que contém plagioclásio ocorrem ao redor dos corpos de dunito e jacupiranguito, por vezes como diques e pequenas intrusões. O mesmo autor propôs a eliminação do termo "jacupiranguito", considerando-o genericamente um clinopiroxenito, pois segundo seu trabalho, o principal piroxênio deste tipo de rocha no Complexo seria o diopsídio e não a titanoaugita, que corresponderia à característica original que definiria o termo jacupiranguito. A definição mais correta para este tipo de rocha, de acordo com Alves (1999), seria um magnetita clinopiroxenito. Entretanto, pelo fato do termo jacupiranguito estar muito difundido tanto na literatura como na mineração, este termo também foi adotado neste trabalho.

\section{3 - Geologia Local}

Os primeiros estudos de detalhe na região, envolvendo mapeamento regional e petrografia, foram os realizados por Melcher $(1954,1966)$, quando foi sugerida uma origem magmática para os carbonatitos intrusivos nos jacupiranguitos.

Os carbonatitos ocupam a feição conhecida como Morro da Mina, aflorando em área elíptica com diâmetros aproximados de $1000 \mathrm{~m}$ e $400 \mathrm{~m}$. A cota máxima original da ocorrência era de 225 metros, estando atualmente ao redor de 160 metros acima do nível do mar. Sondagens rotativas a diamante revelaram que os carbonatitos estendem-se a profundidades superiores a 400 metros abaixo do nível do mar. 
O contato entre jacupiranguitos e carbonatitos mostra zonas de reação, com alternância de bandas milimétricas a decimétricas, ricas em silicatos e carbonatos. No interior do corpo carbonatítico ocorrem xenólitos de jacupiranguitos com diâmetros centimétricos a métricos, além de numerosos diques constituídos por carbonatos, apatita e magnetita, que em alguns casos, apresentam textura orientada e granulação mais fina que suas encaixantes.

Comparados a outros carbonatitos conhecidos no mundo, a ocorrência de Cajati é relativamente pequena (Figura 2.3), com composição homogênea, e alta proporção de carbonatos e apatita, sendo baixa a quantidade dos outros minerais acessórios.

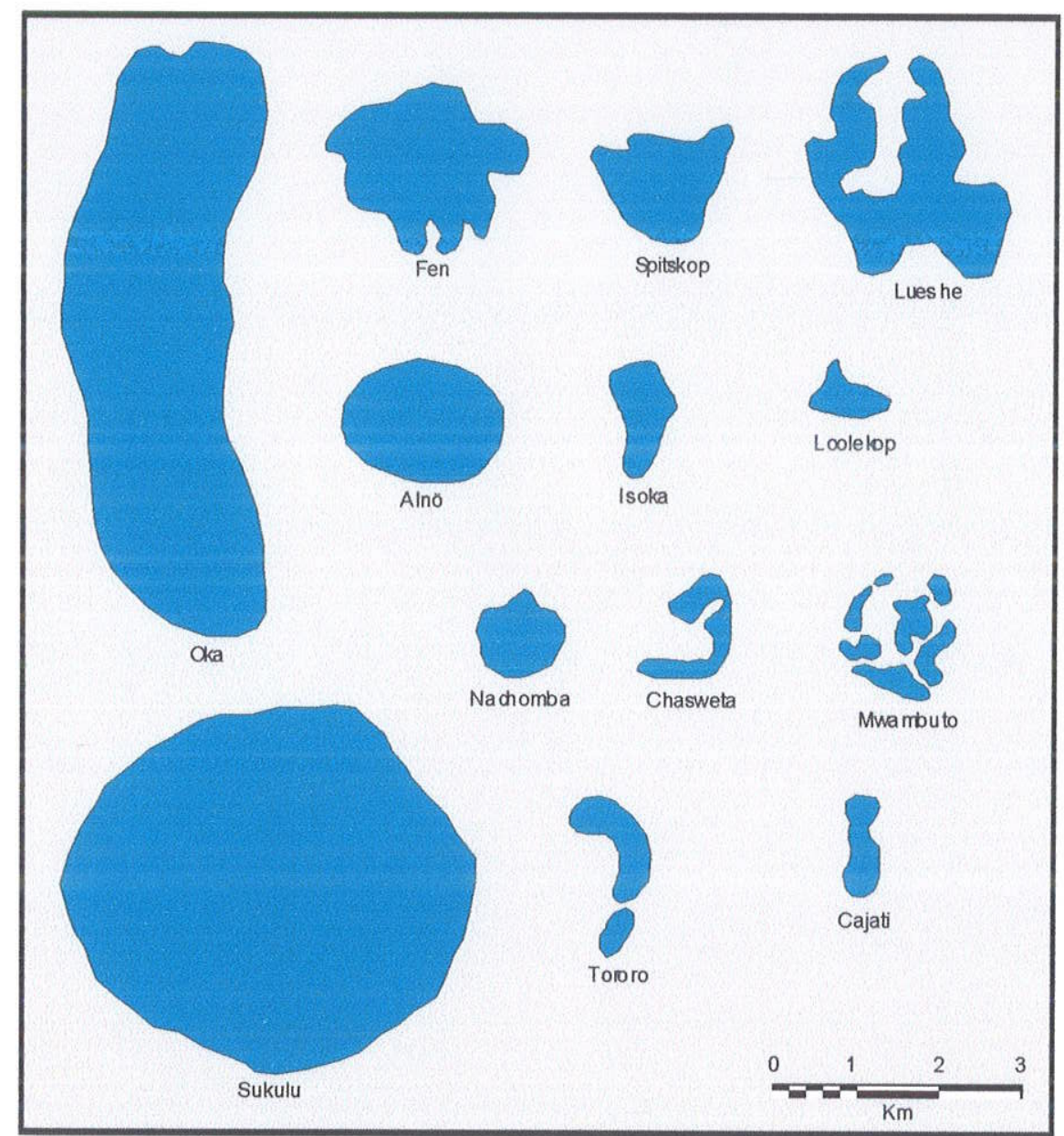

Figura 2.3 - Comparação das ocorrências de corpos de carbonatitos no mundo (conforme Melcher, 1966).

A Tabela 2.1 apresenta a composição mineralógica média do carbonatito da Mina de Cajati. 
Tabela 2.1 - Mineralogia do Carbonatito da Mina de Cajati (Pereira \& Marguti, 1988 apud Alves, 1999).

\begin{tabular}{|c|c|c|c|}
\hline Mineral & Composição Química & Média (\%) & Variação (\%) \\
\hline Calcita & $\mathrm{CaCO}$ & 57 & $30-80$ \\
\hline Dolomita & $\mathrm{CaMg}\left(\mathrm{CO}_{3}\right)_{2}$ & 21 & $1-80$ \\
\hline Apatita & $\mathrm{Ca}_{5}(\mathrm{~F}, \mathrm{Cl}, \mathrm{OH})\left(\mathrm{PO}_{4}\right)_{3}$ & 12 & $3-50$ \\
\hline Magnetita & $\mathrm{Fe}_{3} \mathrm{O}_{4}$ & 7 & $2-70$ \\
\hline Forsterita & $\mathrm{Mg}_{2} \mathrm{SiO}_{4}$ & 2 & $0-20$ \\
\hline Flogopita & $\mathrm{KMg}_{3}\left(\mathrm{AlSi}_{3} \mathrm{O}_{10}\right)(\mathrm{OH})_{2}$ & 2 & $1-20$ \\
\hline Sulfetos & Pirrotita, pirita, calcopirita e vallerita & 2 & $0-20$ \\
\hline Outros & $\begin{array}{c}\text { Baddeleyita, barita, brucita, ilmenita, quartzo } \\
\text { (secundário), serpentina, e clinohumita, entre outros }\end{array}$ & 1 & $1-10$ \\
\hline
\end{tabular}

Os principais elementos estruturais dos carbonatitos, como juntas, falhas, diques e estruturas fluidais, dispostos de maneira radial e concêntrica levaram Melcher (1966) a sugerir um corpo intrusivo na parte sul da ocorrência, cortado por sua vez por uma intrusão posterior com centro na parte norte.

Pelo modelo estrutural do maciço rochoso proposto por Hasui \& Mioto (1989 apud Alves, 1999), as descontinuidades foram geradas durante o resfriamento da chaminé carbonatítica e, mais recentemente, por alívio de carga.

Gaspar \& Wyllie (1983) e Gaspar (1989) indicam que o carbonatito resultou de 5 intrusões sucessivas que levaram a cinco diferentes tipos de carbonatito, de acordo com feições estruturais, mineralógicas e petrográficas. A Figura 2.4 mostra o mapa geológico da Mina de Cajati indicando as cinco intrusões identificadas por Gaspar (1989) e detalhadas na Tabela 2.2. 


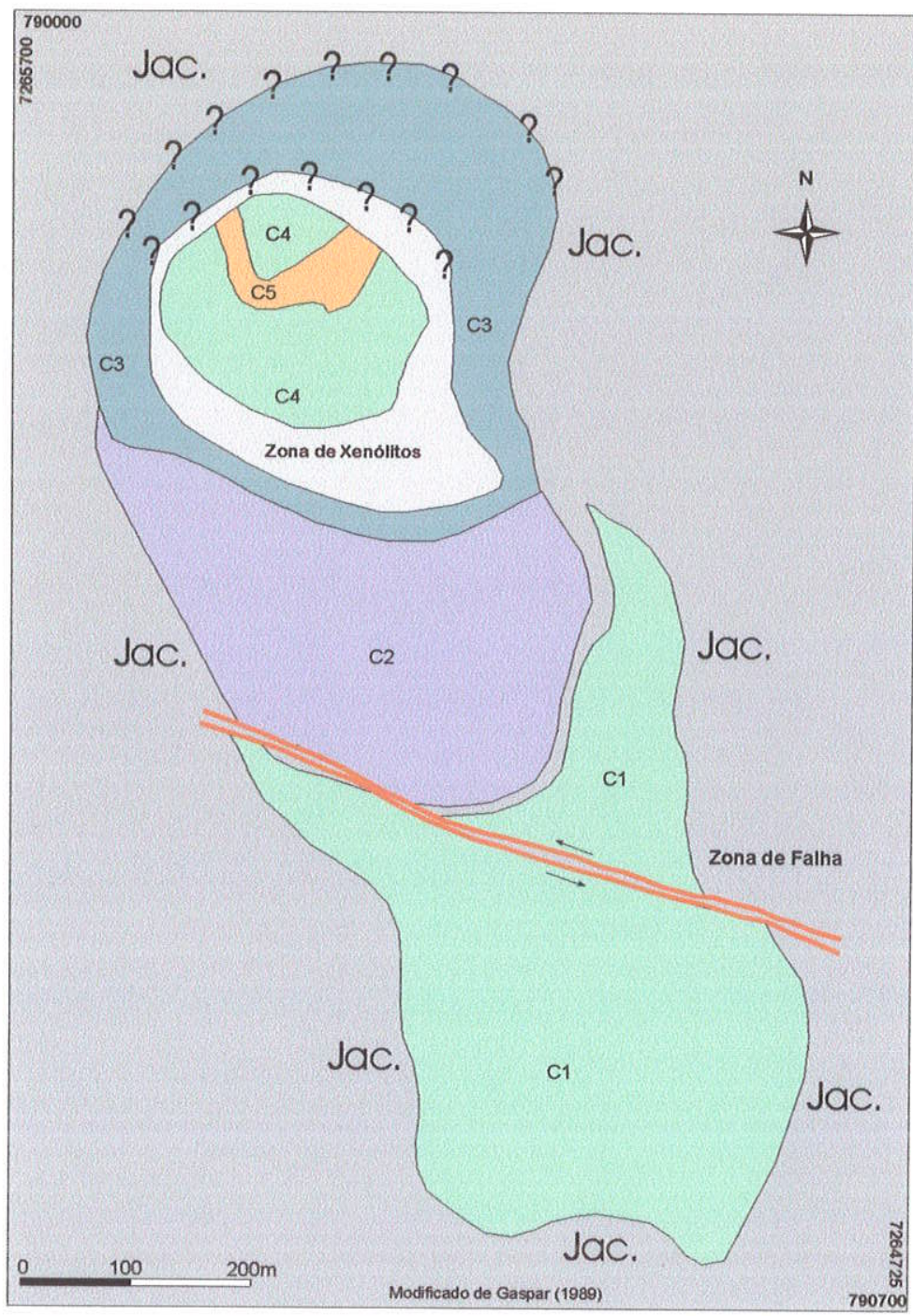

Figura 2.4 - Mapa geológico da Mina de Cajati, modificado de Gaspar (1989) - Jac. = jacupiranguito; C1 a C5 = intrusões carbonatíticas.

Tabela 2.2 - Petrografia e mineralogia das intrusões carbonatíticas que compõem a Mina de Cajati (de acordo com Gaspar \& Wyllie, 1983).

\begin{tabular}{|c|c|c|c|}
\hline Intrusão & Mineralogia Principal $\left({ }^{\star}\right)$ & Granulação & Outras Feições \\
\hline C1 & $\begin{array}{l}\text { Calcita, apatita, magnetita, } \\
\text { olivina, flogopita, dolomita, } \\
\text { sulfetos }\end{array}$ & Grossa & Ligeiramente bandada \\
\hline $\mathrm{C} 2$ & $\begin{array}{c}\text { Calcita, dolomita, apatita, } \\
\text { magnetita, flogopita, sulfetos }\end{array}$ & Fina a média & Finamente bandada \\
\hline C3 & $\begin{array}{l}\text { Calcita, apatita, magnetita, } \\
\text { flogopita, dolomita, olivina, } \\
\text { sulfetos }\end{array}$ & Média a Grossa & $\begin{array}{l}\text { Menor quantidade de } \\
\text { minerais não-silicáticos } \\
\text { relativamente às outras } \\
\text { rochas. Bandamento } \\
\text { menos evidente }\end{array}$ \\
\hline C4 & $\begin{array}{l}\text { Calcita, apatita, magnetita, } \\
\text { olivina, flogopita, dolomita, } \\
\text { sulfetos }\end{array}$ & Média & (1) \\
\hline C5 & $\begin{array}{c}\text { Dolomita, apatita, flogopita, } \\
\text { magnetita, sulfetos, calcita }\end{array}$ & Média a Grossa & $\begin{array}{l}\text { Porcentagem pequena de } \\
\text { silicatos, óxidos e sulfetos. }\end{array}$ \\
\hline
\end{tabular}

(*) Minerais listados em ordem crescente de abundância 
A Figura 2.5 apresenta uma visão panorâmica da mina e de todo o Complexo Industrial. As Figuras 2.6 e 2.7 mostram uma visão mais detalhada da atual situação da mina

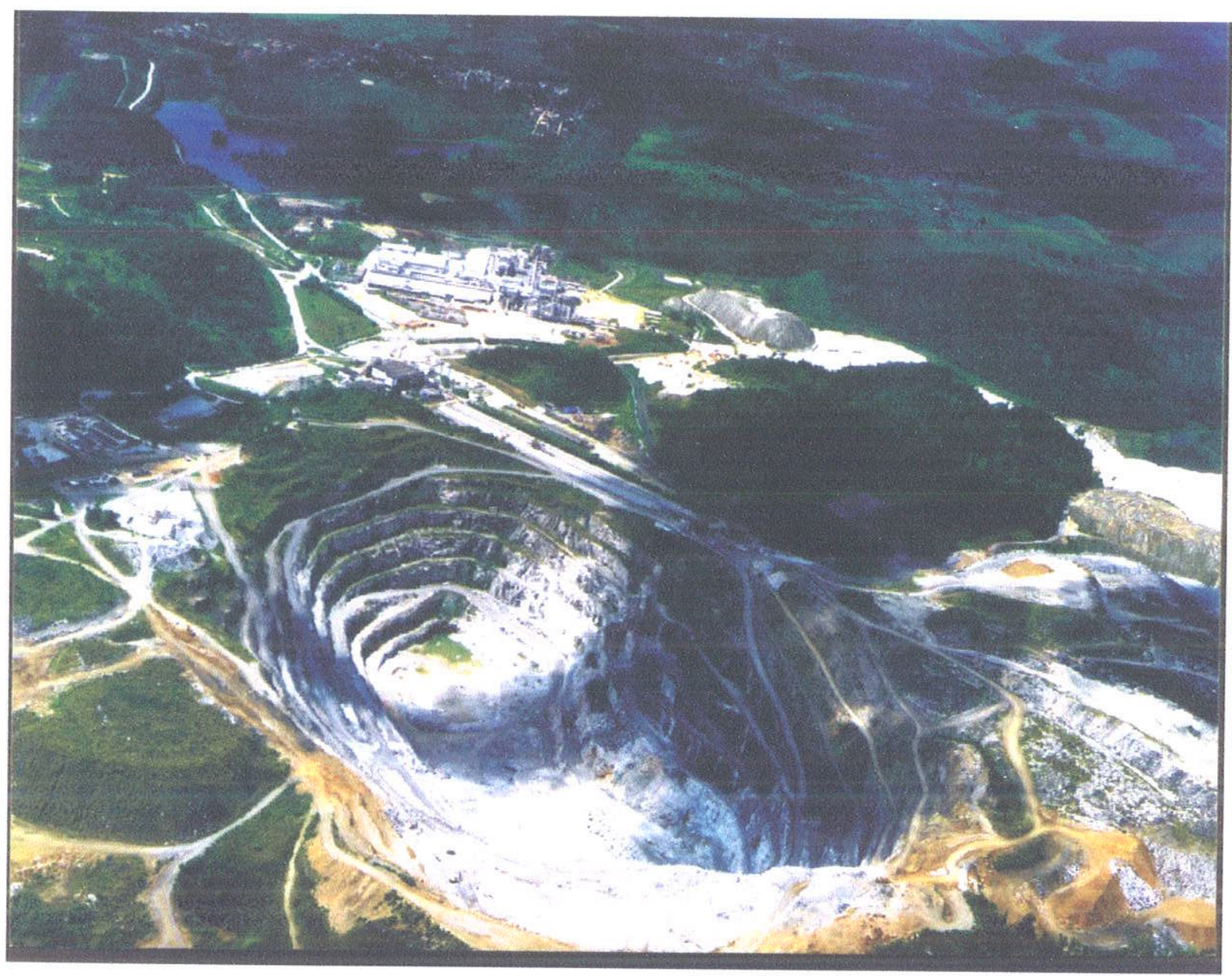

Figura 2.5 - Visão panorâmica da cava da Mina de Cajati e do Complexo Industrial da Bunge Fertilizantes. 


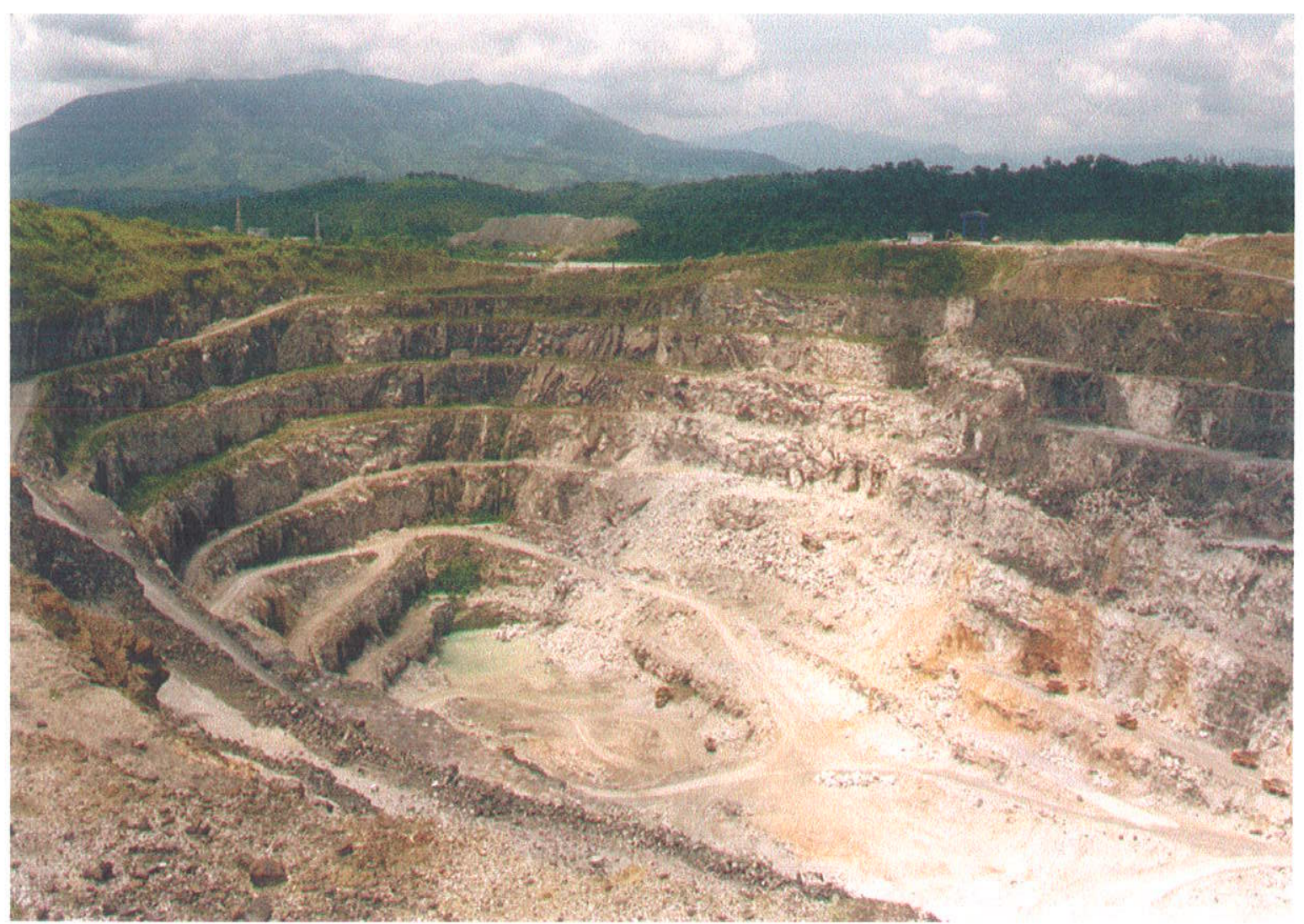

Figura 2.6 -Visão sul da atual cava da Mina de Cajati.

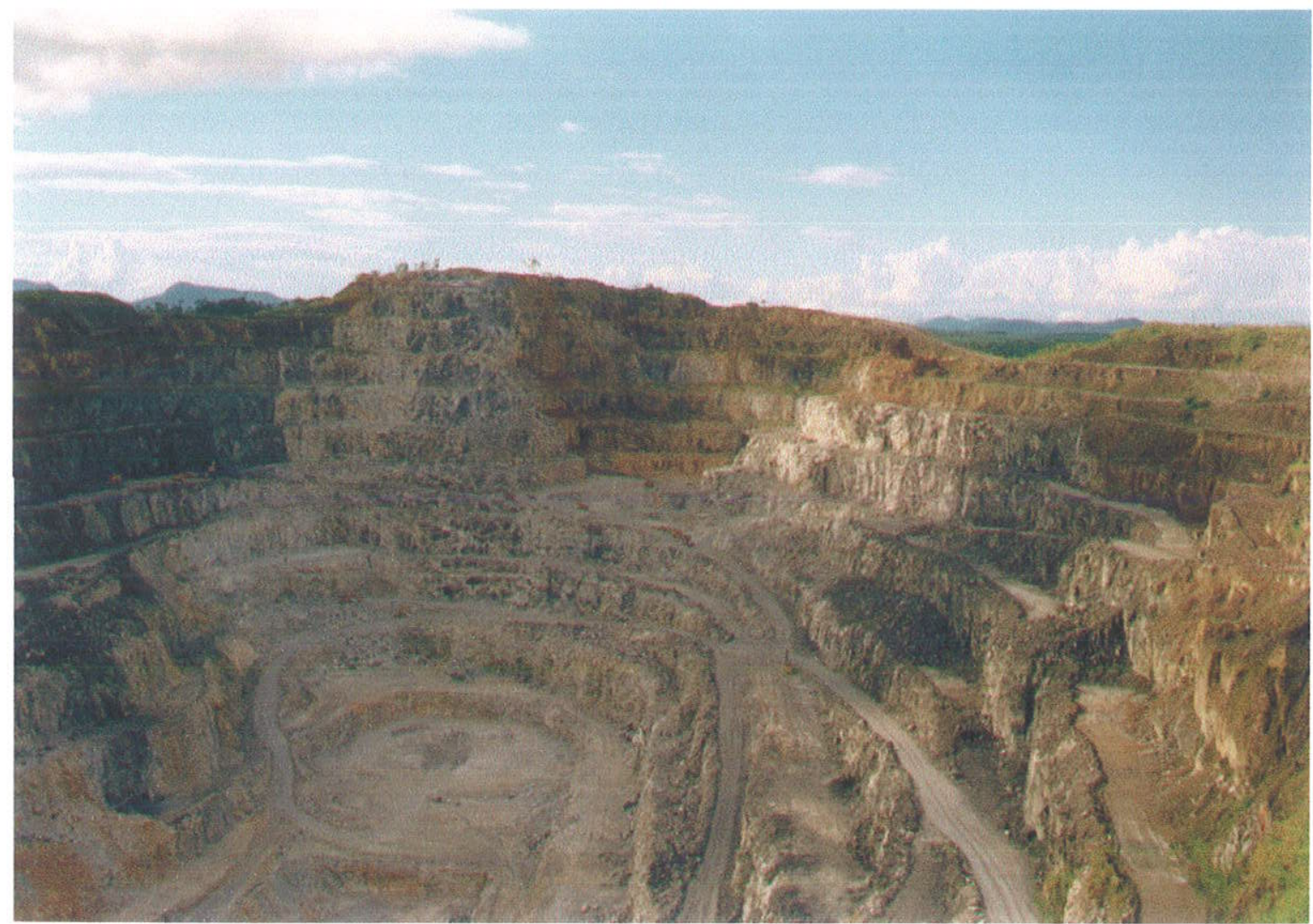

Figura 2.7 - Visão norte da atual cava da Mina de Cajati. 


\section{4 - Histórico da Mina de Cajati}

A produção da Mina de Cajati iniciou-se em 1943 com a lavra de minério residual com altos teores de $\mathrm{P}_{2} \mathrm{O}_{5}$ (maiores que $20 \%$ ), que consistia basicamente de apatita, magnetita e alguns argilo-minerais, todos provenientes da dissolução e lixiviação dos minerais carbonatados da rocha. O minério era beneficiado por lavagem e separação magnética, obtendo-se concentrados de apatita com teores em torno de $40 \%$ de $\mathrm{P}_{2} \mathrm{O}_{5}$ utilizados para a fabricação de fertilizantes (Alves, 1999).

A base econômica da mina, centrada na apatita como principal e praticamente único mineral de minério, começou a sofrer transformação na década de 60 , com a perspectiva de exaustão do material residual. Abaixo deste, encontrava-se o que, até então, era tido como protominério, constituído pelo carbonatito são, com teores médios em torno de $5,5 \%$ de $\mathrm{P}_{2} \mathrm{O}_{5}$.

A partir de 1969, o carbonatito são e a apatita assumiram a condição de minério, através alterações dos processos tecnológicos de beneficiamento, que permitiram a separação física dos minerais através do processo de flotação.

Em 1972, o rejeito calcário da usina de flotação passou a ser aproveitado economicamente, tornando-se matéria-prima para a fabricação de cimento no próprio Parque Industrial (somente o rejeito com teor de $\mathrm{MgO}<4,5 \%$ ).

Em 1985, estudos de reavaliação de reservas possibilitaram a sua elevação para mais de 300 milhões de toneladas de carbonatito até a cota -400 .

A partir do final da década de 80 , com a crise na indústria de fertilizantes, procedeu-se a adequação dos chamados subprodutos, através do desenvolvimento de aplicações industriais para os mesmos. Deste modo, foram desenvolvidos mercados para os diferentes produtos originados da explotação e beneficiamento do carbonatito, tais como: ácido fosfórico "refinado" para indústria alimentícia e farmacêutica (1987), argamassas (1989), foscálcio para alimentação animal e calcário para filler, que corresponde à carga mineral para indústria de papel e tintas (1990), além de corretivos agrícolas, magnetita e brita para construção civil, a partir de áreas extremamente contaminadas com piroxenitos. Segundo Alves (1999), o fosfogesso, que corresponde ao rejeito do ácido fosfórico também começou a ser aproveitado para cimento e como carga mineral. 
O mineral de minério, a apatita, ocorre como pequenos cristais de forma ovóide, alongada, inclusos em carbonato ou sob a forma de agregados de cristais prismáticos alongados, subparalelos. O teor médio de $12 \%$ de apatita corresponde a cerca de $5 \%$ de $\mathrm{P}_{2} \mathrm{O}_{5}$. $\mathrm{O}$ teor de corte praticado atualmente é de $3 \%$ de $\mathrm{P}_{2} \mathrm{O}_{5}$. Adota-se um "teor de corte" de 4,5\% para o $\mathrm{MgO}$ de modo que o rejeito carbonático possa ser aproveitado para a fabricação de cimento.

Atualmente a usina recebe mais de 13.000t/dia de minério, tendo capacidade de atingir até $450.000 t / m e ̂ s$. A relação estéril/minério praticada é de 1,37 . O rejeito da flotação contém entre 0,6 e $0,8 \%$ de $\mathrm{P}_{2} \mathrm{O}_{5}$ em média. A lavra é praticada a céu aberto, com bancadas de 10 e 20 metros de altura, com ângulos de talude maiores que $80^{\circ}$. $\mathrm{O}$ desmonte do material é realizado através de explosivos (dados retirados de Alves, 1999).

Nas Figuras 2.5 a 2.7 têm-se as etapas de processamento do minério (segundo Alves, 1999).

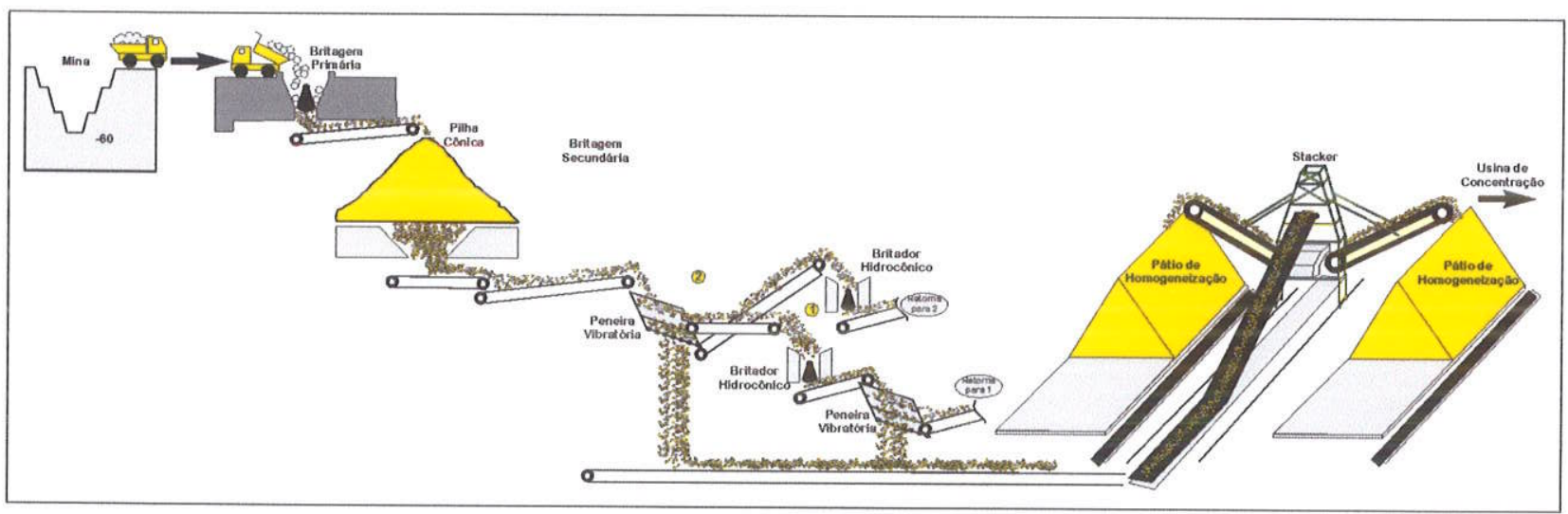

Figura 2.5 Processamento do minério da Mina de Cajati - Britagem e Homogeneização. 


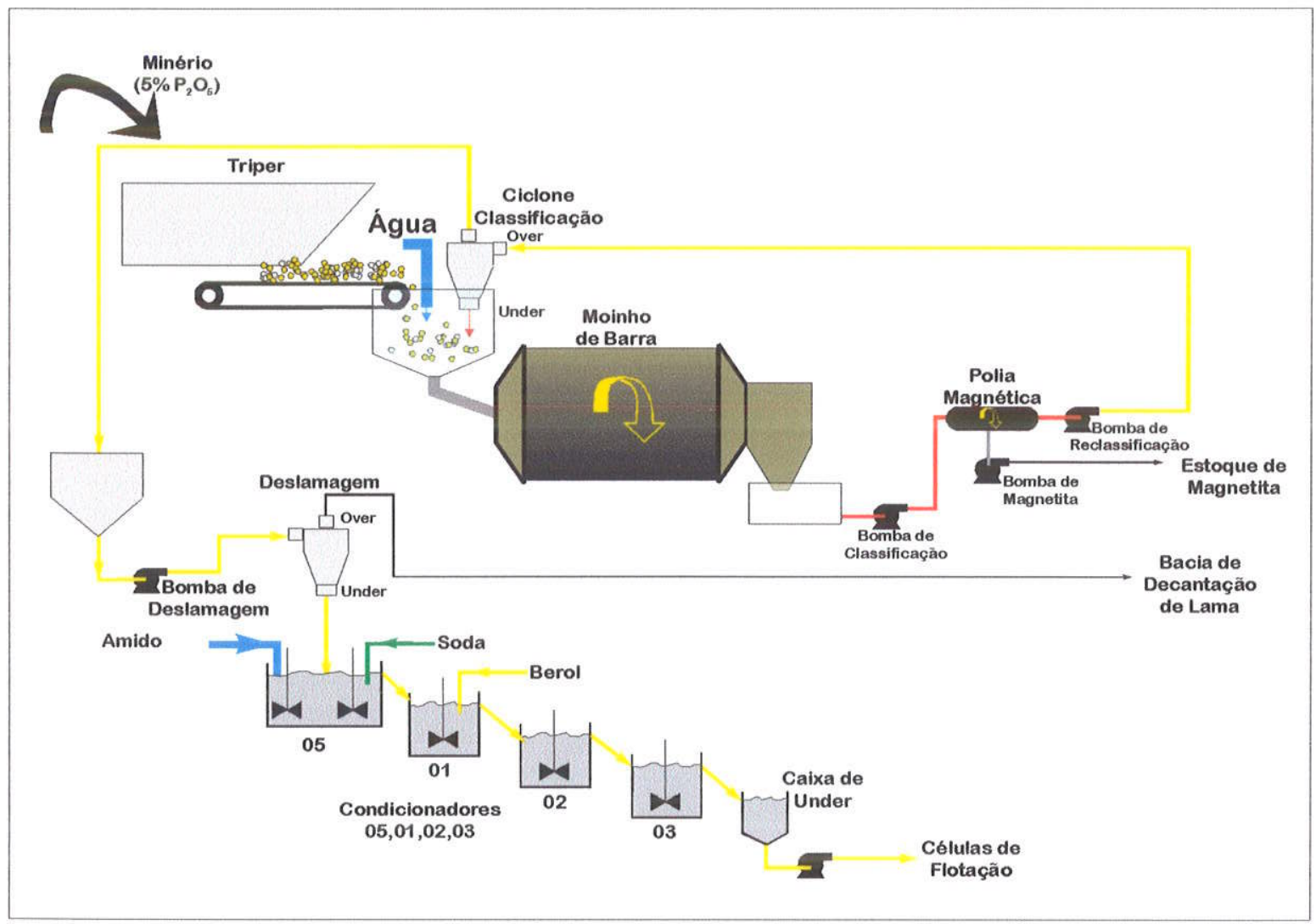

Figura 2.6 Processamento do minério da Mina de Cajati - Moagem e Condicionamento.

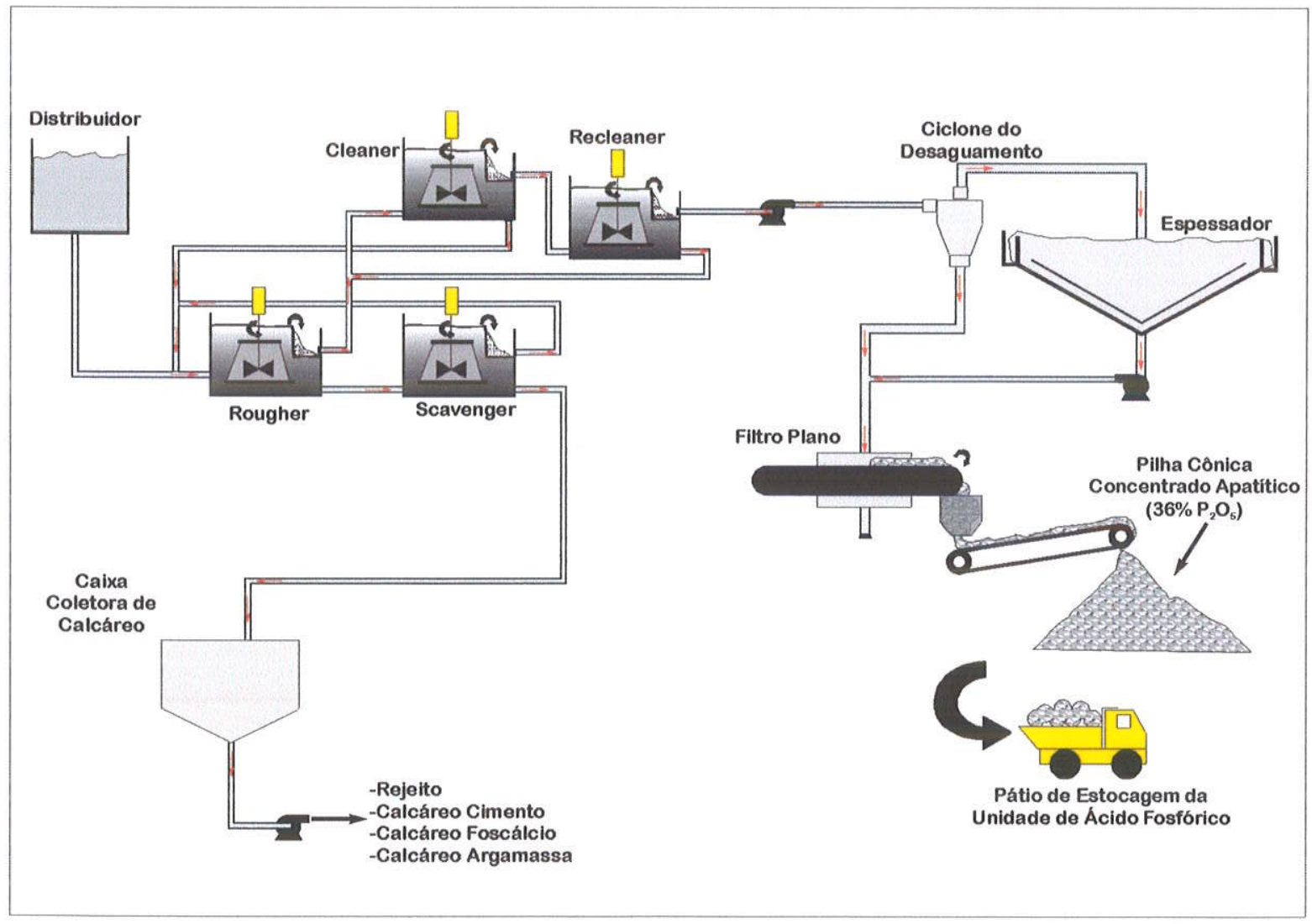

Figura 2.7 Processamento do minério da Mina de Cajati - Flotação e Produto Final. 


\section{CAPÍTULO 3 \\ MATERIAIS E MÉTODOS}

Para a realização deste trabalho utilizou-se o banco de dados obtido junto à Empresa Bunge Fertilizantes S. A.

O banco de dados foi obtido coletado em via magnética, em formatos ASCII e Excel, onde constavam informações das campanhas de sondagens realizadas nos últimos anos no depósito. As informações disponíveis neste banco correspondiam à localização dos furos, com as coordenadas $X$ e $Y$, além da cota da boca dos furos, comprimento total dos furos, tamanho das amostras, azimute e inclinação, tipo de rocha, além dos dados analíticos de $\mathrm{P}_{2} \mathrm{O}_{5}$ e MgO. Salienta-se que estas análises químicas foram realizadas nos laboratórios da própria empresa.

Iniciou-se então a formatação deste banco de dados para os formatos dos softwares ISATIS da Empresa Geovariances e GeoVisual, este último desenvolvido nos laboratórios do Departamento de Geologia Sedimentar e Ambiental do Instituto de Geociências. A base de dados, devidamente conferida, foi então submetida a um tratamento sistemático conforme o desenvolvimento descrito a seguir.

\section{1 - Desenvolvimento do Trabalho}

A seguir, serão detalhadas as atividades desenvolvidas para a realização deste projeto.

\section{Revisão Bibliográfica}

$\mathrm{Na}$ pesquisa bibliográfica procurou-se enfocar a geologia da área em estudo, através de trabalhos de cunho acadêmico e de relatórios internos da empresa. Esta pesquisa teve por objetivo principal a familiarização com a área de estudo e com a subdivisão adotada pela mineração em relação aos vários tipos de minérios.

Procurou-se também fazer uma revisão sobre os conceitos de geoestatística, modelagem de depósitos e avaliação de reservas, escopo deste trabalho. 


\section{Trabalhos de Campo}

Procurou-se neste trabalho reconhecer em campo algumas feições do depósito em estudo para um melhor entendimento de sua gênese e para a elaboração do modelo tridimensional. Observaram-se as relações de contatos entre o corpo de minério e a rocha encaixante, bem como as relações estruturais entre os corpos, com a presença de uma zona de falha e outra de xenólitos cortando o corpo.

\section{Aquisição dos Dados}

O banco de dados foi adquirido nos formatos ASCll e Excel. Este banco apresentou as informações dos furos de sonda das campanhas realizadas nos últimos anos no depósito. As informações consistiam da localização dos furos, com as suas coordenadas e cotas, comprimento total e atitudes (direção e mergulho), intervalos com o tipo de material, sendo ou minério ou estéril, além dos teores dos elementos $\mathrm{P}_{2} \mathrm{O}_{5}$ e MgO dos intervalos considerados como minério.

Após a aquisição do banco de dados, procedeu-se a formatação do mesmo para a entrada nos Softwares ISATIS e GeoVisual.

\section{Regularizacão de Amostras e Análise Estatística}

Procedeu-se à análise estatística dos dados anteriormente formatados. Para esta análise, foi realizada a regularização das amostras, utilizando um intervalo de dez metros. A regularização é efetuada devido ao fato das análises químicas representarem valores pontuais. Como a lavra será realizada em um volume significativamente maior, deve-se conhecer os teores do furo ao longo de uma espessura constante (Figura 3.1). A regularização, ou ainda, composição das amostras, pode ser realizada ao longo dos furos ou ao longo de espessuras constantes. O intervalo de dez metros foi o escolhido por se tratar da altura das bancadas atualmente existentes na mina. Para isso, foi utilizada a seguinte fórmula de teor composto:

TC $=\frac{\text { iteor*espessura }}{\sum \text { espessura }}$ 


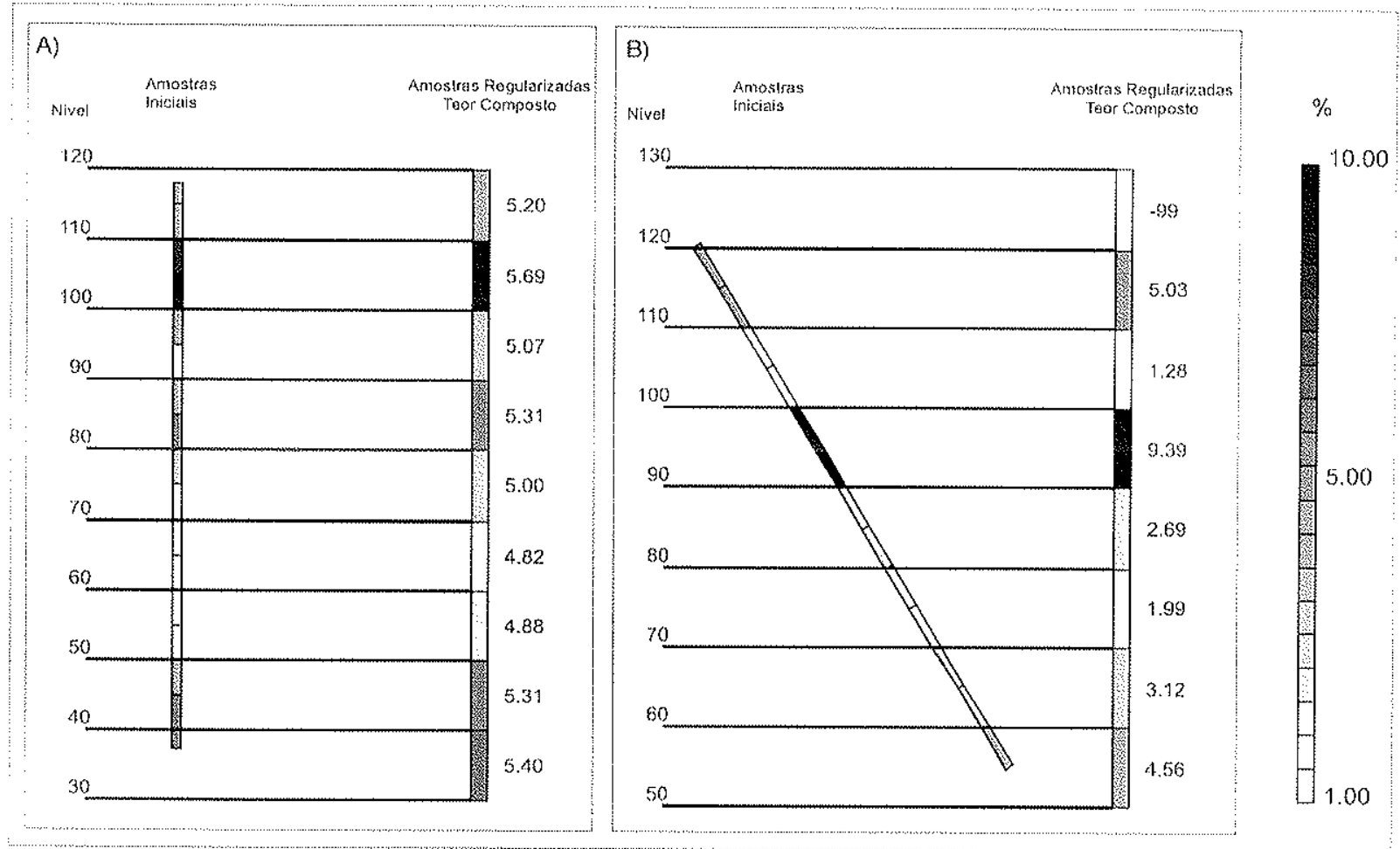

Figura 3.1 - Esquema da regularização dos teores de furos de sonda - (A) Furo vertical; (B) Furo Inclinado, conforme visualização proporcionada pelo software Geovisual.

Com os dados regularizados, calculou-se as estatísticas para o $\mathrm{P}_{2} \mathrm{O}_{5}$ e $\mathrm{MgO}$, as duas variáveis analisadas para a avaliação, a fim de se observar a presença de valores discrepantes ou anômalos presentes no conjunto de dados.

Estas estatísticas correspondem à média, desvio padrão, variância, grau de assimetria e coeficiente de curtose. Procurou-se também observar alguma possivel correlação entre os teores de $\mathrm{P}_{2} \mathrm{O}_{5}$ e $\mathrm{MgO}$.

Deve-se ressaltar que o mineral de minério aproveitado na mineração é a apatita, do qual $\circ \mathrm{P}_{2} \mathrm{O}_{5}$ é retirado para a produção de fertilizantes fosfatados. $O$ interesse pelo teor de $\mathrm{MgO}$ se dá pelo fato do rejeito carbonatítico ser aproveitado na produção de cimento, no qual o teor de magnésio é um dos limitantes.

Neste mesmo estudo estatístico, foram construidos histogramas e curvas acumulativas das duas variáveis, para se verificar a distribuição de freqüências destes dados.

Primeiramente, o conjunto de dados foi analisado como um todo, tentando identificar e separar diferentes populações que porventura comporiam o conjunto dos dados. A presença de mais de uma população implicou na realização de estudos distintos para cada uma delas. 


\section{Análise Geoestatística}

A partir do conhecimento dos parâmetros estatísticos, iniciou-se a análise geoestatística dos dados. Esta análise é a principal etapa do projeto, pois é a partir dela que serão obtidos os modelos de correlação espacial que serão utilizados na estimativa dos teores, no processo conhecido por krigagem.

A primeira tarefa realizada nesta análise foi a construção de semivariogramas direcionais experimentais. Para isso, foi levada em conta a dimensão da malha de sondagens, que está relacionada à distância $h$ entre os pares de pontos que serão utilizados para a obtenção do semivariograma.

Neste trabalho, a disposição das sondagens ocorre de forma irregular, resultado de inúmeras fases de pesquisa mineral efetuadas no depósito ao longo dos anos. Com isso, adotou-se uma distância média entre os furos para cada uma das regiões estudadas, a fim de facilitar o estudo.

A escolha das direções levou em conta a natureza intrusiva do depósito. Assim, foram escolhidas duas direções para a análise: uma contida no plano horizontal (D1) e outra contida no plano vertical (D2), ou seja, analisando a variabilidade dos dados ao longo do sentido da colocação da intrusão.

Deste modo, foram obtidos os semivariogramas experimentais para cada uma das variáveis presentes nos grupos de análise.

De posse destes semivariogramas experimentais, tratou-se de fazer o ajuste de um modelo teórico, cujas propriedades matemáticas são conhecidas.

$O$ ajuste foi realizado levando-se em conta os dois semivariogramas direcionais (D1 e D2) obtidos para cada uma das variáveis. Primeiramente, procurou-se determinar qual modelo de semivariograma melhor se ajustaria aos semivariogramas experimentais. Posteriormente, determinou-se os parâmetros dos semivariogramas, ou seja, efeito pepita, patamar e amplitude. Neste estudo, foram consideradas anisotropias nas diferentes direções estudadas, sendo determinados os respectivos coeficientes de anisotropia.

Quando da ocorrência de anisotropias, torna-se necessário corrigi-las, de modo que se possa utilizar o modelo teórico de semivariograma ajustado ao semivariograma experimental, sem prejuízo da estimativa. Segundo Issaks \& Srivastava (1989), para combinar semivariogramas experimentais de diferentes direções em um único modelo 
que seja consistente, deve-se definir uma transformação que reduza todos os semivariogramas direcionais a um modelo comum com amplitude igual a 1 . Esta redução é feita através do cálculo do fator ou razão de anisotropia, considerando a relação entre a menor e maior amplitude dos semivariogramas direcionais. Quando o sistema de coordenadas dos dados não coincide com o sistema dos eixos de anisotropia, deve-se realizar uma transformação, rotacionando-se o sistema dos eixos de anisotropia.

A confiabilidade dos ajustes dos modelos teóricos aos semivariogramas experimentais foi verificada utilizando-se a técnica conhecida como validação cruzada. A validação cruzada consiste de um procedimento no qual uma variável medida em um ponto é temporariamente eliminada e seu valor naquele ponto é estimado através dos pontos vizinhos. Após a repetição deste procedimento para todos os pontos da amostra $Z(x)$ é obtido um conjunto de valores estimados $Z^{*}(x)$

As seguintes medidas podem ser obtidas para comparar o erro experimental entre os valores originais e os estimados para cada ponto $X_{i}$ :

Erro Médio $=\frac{1}{n} \sum_{i=1}^{n}\left(Z\left(x_{i}\right)-Z^{*}\right)$

Variância do Erro $=\frac{1}{n} \sum_{i=1}^{n}\left(Z\left(x_{i}\right)-Z^{*}\right)^{2}$

Erro Padrão da Média $=\frac{1}{n} \sum_{i=1}^{n}\left(\frac{\left(Z\left(x_{i}\right)-Z^{*}\right)}{S}\right)$

Variância do Erro Padrão $=\frac{1}{n} \sum_{i=1}^{n}\left(\frac{\left(Z\left(x_{i}\right)-Z^{*}\right)}{S}\right)^{2}$

Um ajuste ideal do semivariograma implica em valores de erro médio e variância iguais a zero. Porém, esta situação ideal é rara. Por isso, os valores desejados para um ajuste poder ser considerado adequado são: Erro Médio $=0$ ou muito próximo de zero, Erro Padrão da Média =0 ou muito próximo de zero e Variância do Erro Padrão $=1$.

A obtenção de erro médio igual a zero pode não significar que a estimativa baseada no modelo ajustado de semivariograma é adequada. As Figuras 3.2a e 3.2b mostram dois casos extremos, onde no primeiro o erro médio é igual a zero e no 
segundo diferente de zero.

Na Figura 3.2a o ajuste é perfeito, o que é muito dificil de se realizar na prática, desde que os dados apresentem uma certa variabilidade. Assim, a presença de variabilidade e a amostragem efetuada dentro do limite econômico, não é possível, em geral, obter validações cruzadas com erros médios iguais a zero. O mais comum é a ocorrência de enviesamento condicional, no qual os teores baixos são superestimados e os teores altos são subestimados. A este efeito denomina-se efeito de suavização da krigagem ordinária (Olea \& Pawlowsky, 1996).
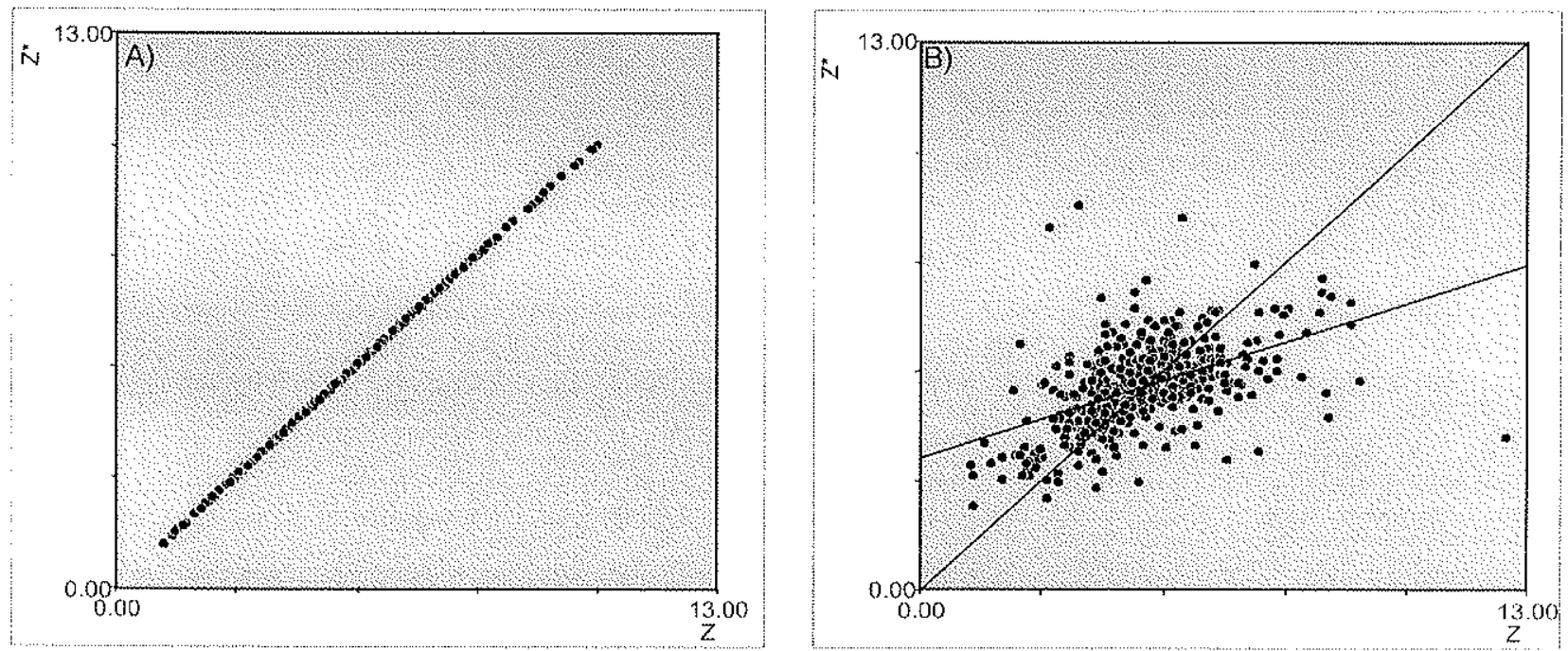

Figura 3.2 - Gráficos mostrando a correlação entre os valores amostrais $(Z)$ e os valores estimados $\left(Z^{*}\right)$ onde o erro médio é igual a zero em $(A)$ e diferente de zero em $(B)$, caracterizando, neste caso, o chamado efeito de suavização, segundo Olea \& Pawlowsky (1996).

\section{Krigagem Ordinária}

Antes de iniciar a estimativa dos teores, elaborou-se um modelo de blocos do depósito, com o objetivo de se estimar os teores para cada um dos blocos. As dimensões dos blocos deste modelo foram definidas a partir dos blocos de lavra atualmente praticados na Mina de Cajati. Desta forma, o modelo de blocos foi definido a partir de blocos com $25 \mathrm{~m} \times 25 \mathrm{~m} \times 10 \mathrm{~m}$.

Para a execução da krigagem foram definidos os chamados parâmetros de vizinhança, que irão balizar o processo de estimativa. Estes parâmetros consistem, basicamente, na determinação do número de setores angulares em que será feita a busca de amostras, o número máximo, mínimo e ideal de amostras utilizadas por setor para a estimativa e os raios de busca. O valor máximo dos raios de busca adotados 
correspondeu aos valores das amplitudes obtidas nos semivariogramas, pois estas medidas representam uma distância limite, a partir da qual os dados passam do campo estruturado para o campo aleatório. Por não haver continuidade espacial das amostras além do valor da amplitude, as amostras ficam limitadas para a estimativa de blocos além deste valor.

Após o cálculo da estimativa dos teores, procedeu-se com a seleção dos blocos que apresentaram valores acima do teor de corte adotado pela Empresa como economicamente viável para a lavra, que corresponde a teores de $\mathrm{P}_{2} \mathrm{O}_{5}$ maiores que 3 $\%$. O MgO, por não ser considerado minério, não possui um teor econômico de corte. $\mathrm{O}$ teor de 4,5\% de $\mathrm{MgO}$ corresponde a um teor de corte para fins de processo, pois este valor serve apenas para definir a utilização ou não do rejeito carbonatítico na produção de cimento.

Ao realizar o cálculo de estimativa dos teores, também foi calculada a variância de interpolação associada a esta estimativa, através do software GeoVisual.

\section{Cálculo de Recursos/Reservas}

Estimado os teores nos blocos, calculou-se o volume total de minério da reserva, com a exportação dos dados selecionados para uma planilha Excel. Conhecendo o teor estimado de cada bloco de krigagem, e as dimensões do bloco, previamente determinadas quando da construção do modelo de blocos, calculou-se o valor total da reserva para $\mathrm{P}_{2} \mathrm{O}_{5}$, até o nível -250. Para isso, adotou-se a seguinte fórmula de cálculo de recursos/reservas:

$$
\mathrm{R}=\mathrm{VDT}
$$

onde $\mathrm{R}$ corresponde à massa total de $\mathrm{P}_{2} \mathrm{O}_{5}$ de cada bloco; $\mathrm{V}$ o volume do bloco, de dimensões $25 \times 25 \times 10 \mathrm{~m}$; T o teor krigado para cada bloco; e D corresponde à densidade aparente do minério, determinado em $2,7 \mathrm{ton} / \mathrm{m}^{3}$, a partir de ensaios realizados e adotados nos cálculos da empresa.

\section{Modelagem do Corpo de Minério}

A elaboração do modelo tridimensional do corpo de minério foi feita a partir de perfis verticais e seções horizontais obtidos junto a empresa. Estas foram passadas 
para computador através de digitalização, utilizando o software Datamine e "linkadas" de modo a compor o modelo tridimensional do depósito.

Esta "linkagem" levou em conta informações sobre a geologia do corpo, considerando sua natureza intrusiva.

Nas informações disponíveis para a elaboração deste modelo geológico, foi considerado o nível até a cota de 250 metros abaixo do nível do mar, devido à escassez de informação nos níveis mais inferiores (até a cota $-400 \mathrm{~m}$ ).

\section{2 - O Banco de Dados}

O banco de dados utilizado para a elaboração deste trabalho consiste de 144 furos de sonda rotativa diamantada que foram executados em diversas campanhas de pesquisa na Mina de Cajati durante os últimos 15 anos, totalizando cerca de 15.000 metros de testemunhos de sondagem.

Por pertencerem a campanhas distintas, ocorrem diferenças nos comprimentos das amostras. Entretanto, mais de $90 \%$ das amostras encontram-se no intervalo de zero a 10 metros, conforme observado na Figura 3.3.

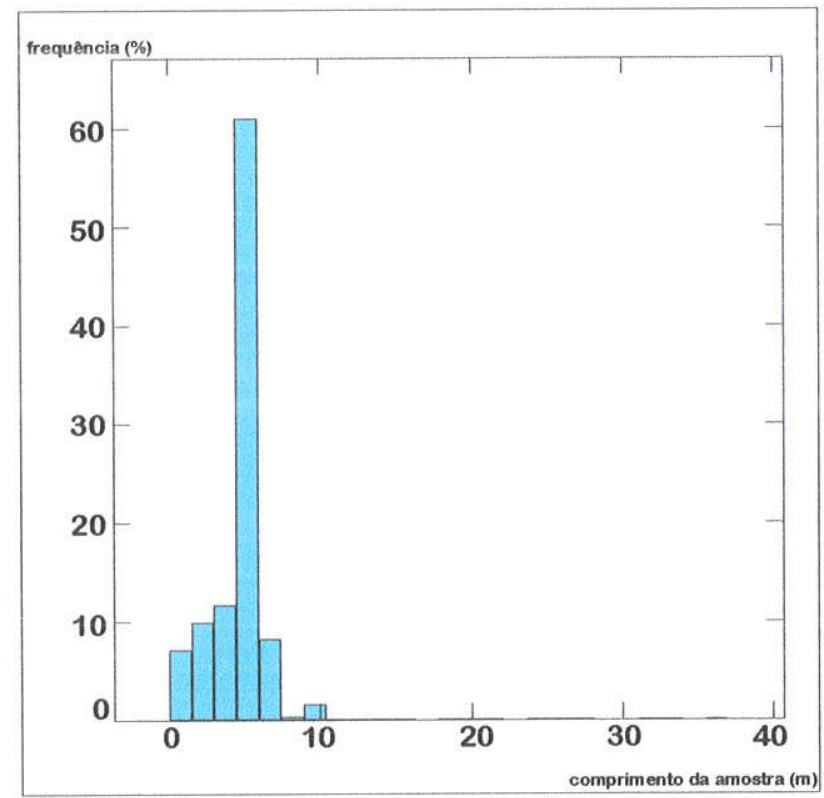

Figura 3.3 - Variação dos comprimentos das amostras presentes no banco de dados. 
Neste estudo optou-se pela regularização da amostras utilizando-se o comprimento de 10 metros, que corresponde a altura das bancadas atualmente adotadas na lavra.

O banco de dados contendo as informações destes furos apresenta ainda a variável TIPO DE ROCHA, no qual as amostras são classificadas segundo os critérios adotados na mineração. A tabela 3.1 apresenta os tipos litológicos atualmente adotados na lavra.

Tabela 3.1 - Tipos Litológicos Adotados na Lavra da Mina de Cajati.

\begin{tabular}{|c|c|}
\hline Típo Litológico & Definição \\
\hline Jacupiranguito & Estéril \\
\hline Carbonatito Calcítico Sul & $\mathrm{MgO}<=4,3 \%$ \\
\hline Carbonatito Calcitico Intermediário & $\mathrm{MgO}<=4,3 \%$ \\
\hline Carbonatito Calcítico Norte & $4,3<=\mathrm{MgO}<8,0$ \\
\hline Carbonatito Magnesiano Sul & $4,3<=\mathrm{MgO}<8,0$ \\
\hline Carbonatito Magnesiano Norte & $\mathrm{MgO}>=8,0$ \\
\hline Carbonatito Dolomítico Intermediário & $\mathrm{MgO}>=8,0$ \\
\hline Carbonatito Dolomítico Norte & $\begin{array}{c}\text { Carbonatito apresentando xenólitos } \\
\text { métricos de jacupiranguito }\end{array}$ \\
\hline Zona de Xenólitos & Carbonatito de coloração alaranjada \\
\hline
\end{tabular}

A Figura 3.4 apresenta a disposição dos furos de sonda em relação à cava da Mina de Cajati. 




Figura 3.4 - Disposição dos furos de sonda na cava da Mina de Cajati. 


\section{CAPÍTULO 4 \\ ANÁLISE ESTATÍSTICA}

Antes de se proceder à análise geoestatística, é recomendável que se realize uma análise estatística dos dados disponiveis e/ou obtidos a partir de composições de furos de sondagem. Esta análise estatística permite determinar o teor médio do depósito e a distribuição de freqüências dos teores. O teor médio permite uma análise preliminar da viabilidade técnico-econômica do depósito. A distribuição de frẹuuência permite determinar a porcentagem de teores acima de um determinado teor de corte. Nesta análise, ainda é possivel determinar a dispersão dos teores do depósito, relacionada à variabilidade natural, através do coeficiente de variação.

\section{1 - Distribuição de Freqüências}

A análise estatística descreve como as unidades de uma população estão distribuídas sobre o intervalo amostrado (Yamamoto et al., 2000). Ocorrem dois tipos de distribuição de freqüências: simples ou acumulada.

A distribuição do tipo simples é obtida tabulando-se os dados em intervalos constantes. Os dados assim agrupados, podem ser representados graficamente na forma de histograma, onde geralmente se lançam os intervalos de medida na abscissa e as freqüências na ordenada. O desenho de uma curva suave sobre o histograma gera uma função que descreve de distribuição de freqüências dos dados, denominada função de distribuição ou função densidade de probabilidade.

Para a obtenção de freqüências acumuladas, o procedimento é o mesmo, apenas os dados devem ser agrupados de forma acumulada. O desenho de uma curva suave sobre esse polígono dá origem à função de distribuição acumulada, a qual descreve a proporção da população que é menor ou maior que um dado valor de referência. Através desta última representação, é possivel fazer um pré-estudo de viabilidade técnica ou econômica, dependendo da proporção encontrada acima ou abaixo do teor de corte. 
$\mathrm{Na}$ análise de dados para avaliação de reservas existem duas distribuições importantes a serem consideradas, a distribuição normal e a distribuição lognormal (Figura 4.1).
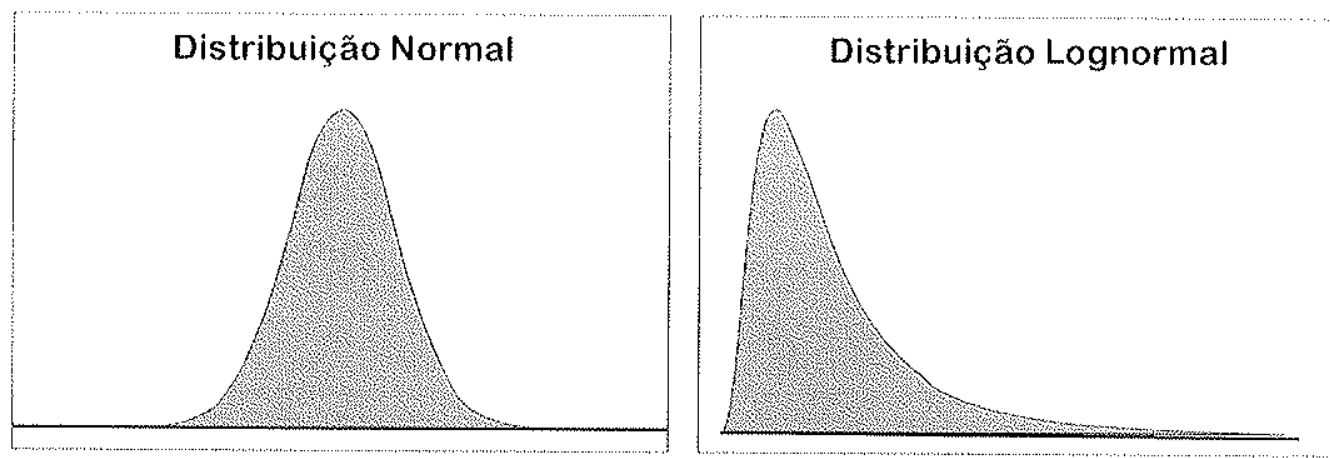

Figura 4.1 - Tipos de distribuição de freqüências: distribuição normal ou gaussiana; distribuição lognormal.

A distribuição normal ou gaussiana é a mais utilizada em estatística, já que um grande número de variáveis aleatórias ocorre sob esta forma.

A função que descreve matematicamente esta distribuição é dada pela equação:

$$
f(x)=\frac{1}{\sigma \sqrt{2 \pi}} e^{-1 / 2[(x-\mu) / \sigma]^{2}}
$$

onde: $f(x)$ é a função densidade de probabilidade; $x$ é uma observação e $\mu$ e $\sigma$ são respectivamente a média e o desvio padrão que definem a forma da curva.

A distribuição normal é a distribuição teórica mais utilizada na prática, já que suas propriedades são bem conhecidas, sendo matematicamente mais conveniente trabalhar com ela. A maioria das observações segue uma distribuição normal ou aproximadamente normal.

A distribuição lognormal é um tipo encontrado em muitos problemas de avaliação de reservas, principalmente em casos de metais raros, caracterizando-se por uma distribuição com assimetria positiva, apresentando uma grande quantidade de valores baixos e poucos valores altos. Davis (1986) exemplifica com os volumes de campos de petróleo de uma dada região, onde há forte assimetria positiva, ou seja, grande concentração de valores menores, existindo uma cauda longa em direção aos valores maiores. 
A função densidade de probabilidade desta distribuição é dada pela equação:

$f(x)=\frac{1}{x \beta \sqrt{2 \pi}} e^{-1 / 2[(\log x-\alpha) / \beta]^{2}}$

onde : $\alpha$ é a média dos logaritmos de $\mathrm{x} ; \beta$ é o desvio padrão dos logaritmos de $\mathrm{X}$ em relação à $\alpha$.

A distribuição lognormal é sempre assimétrica para a direita (assimetria positiva), sendo o grau de assimetria dependente somente do valor de $\beta^{2}$, que corresponde à variância dos logaritmos das observações (Kock \& Link, 1971). A variação da assimetria da distribuição lognormal pode ser observada na Figura 4.2.

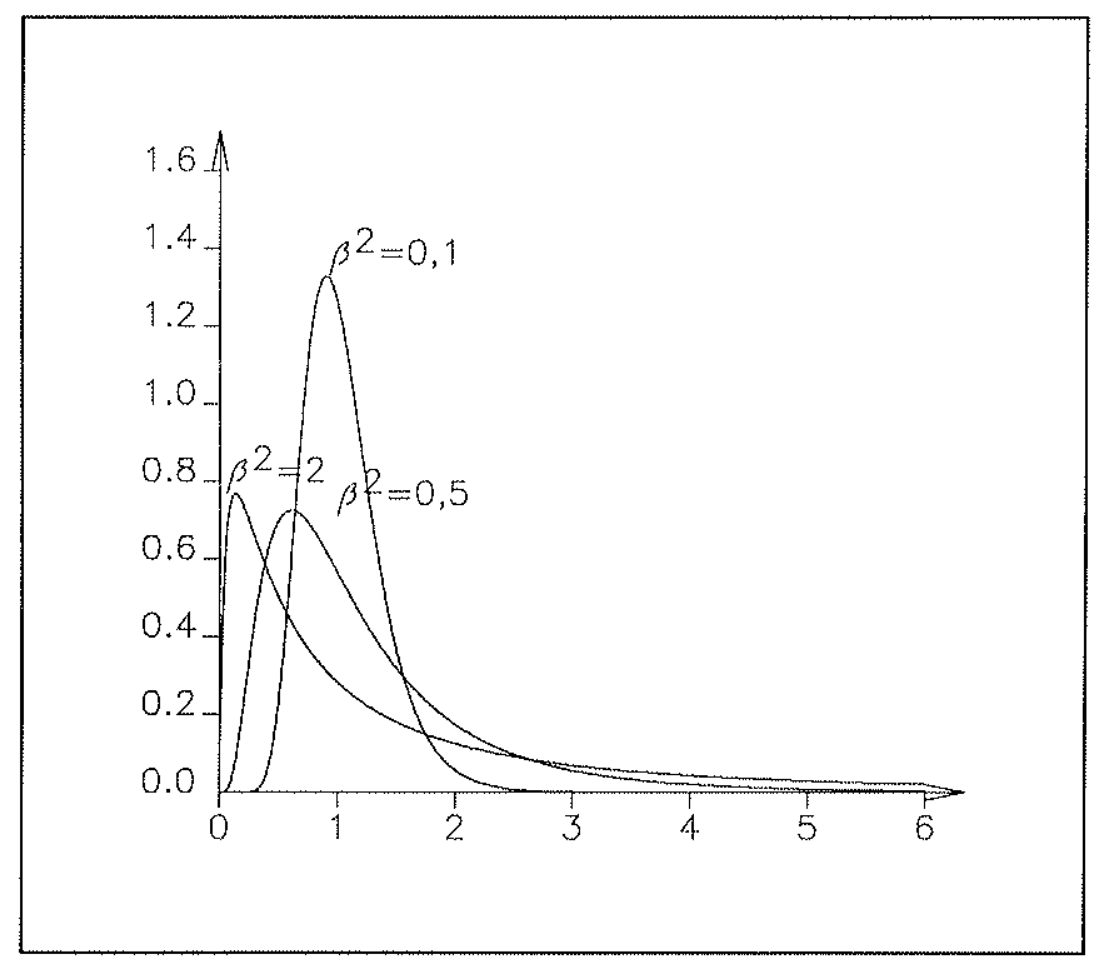

Figura 4.2 - Curvas de distribuição lognormal com $\alpha$ e $C$ iguais a zero e três valores de $\beta^{2}$, segundo Aitchison \& Brown (1957, apud Koch \& Link, 1971).

A transformação não linear corresponde a mudança de uma distribuição lognormal em uma distribuição normal ou aproximadamente normal. Entretanto, algumas distribuições de freqüências apresentam-se após a transformação logarítmica com certa assimetria negativa (assimétrica para a esquerda), que pode ser corrigida 
pela adição de uma constante (terceiro parâmetro) às observações originais, antes da transformação logarítmica (Krige, 1978 apud Yamamoto et al., 2000).

A função densidade de probabilidade da distribuição lognormal a três parâmetros é descrita pela seguinte equação:

$$
f(x)=\frac{1}{(x+C) \beta \sqrt{2 \pi}} e^{-1 / 2[(\log (x+c)-\alpha) / \beta]^{2}}
$$

A constante $C$ (terceiro parâmetro da distribuição lognormal) pode ser estimada, segundo Landim (1985), pela equação:

$C=\frac{M^{2}-p 1 p 2}{p 1+p 2-2 M}$

onde: $\mathrm{M}$ é a mediana, ou seja, o valor de teor correspondente a $50 \%$ da distribuição; $p 1$ é o valor de teor correspondente a um percentil entre 5 e 20\%; p2 é o valor de teor correspondente a um percentil entre 100-p1.

\section{2 - Estatística Descritiva}

Após conhecer a distribuição de freqüências dos dados, pode-se obter alguns parâmetros estatísticos que a caracterizam, o que permitirá um estudo das propriedades da população em termos do valor médio medido e da forma como os demais valores encontram-se distribuídos em torno deste valor médio (Yamamoto et al., 2000). Esses parâmetros são a média, a variância e o desvio padrão, o coeficiente de variação, a assimetria e a curtose.

\subsection{1 - Média ou Esperança Matemática}

Corresponde a uma medida de tendência central dos dados, calculada segundo:

$$
E(X)=\sum_{i=1}^{n} x_{i} P\left(x_{i}\right)
$$


onde: $E(x)$ é a esperança matemática ou média da população; $x_{i}$ corresponde a iésima observação da variável $\mathrm{X}$; e $\mathrm{P}\left(\mathrm{X}_{\mathrm{i}}\right)$ é a probabilidade associada à ocorrência da iésima variável $\mathrm{x}$.

Assumindo que as probabilidades associadas às $\mathrm{n}$ variáveis aleatórias são iguais entre si e, portanto, iguais a $1 / n$, teremos:

$E(X)=\bar{X}=\frac{1}{n} \sum_{i=1}^{n} x_{i}$

Outras das chamadas medidas de tendência central seriam a mediana, que consiste na observação correspondente a $50 \%$ de uma população (Figura 4.3) e a moda, que corresponde ao valor médio da classe de maior freqüência da distribuição (Figura 4.4).

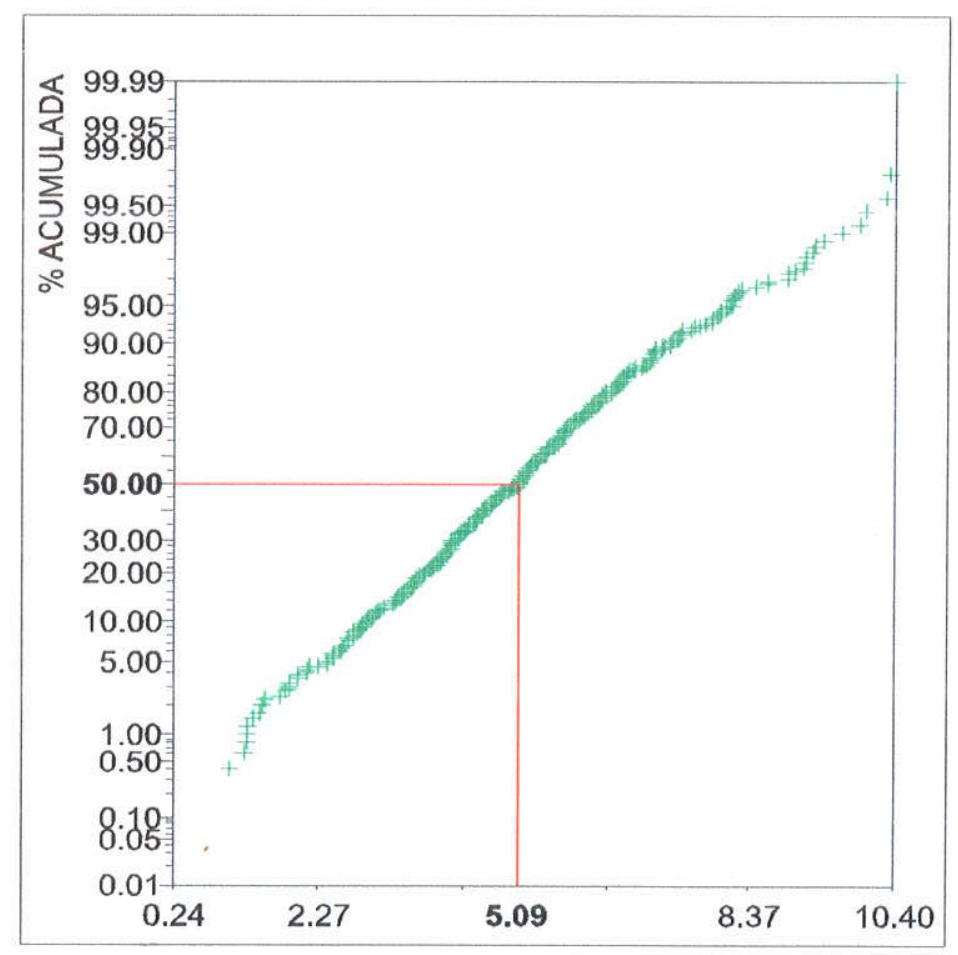

Figura 4.3 - Curva de freqüência acumulada destacando a mediana da distribuição. 


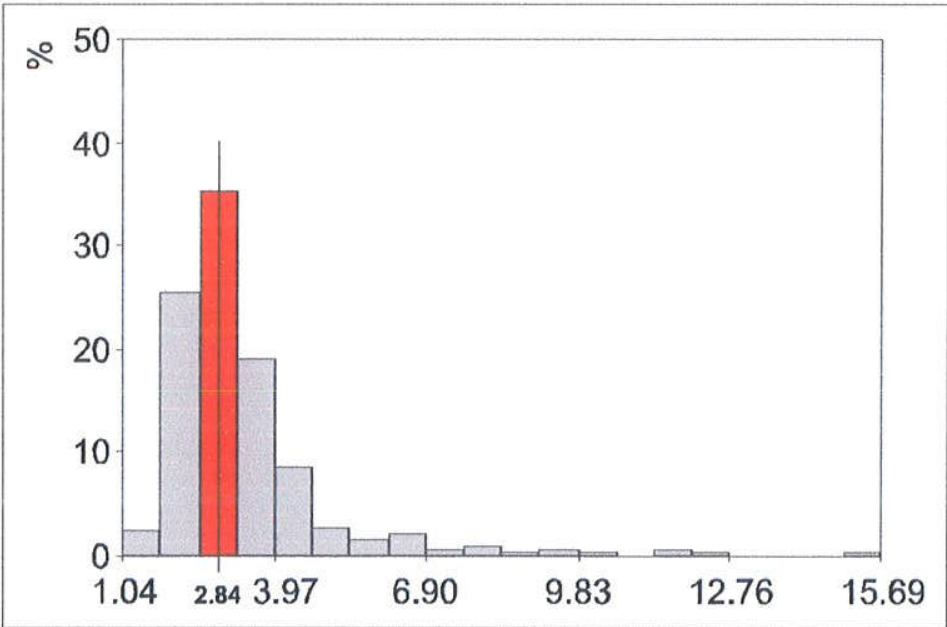

Figura 4.4 - Histograma destacando a moda, correspondendo ao ponto médio da classe de maior freqüência.

\subsection{2 - Variância}

Corresponde à dispersão dos valores $x_{i}$ em relação ao valor médio do conjunto de dados.

$\operatorname{Var}(X)=S^{2}=\frac{1}{n} \sum_{i=1}^{n}\left(x_{i}-\bar{x}\right)^{2}$

O desvio padrão corresponde a raiz quadrada da variância e, portanto, possui a mesma unidade da média.

\subsection{3 - Coeficiente da Variação}

Corresponde a outra medida de dispersão em torno da média e é obtido pela divisão do desvio padrão pela média.

$C V=\frac{S}{\bar{X}}$

Como o coeficiente de variação é adimensional, ele é freqüentemente utilizado na comparação de dispersões relativas de valores entre diferentes distribuições. 0 coeficiente de variação é muito útil quando se quer saber se os dados devem ser 
tratados pela teoria lognormal ou normal. Segundo Finney (1941 apud Yamamoto \& Bettencourt, 1992), quando o coeficiente de variação for menor que 1,2, a média aritmética representa mais de $90 \%$ da eficiência da estimativa da média logarítmica.

\subsection{4-Assimetria}

A assimetria representa o grau de simetria de uma distribuição de freqüências em torno da média. Pode ser positiva, se a cauda da distribuição estiver à direita da média, e negativa, se a cauda estiver à esquerda. A assimetria positiva é observada na maioria das distribuições de freqüências de variáveis de depósitos minerais com alta variabilidade natural, como depósitos de metais raros, ouro, urânio, etc., que implicam em distribuições lognormais. Por outro lado, a assimetria negativa é verificada na distribuição de freqüências de elementos que apresentam teor máximo estequiométrico, como, por exemplo, $\mathrm{CaO}$ em calcários, cujo limite máximo é de $56 \%$, considerando que o calcário é constituído somente por calcita.

\section{$4.2 .5-$ Curtose}

A curtose corresponde ao grau de achatamento de uma distribuição em relação a uma distribuição normal. Reflete a dispersão dos valores em torno da média (Spiegel, 1994). Dependendo do grau de achatamento, uma distribuição pode ser leptocúrtica (curva pouco achatada, com pequena dispersão em torno da média), platicúrtica (curva muito achatada em relação à distribuição normal, com grande dispersão em torno da média) e mesocúrtica (grau de achatamento intermediário entre os dois anteriores).

\section{3 - Teste de Correlação}

Segundo Davis (1986), é possivel estender os procedimentos usados para o cálculo da variância de uma única propriedade para o cálculo da medida de variabilidade mútua entre duas variáveis. A covariância mede, deste modo, a distribuição de valores de duas variáveis em torno de uma média comum.

A covariancia pode ser expressa por: 
$\operatorname{COV}[X Y]=E[X Y]-E[X] E[Y]$

Para a estimativa do grau de correlação entre as variáveis pode ser utilizado o coeficiente de correlação linear $r$ que representa a razão entre a covariância e o produto dos desvios padrões das variáveis:

$$
r_{X Y}=\frac{\operatorname{CoV}[X Y]}{\sqrt{\operatorname{Var}[X]} \sqrt{\operatorname{Var}[Y]}}
$$

O coeficiente de correlação, por representar uma razão, é livre de unidade de medida.

Como a covariância não pode exceder o produto dos desvios padrões das variáveis, o coeficiente de correlação pode assumir apenas valores entre -1 e +1 .

- $\quad r_{X Y}=+1$ - indica a existência de uma completa relação entre as variáveis;

- $\quad r_{X Y}=-1$ - indica a existência de uma completa relação inversa, ou seja, quando uma variável aumenta seu valor a outra diminui;

- $\quad r_{X Y}=0$ - indica a ausência de qualquer relação entre as duas variáveis.

Para saber o significado de coeficientes de correlação intermediários, é possível realizar o teste de correlação (teste $\boldsymbol{t}$ de Student) para verificar se o grau correlação entre as variáveis é significativamente diferente de zero.

Para isso são testadas duas hipóteses (Davis, 1986):

- $\quad H 0 r_{X Y}=0$ - hipótese nula, onde o valor de correlação linear não é significativamente diferente de zero, ou seja, não há correlação.

- H1 $r_{X Y} \neq 0$ - hipótese alternativa, onde o valor de correlação linear é significativamente diferente de zero, ou seja, há correlação.

O valor de $\mathbf{t}$ obtido a partir dos dados é calculado da seguinte maneira:

$$
t=\frac{r_{X Y} \sqrt{n-2}}{\sqrt{1-r_{X Y}}}
$$

onde $\mathrm{n}$ corresponde ao tamanho da amostra e n-2 ao número de graus de liberdade. 
O valor assim obtido deve ser comparado ao valor da distribuição teórica, devendo ser escolhido o grau de significância desejado para o teste (Figura 4.5). Por tratar-se de um teste de duas caudas (valores positivos e negativos), o grau de significância deve ser dividido entre os dois lados. Se os valores de t calculados estiverem nos campos de rejeição da hipótese nula, existe correlação significantemente diferente de zero entre as variáveis, caso contrário, confirma-se a hipótese nula.

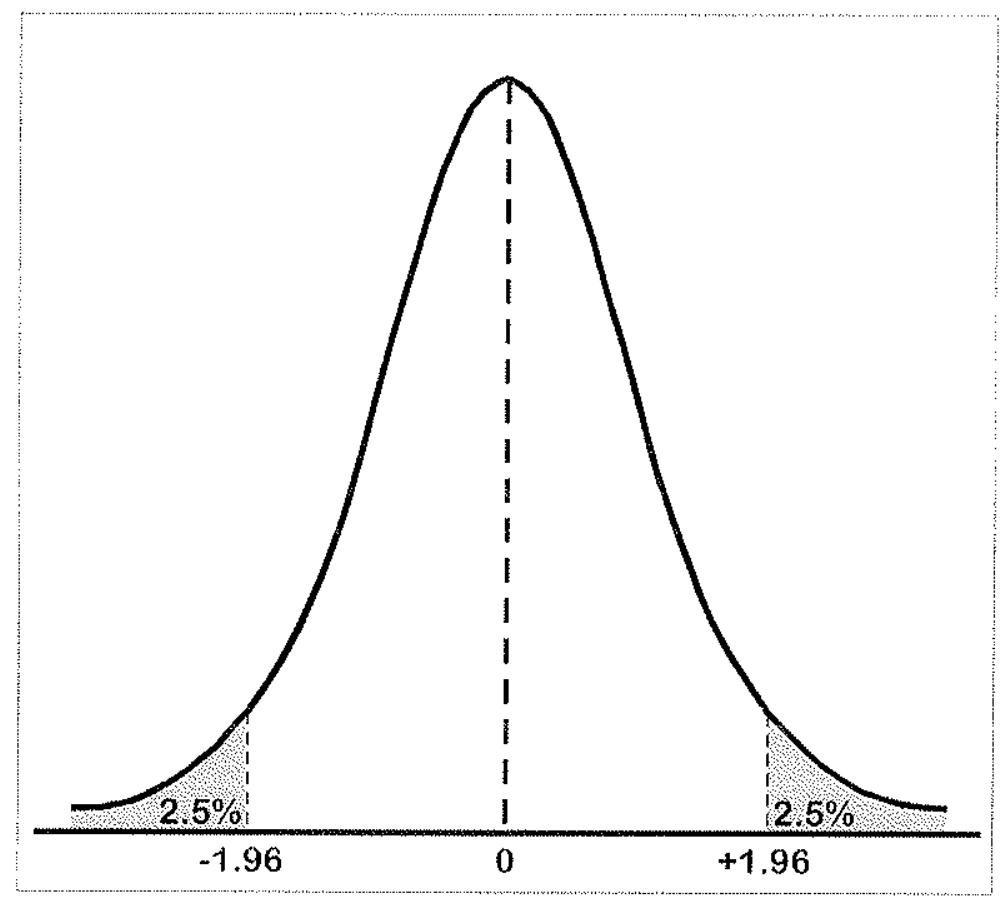

Figura 4.5 - Curva de distribuição t de Student $(n>30)$ com duas áreas criticas (cinza) limitando $5 \%$ da área sobre a curva, para o caso de testes de duas caudas. 


\section{CAPÍTULO 5}

\section{ANÁLISE GEOESTATÍSTICA}

A geoestatística é a aplicação de métodos matemáticos e estatísticos em problemas das Ciências da Terra. Atualmente sua utilização é ampla, podendo ser aplicada, por exemplo, na determinação de elementos traços em rochas, em análise de dados geoquímicos de pesquisa mineral, determinação do tipo de amostragem, na estimativa espacial e temporal, em simulação, em análise de riscos e em quantificação de reservas.

Segundo Clark (1979), o procedimento para a avaliação geoestatística de reservas em um depósito mineral pode ser dividido em duas partes:

- investigação e modelagem de uma estrutura física e estatística de um corpo mineral através da semivariografia;

- processo de krigagem propriamente dito, que depende exclusivamente dos semivariogramas elaborados na etapa anterior.

O cálculo de um teor médio para um bloco na jazida, a partir dos dados de teores obtidos nas amostras coletadas ao longo dos furos de sondagem corresponde a um problema de estimativa, que usa as informações dos pontos vizinhos, considerando a posição espacial relativa das amostras e dos seus teores. A krigagem proporciona uma estimativa linear ótima, bem como o cálculo da variância da krigagem, que corresponde ao erro associado à mesma (Yamamoto \& Bettencourt, 1992).

Assim como as técnicas estatísticas, a geoestatística baseia-se em conceitos probabilísticos. Porém, Clark (1979) assume que a distribuição das diferenças nos teores entre dois pontos amostrados é a mesma em todo o depósito, dependendo somente da orientação espacial destes pontos, ou seja, da distância entre eles e da sua orientação. Esta suposição é intitulada hipótese intrínseca ou de quaseestacionaridade.

Segundo Royle (1979), os principais argumentos para o uso da geoestatística seriam:

- a geoestatística é completamente baseada na prática de boa avaliação fundamentada em uma teoria racional, em vez de uma avaliação mineira intuitiva praticada anteriormente; 
- reconhecimento do fato que a variação total é parte aleatória, parte espacial, conduzindo a estimativas que não são enviesadas e que possuem pequenos erros de estimativa;

- a geoestatística explica porque alguns tipos tradicionais de estimador produzem estimativas enviesadas - estes estimadores podem ser removidos pelo uso de outros tipos de estimadores (krigagem).

A utilização da geoestatística não pode substituir bons dados e informações adicionais, nem o julgamento de um profissional que conheça a natureza geológica/tecnológica do depósito. Assim, não se deve utilizar a geoestatística com a ilusão de economia de tempo de trabalho.

\section{1 - Variáveis Regionalizadas}

As variáveis regionalizadas representam os valores das variáveis referenciadas geograficamente. Uma variável regionalizada corresponde a qualquer função numérica com uma distribuição espacial que varia de um lugar a outro com continuidade aparente, mas cujas variações não podem ser representadas por uma função deterministica (Blais \& Carlier, 1968 apud Olea, 1975). Em geologia, todas as observações quantitativas realizadas em duas ou três dimensões, sejam elas geoquímicas, geofísicas, sedimentológicas, estruturais, etc., podem ser consideradas como exemplos de variáveis regionalizadas.

Segundo Yamamoto \& Rocha (2000), o conceito de variáveis regionalizadas foi introduzido para descrever quantitativamente variações espaciais em corpos de minério, e representam os valores de variáveis referenciadas geograficamente.

Um bom exemplo para o entendimento das variáveis regionalizadas foi elaborado por (Royle, 1979) e explicado a seguir.

Considerando as duas séries de números, cada série apresentando as seguintes médias e variâncias:

Série $A: 173629485$ - média $=5$ e variância $=6,7$

Série B : 1355798642 - média $=5$ e variância $=6,7$ 
Apesar destas duas séries apresentarem os mesmos valores dos parâmetros estatísticos, elas representam dois tipos de seqüências, sendo a primeira mais errática que a segunda.

Deste modo, a análise dos parâmetros estatísticos, neste caso, é de pouca utilidade pois a estatística clássica baseia-se no princípio de independência entre amostras e não consegue distinguir os dois conjuntos. Amostras obtidas de um depósito mineral estão, de certa forma, relacionadas entre si. Assim, a introdução do conceito de variáveis regionalizadas pela geoestatística tenta resolver estes tipos de problemas.

No exemplo anterior, poderia se calcular a soma das diferenças dos quadrados dos valores das amostras, separadas por uma determinada distância. Este valor, dividido pelo número de pares de amostras, dá sentido a uma medida de variância, com significado espacial, pois depende da distância utilizada. A Tabela 5.1 apresenta os valores das variâncias espaciais das duas seqüências calculadas para até quatro intervalos de amostragem.

Tabela 5.1 - Variância espacial para as duas seqüências de números.

\begin{tabular}{|c|c|c|}
\hline Intervalo de amostragem & Variáncia Espacial A & Variância Espacial B \\
\hline 1 & 22,00 & 3,63 \\
\hline 2 & 3,00 & 12,86 \\
\hline 3 & 23,67 & 23,83 \\
\hline 4 & 3,80 & 29,60 \\
\hline
\end{tabular}

A representação destes dados sob uma forma gráfica, lançando-se as variâncias espaciais em função dos intervalos de amostragem, pode ser observada na Figura 5.1. 




Figura 5.1 - Variância espacial em função dos intervalos de amostragem para as séries A e B.

Por este gráfico, percebe-se que a série A é muito dispersa, enquanto a série B apresenta-se mais uniforme. Nesta última série, as variâncias espaciais aumentam à medida que aumenta a distância entre as amostras. Este comportamento é o desejado para os corpos de minério, dentro de alguma escala de amostragem.

As características das variáveis regionalizadas que os métodos estatísticos convencionais não conseguem reconhecer são:

- localização: a posição relativa das amostras e a sua distribuição espacial exercem influência sobre a correlação espacial da variável regionalizada;

- $\quad$ suporte: corresponde à unidade amostral, seja ela pontual, volumétrica, etc;

- $\quad$ continuidade: para uma variável ser considerada regionalizada, deve existir uma variação espacial ponto a ponto, variação esta que pode ser expressa matematicamente por meio do semivariograma;

- $\quad$ anisotropia: corresponde a diferenças de variações entre as diferentes direções estudadas. 


\section{2 - Semivariograma}

Para descrever o comportamento do fenômeno regionalizado, utiliza-se o semivariograma, que corresponde à diferença entre valores de amostras em um depósito, tomados simultaneamente em dois pontos, segundo uma determinada direção.

A função semivariograma $\gamma(h)$ é definida como sendo a esperança matemática do quadrado da diferença entre os valores de pontos, separados por uma distância h, conforme a equação:

$Y(h)=E\left\{[Z(x+h)-Z(x)]^{2}\right\}$

ou em termos computacionais :

$Y(h)=\frac{1}{2 n} \sum_{i=1}^{n}[Z(x+h)-Z(x)]^{2}$

onde $\gamma(h)$ é a função semivariograma; n é o número de pares de pontos separados por uma distância $h ; Z(x+h)$ é o valor da variável regionalizada no ponto $(x+h) ; Z(x)$ é o valor da variável regionalizada no ponto $x$.

A variância é conhecida em notação geoestatística como $C(0)$, ou seja, a covariância para distância de separação nula.

Pode-se expressar a função semivariograma $\gamma(h)$ em termos de variância $C(0)$ e da covariância $C(h)$, segundo a expressão:

$\mathrm{V}(\mathrm{h})=\mathrm{C}(0)-\mathrm{C}(\mathrm{h})$

A função semivariograma é direcional, pois o semivariograma é calculado em uma direção predefinida. Na prática, é utilizada a chamada análise estrutural, onde são construídos semivariogramas segundo várias direções do depósito, visando conhecer a estruturação da mineralização. A partir da interpretação do semivariograma, obtém-se parâmetros que descrevem o comportamento espacial das variáveis regionalizadas. 
Semivariogramas em diferentes direções podem dar valiosas informações sobre a continuidade ou ausência de variação ao longo do depósito.

Deste modo, deve-se iniciar a análise geoestatística com o cálculo de semivariogramas em diferentes direções, aproveitando o conhecimento sobre o depósito. Nos casos de depósitos desconhecidos, pode-se utilizar a sugestão de Yamamoto \& Rocha (2000) na qual os semivariogramas devem ser construídos, em intervalos de $45^{\circ}$, iniciando na direção $\mathrm{N}-\mathrm{S}$. Pode-se ainda, no caso de malhas regulares, especificar as direções segundo a orientação da linha base $\left(0^{\circ}, 45^{\circ}, 90^{\circ} \mathrm{e}\right.$ $135^{\circ}$, em sentido anti-horário).

A restrição teórica para as distâncias entre pontos utilizados na construção do semivariograma corresponde a um quarto da extensão total do domínio das amostras. Entretanto, na prática, utiliza-se a metade do dominio amostral. Observa-se que à medida que as distâncias aumentam entre os pares de pontos, poucos pares entram nos cálculos, implicando que pontos próximos à origem (pequenas distâncias) serão mais confiáveis do que aqueles a grandes distâncias (Clark, 1979).

Em muitos casos, os dados ocorrem irregularmente distribuídos no espaço bidimensional, não sendo possivel, a princípio, encontrar pares de amostras suficientes, utilizando-se unicamente $o$ espaçamento $h$ para $o$ cálculo do semivariograma. Para resolver este problema, Landim (1985) sugere a utilização de uma tolerância $\Delta$ h para o espaçamento $h$ entre os pares de amostras e um ângulo de tolerância $\Delta$ h para a direção de semivariografia. Deste modo, para o cálculo do semivariograma de uma distribuição irregular de pontos, ao longo de uma direção $\alpha$, considera-se todas as amostras que se encontram no ângulo $\alpha \pm \Delta \alpha$ e, em seguida, classificam-se os pares de amostras em classes de distância $h \pm \Delta h, 2 h \pm \Delta h, \ldots$, onde $h$ é a distância básica (Figura 5.2). 


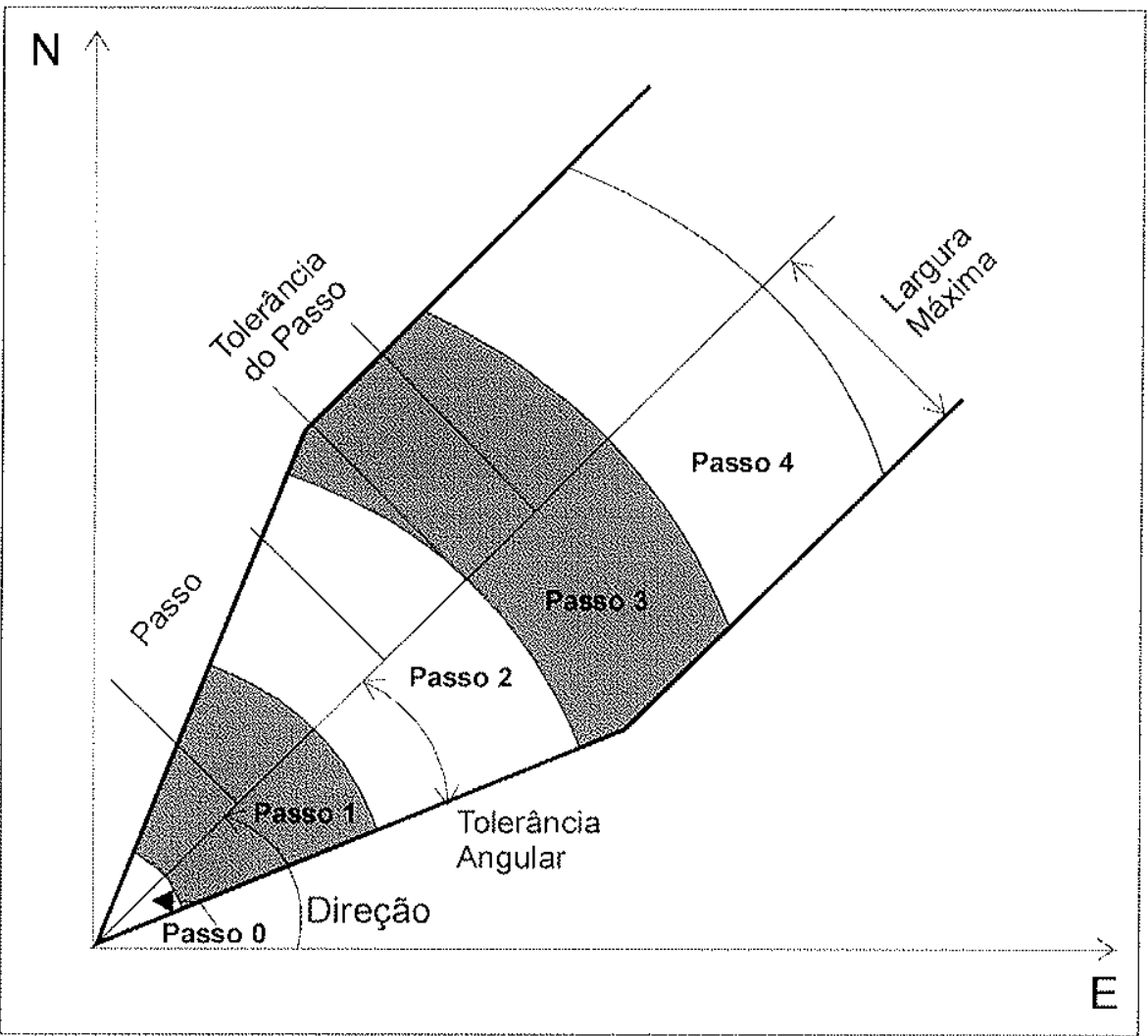

Figura 5.2 - Desenho mostrando a direção do semivariograma, os passos, a tolerância angular, a largura máxima e a tolerância do passo (modificado de Pannatier, 1994 apud Yamamoto \& Rocha, 2000).

Após a definição da direção e da tolerância angular, do passo, sua tolerância e o número de passos, calcula-se a nuvem de semivariograma aplicando-se a expressão $Y(h)=\left[Z\left(x_{i}+h\right)-Z\left(x_{i}\right)\right]^{2}$ para cada par de pontos.

A seguir, calcula-se o valor da variância espacial média para o valor do passo que está sendo analisado. Este valor médio é então plotado em um gráfico que relaciona a distância média (passo + tolerância do passo) que separa as duas amostras e o valor de $\gamma(h)$ (variância espacial) médio encontrado (segundo Rocha, 1999).

$\mathrm{Na}$ Figura 5.3, são apresentados os principais elementos que compõem um semivariograma típico. 




Figura 5.3 - Semivariograma típico e seus elementos.

Os principais elementos do semivariograma são:

- $\quad$ amplitude: é a distância a partir da qual as amostras passam a não possuir correlação espacial entre si;

- patamar: valor da variância correspondente ao início do campo aleatório. Corresponde à variância regionalizada.

- $\quad$ efeito pepita: é o valor da função semivariograma na origem ( $h=0)$, também sendo chamado de variância aleatória;

- $\quad$ variância espacial: diferença entre a variância regionalizada (patamar) e a variância aleatória (efeito pepita);

- anisotropia: variações de comportamentos espaciais ao longo de diferentes direções do depósito. A anisotropia pode ser subdividida em anisotropia geométrica, quando ocorrem variações da amplitude conforme as direções; anisotropia zonal, quando há variação do patamar conforme as direções; e anisotropia mista, quando tanto o patamar quanto a amplitude variam conforme as direções (Figura 5.4); 

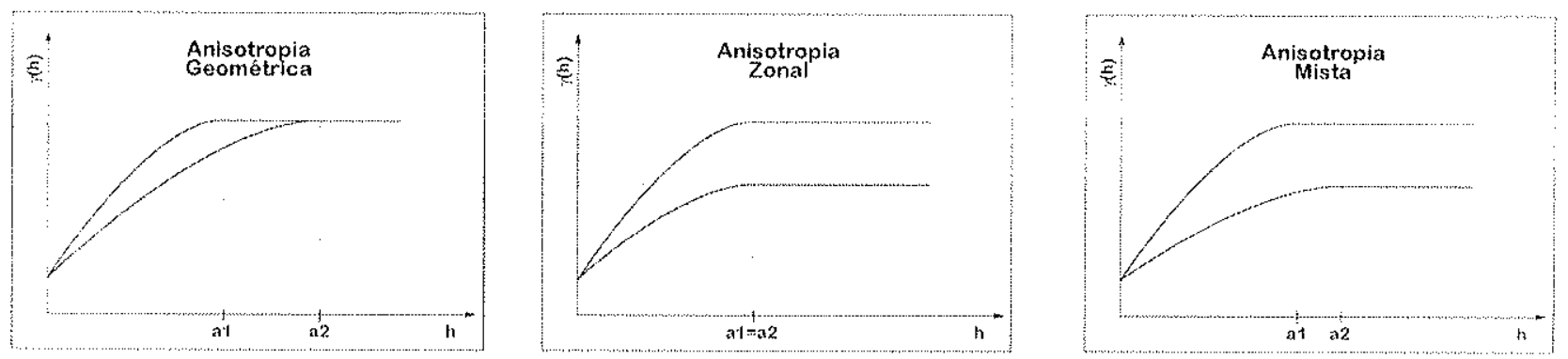

Figura 5.4 - Tipos de anisotropias.

- comportamento próximo à origem: corresponde ao grau de continuidade da mineralização. Pequenas distâncias, a princípio, devem apresentar baixa variância espacial. Podem ser descritos quatro tipos básicos de comportamento, descritos a seguir e visualizados na Figura 5.5.
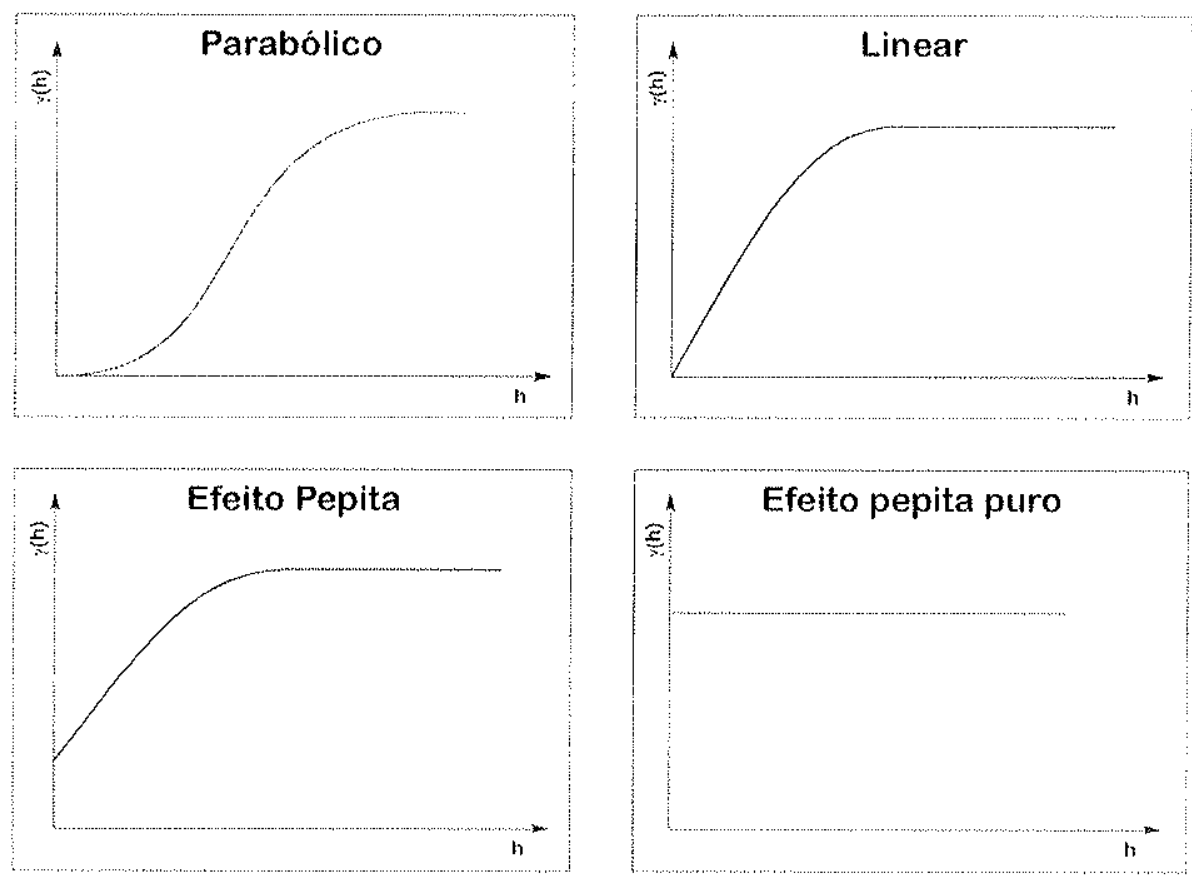

Figura 5.5 - Tipos de comportamento do semivariograma próximos à origem.

- parabólico: representa um alto grau de continuidade das amostras selecionadas;

- linear: representa uma grande homogeneidade à pequenas distâncias, aumentando progressivamente a medida que há o incremento destas distâncias. Comportamento típico de muitos depósitos de minerais metálicos;

- efeito pepita: apresenta uma descontinuidade na origem, que pode ser reflexo de dois fatores: erros de medida na amostragem e micro variabilidades; 
- efeito pepita puro: o efeito pepita puro é um fenômeno de difícil ocorrência em mineralizações, mas quando da sua ocorrência, indicando a inexistência de correlação espacial entre os dados, inviabiliza a utilização da metodologia geoestatística de estimativa. Burguess \& Webster (1980 apud Yamamoto, 2000a) citam que o termo efeito pepita teve origem na mineração de ouro, onde a inclusão de uma pepita de ouro em uma pequena amostra de um testemunho de sondagem é um evento aleatório.

\subsection{1 - Modelos Teóricos de Semivariogramas}

Por se querer inferir a estrutura de um depósito e o comportamento das variações de teores em áreas não amostradas a partir de um conjunto de pontos amostrados, deve-se ajustar o semivariograma experimental a um modelo matemático conhecido, que representaria o comportamento do depósito como um todo. Yamamoto (1991) escreve que a correlação do modelo construído ao modelo teórico é feita de maneira interativa, com um programa de computador. O programa MODVARG, do sistema GeoVisual é um bom exemplo de programa desta natureza, pois o modelo de semivariograma é apresentado automaticamente a cada mudança de parâmetro. $O$ ajuste deste semivariograma experimental a modelos teóricos fornece as informações para se proceder a krigagem.

Os modelos mais utilizados na prática são o modelo esférico ou de Matheron, o modelo exponencial e o modelo gaussiano. Podem ser citados ainda, o modelo potencial e o logarítmico. A Figura 5.6 apresenta os principais modelos de semivariogramas teóricos encontrados na natureza, segundo Rocha (1999). 


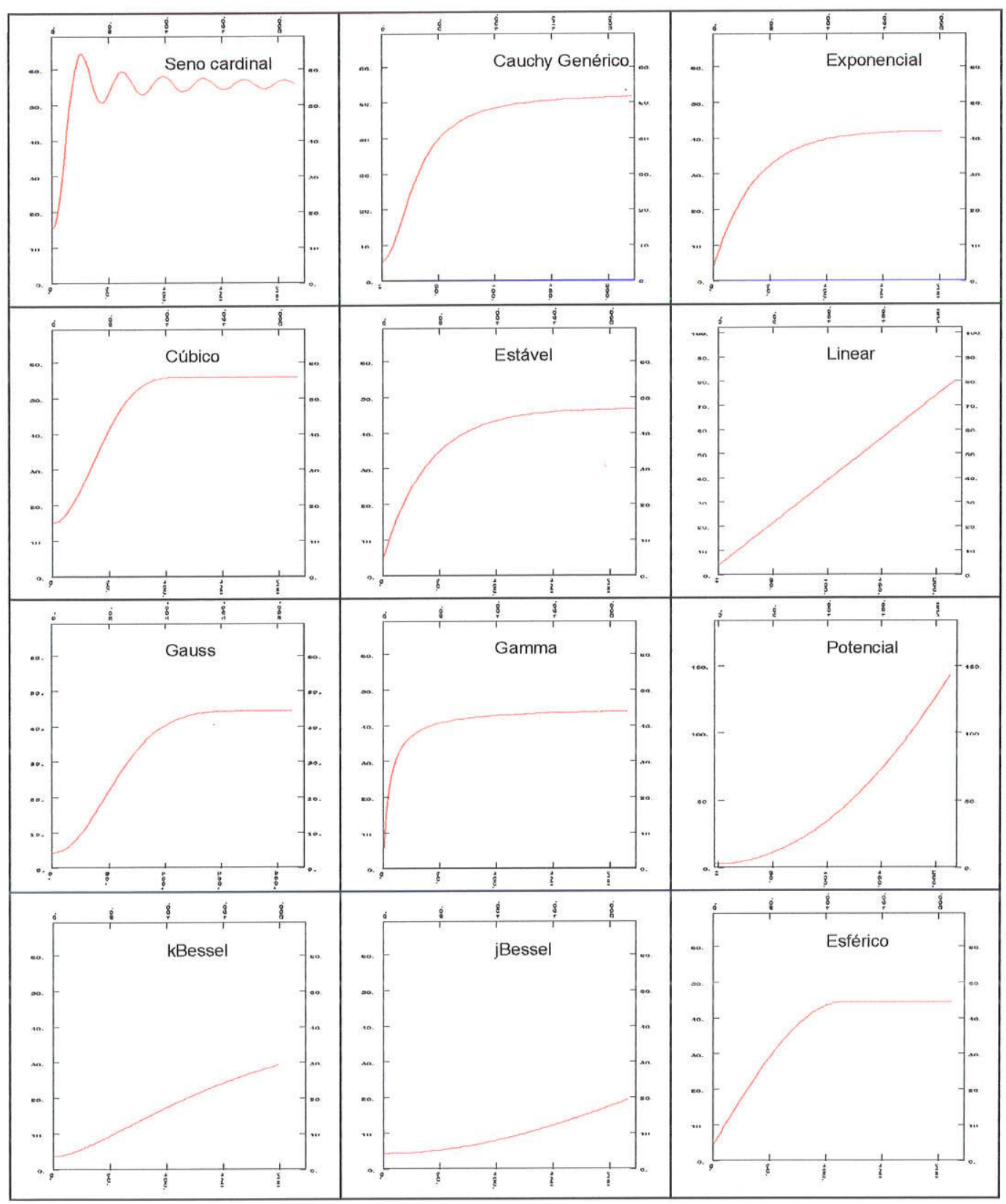

Figura 5.6 - Principais modelos de semivariogramas teóricos segundo Rocha (1999).

\section{3 - Estimativas por Krigagem Ordinária}

Após a análise geoestatística, na qual os semivariogramas experimentais foram calculados e os modelos teóricos foram ajustados, passa-se ao cálculo de estimativas pela técnica da krigagem ordinária. A krigagem ordinária tem como característica principal a precisão local das estimativas, mas com perda da precisão global devido ao efeito de suavização (suavização da variância e do semivariograma). 
Antes de passar a estimativa propriamente dita, a krigagem como qualquer outro método de interpolação requer a definição de certas condições de controle visando estimativas de qualidade. Primeiramente, deve-se definir a fronteira dos dados onde as técnicas de estimativa serão aplicadas para o cálculo dos recursos/reservas, cálculos estes realizados em blocos de cubagem. As dimensões destes blocos devem ser compatíveis com a densidade média de amostragem nas três direções do depósito. $\mathrm{O}$ conjunto de blocos de cubagem que compõem o depósito é chamado modelo tridimensional de blocos.

As dimensões dos blocos de cubagem devem ser compatíveis com a densidade de amostragem. Segundo Vallée \& Côte (1992), a krigagem de blocos com dimensões muito menores que a metade da malha de amostragem deveria ser evitada, pois tais estimativas exibem extrema variabilidade (Figura 5.7).

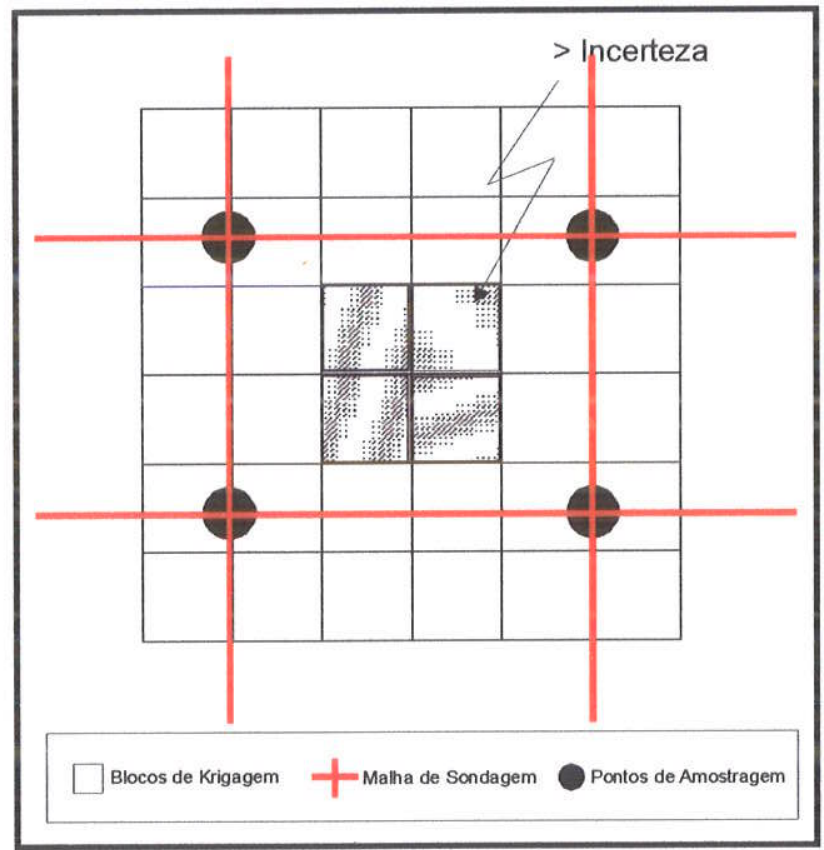

Figura 5.7 - Influência da dimensão de blocos de krigagem menores que a metade da malha de amostragem.

A grande diferença dos métodos convencionais para a krigagem ordinária de blocos está na geometria e dimensão dos blocos de cubagem. Entretanto, a principal diferença está na forma de cálculo dos teores, já que a krigagem faz uso das funções matemáticas de interpolação. Além destas funções, a krigagem faz uso dos princípios 
de interpretação utilizados nos métodos convencionais, os quais são aplicados para interpolação de teores nos blocos de cubagem.

Para o cálculo do recurso/reserva de um depósito a krigagem ordinária, deve-se considerar, segundo Yamamoto (2000a), os blocos de cubagem pertencentes ao domínio do depósito e que apresentarem um mínimo de informação, segundo critérios de seleção de amostras.

\subsection{1 - Definição da vizinhança}

Uma das principais etapas do trabalho de avaliação de recursos/reservas de blocos de cubagem consiste na seleção das amostras que serão efetivamente utilizadas para a estimativa dos blocos. Os critérios para esta seleção de pontos vizinhos ao bloco, bem como o número de pontos, devem ser estabelecidos no início do processo de avaliação. Dependendo do modo de pesquisa, diferentes subconjuntos de amostras poderão ser definidos e, portanto, diferentes resultados poderão ser obtidos. A escolha das amostras deve ser feita de tal modo que garanta uma boa amostragem espacial, evitando agrupamentos de pontos.

Harbaugh et al. (1977) estabeleceram critérios de seleção de amostras por quadrantes ou octantes, a fim de se evitar agrupamentos de pontos. Por estes critérios, os pontos de dados seriam escolhidos de tal modo que as amostras selecionadas estariam igualmente distribuidas em torno do ponto a ser estimado. Os critérios de seleção de amostras por quadrantes ou octantes dividem a região deste ponto em quatro ou oito setores, respectivamente, e selecionam as amostras mais próximas por setor até se completar um número desejado de amostras para fins de estimativa.

Deve-se definir, da mesma forma número de amostras a ser utilizado nos métodos de estimativa dos blocos de cubagem. Este número de amostras não deve ser excessivamente pequeno, o que acarretaria um valor estimado muito semelhante ao ponto mais próximo, nem excessivamente grande, o que resultaria em um valor estimado bastante suavizado.

Deste modo, Yamamoto (2000a) sugere fixar o número em 8 amostras, que se ajustaria perfeitamente aos critérios de quadrante ( 2 amostras por quadrante) ou octante (1 amostra por octante) no plano, ou então ao critério de octante tridimensional. Entretanto, esta condição pode ser alterada para um mínimo de 4 amostras em regiões 
de borda do corpo de minério, onde a condição inicial de seleção de amostras pode não ser satisfeita.

A Figura 5.8 apresenta o critério de seleção de amostras por quadrantes, onde foram escolhidas duas amostras por setor.

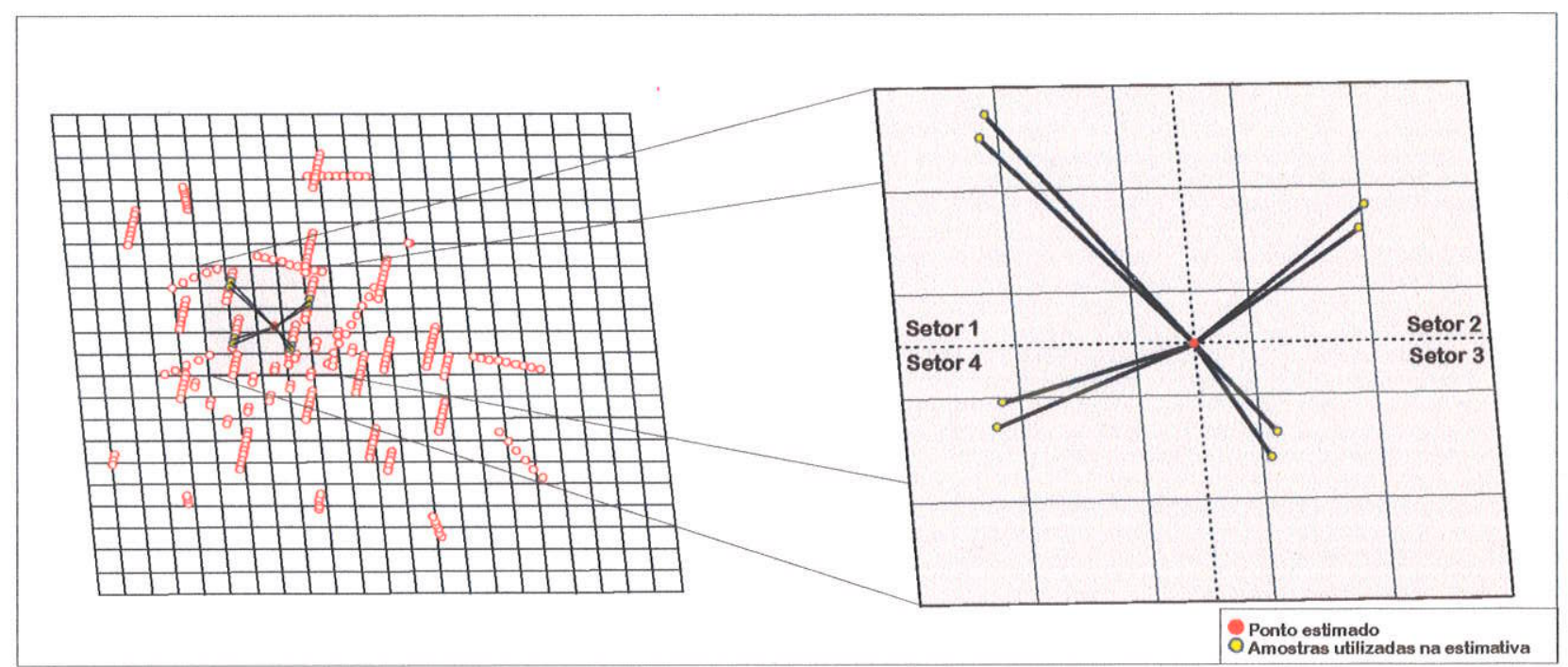

Figura 5.8 - Critério de seleção de amostras por quadrante, com a escolha de duas amostras por setor.

\subsection{2 - Krigagem}

A krigagem é o nome dado a uma coleção de técnicas generalizadas de regressão linear que caracterizam uma variância de estimativa, definida a partir de um modelo de covariância, podendo ter ou não restrições para eliminações de vieses (Olea, 1991).

Para introduzir o conceito da krigagem, deve-se começar pela teoria da krigagem simples (KS). O estimador da KS é definido como:

$Z_{\mathrm{KS}}^{*}\left(X_{0}\right)=\sum_{i=1}^{n} \lambda_{i}^{K S}\left[Z\left(X_{i}\right)-m\right]+m$

A krigagem simples trabalha com uma média $\mathrm{m}$, supostamente constante em todo o domínio da estimativa e que é calculada como a média dos dados. Este tipo de krigagem é algumas vezes chamado de krigagem com média conhecida (Wackernagel, 1995). 
Ao contrário da regressão múltipla, a média m é a mesma para todos os pontos, pois se assume que a função $Z\left(x_{0}\right)$ possua estacionaridade de segunda ordem, ou seja:

$E[Z(x+h)]=E[Z(x)]$

$\operatorname{Cov}[Z(x+h), Z(x)]=C(h)$

A variância de estimativa $\sigma_{l}^{2}$ é expressa por :

$\sigma_{\mathrm{E}}^{2}=\operatorname{Var}\left(Z_{\mathrm{KS}}^{*}\left(\mathrm{X}_{0}\right)-\mathrm{Z}\left(\mathrm{X}_{0}\right)\right)=\mathrm{E}\left[\left(\mathrm{Z}_{\mathrm{KS}}^{*}\left(\mathrm{X}_{0}\right)-\mathrm{Z}\left(\mathrm{X}_{0}\right)\right)^{2}\right]$

$\sigma_{\mathrm{E}}^{2}=\mathrm{E}\left[\left(Z_{\mathrm{KS}}^{*}\left(X_{0}\right)\right)^{2}+\left(Z\left(X_{0}\right)\right)^{2}-2 Z_{\mathrm{KS}}^{*}\left(X_{0}\right) Z\left(X_{0}\right)\right]$

$=\sum_{i=1}^{n} \sum_{j=1}^{n} \lambda_{i}^{\mathrm{Ks}} \lambda_{j}^{\mathrm{KS}} \mathrm{C}\left(\mathrm{X}_{\mathrm{i}}-\mathrm{X}_{j}\right)+\mathrm{C}\left(\mathrm{X}_{0}-\mathrm{X}_{0}\right)-2 \sum_{\mathrm{i}=1}^{\mathrm{n}} \lambda_{\mathrm{i}}^{\mathrm{Ks}} \mathrm{C}\left(\mathrm{X}_{\mathrm{i}}-\mathrm{X}_{0}\right)$

Escreve-se $\operatorname{cov}\left[Z\left(X_{i}\right), Z\left(X_{j}\right)\right]=C\left(X_{i}-X_{j}\right)$ devido a covariância espacial depender somente da diferença entre os pontos do domínio.

Esta variância de estimativa é mínima quando sua primeira derivada parcial for zero

$\frac{\partial \sigma_{E}^{2}}{\partial \lambda_{i}^{K S}}=0 \quad$ para $i=1, \ldots, n$

Deste modo, tem-se:

$2 \sum_{j=1}^{n} \lambda_{i}^{k s} C\left(X_{i}-X_{j}\right)-2 C\left(X_{i}-X_{0}\right)=0$

E o sistema de equação da KS é escrito:

$\sum_{j=1}^{n} \lambda_{j}^{K S} C\left(X_{i}-X_{j}\right)=C\left(X_{i}-X_{0}\right) \quad$ para $i=1, \ldots, n$ 
O termo da esquerda descreve as covariâncias entre os pontos. O termo da direita descreve a covariância entre cada dado e o ponto a ser estimado. A resolução deste sistema proporciona pesos ótimos $\lambda_{\mathrm{i}}$.

Um segundo interesse corresponde à variância ótima para cada ponto a ser estimado. Ela é obtida pela substituição do termo da esquerda do sistema de krigagem pelo primeiro termo do lado direito da expressão (5.1). Esta é a variância da krigagem simples.

$$
\begin{aligned}
& \sigma_{K S}^{2}=\sum_{i=1}^{n} \lambda_{i}^{K S} C\left(X_{i}-X_{0}\right)+C\left(X_{0}-X_{0}\right)-2 \sum_{i=1}^{n} \lambda_{i}^{K S} C\left(X_{i}-X_{0}\right) \\
& \sigma_{K S}^{2}=C(0)-\sum_{i=1}^{n} \lambda_{i}^{K S} C\left(X_{i}-X_{0}\right)
\end{aligned}
$$

Como visto anteriormente, a krigagem simples trabalha com uma média constante em todo o domínio, que dificilmente ocorre na prática. Deste modo, pode-se definir a média local através da técnica da krigagem da média.

Assim sendo, na krigagem da média $(K M)$, a função $m(x)$, que descreve a média dos dados, é calculada localmente, como uma constante, utilizando os dados dentro de uma vizinhança móvel. Em outras palavras, $m$ é considerado constante para distâncias menores que o diâmetro da vizinhança (Wackernagel, 1995).

A krigagem da média pode ser expressa pela combinação linear:

$$
m^{*}=\sum_{i=1}^{n} \lambda_{i}^{K M} Z\left(X_{i}\right) \quad \operatorname{com} \sum_{i=1}^{n} \lambda_{i}^{K M}=1
$$

Da mesma forma como a krigagem simples, a krigagem da média procura determinar a média local com mínima variância. Assim, a variância entre a média krigada e a média local $\operatorname{var}\left[\mathrm{m}^{*}-\mathrm{m}\right]$ deve ser minimizada : 


$$
\begin{aligned}
& \operatorname{var}\left[m^{*}-m\right]=E\left[\left(m^{*}-m\right)^{2}\right] \\
& =E\left[m^{* 2}-2 m * m+m^{2}\right] \\
& =\sum_{i=1}^{n} \sum_{j=1}^{n} \lambda_{i} \lambda_{j} E\left[Z\left(x_{i}\right) Z\left(x_{j}\right)\right]-2 m \sum_{i=1}^{n} \lambda_{i} E\left[Z\left(x_{i}\right)\right]+m^{2} \\
& =\sum_{i=1}^{n} \sum_{j=1}^{n} \lambda_{i} \lambda_{i} E\left[Z\left(x_{i}\right) Z\left(x_{j}\right)\right]-m^{2} \\
& =\sum_{i=1}^{n} \sum_{j=1}^{n} \lambda_{i} \lambda_{j} E\left[Z\left(x_{i}\right) Z\left(x_{j}\right)\right]-\sum_{i=1}^{n} \sum_{j=1}^{n} E\left[Z\left(x_{i}\right)\right] E\left[Z\left(x_{j}\right)\right] \\
& =\sum_{i=1}^{n} \sum_{j=1}^{n} \lambda_{i} \lambda_{j}\left[E\left[Z\left(x_{i}\right) Z\left(x_{j}\right)\right]-E\left[Z\left(x_{i}\right)\right] E\left[Z\left(x_{j}\right)\right]\right]=\operatorname{cov}\left(x_{i}-x_{j}\right)
\end{aligned}
$$

$\operatorname{var}\left[m^{*}-m\right]=\sum_{i=1}^{n} \sum_{j=1}^{n} \lambda_{i} \lambda_{j} \operatorname{cov}\left(x_{i}-x_{j}\right)$

O mínimo da variância de estimativa, sujeita à condição de não enviesamento, pode ser determinado através do Lagrangiano:

$$
L\left(\lambda_{i}, i=1, n, \mu_{0}\right)=\sum_{i=1}^{n} \sum_{j=1}^{n} \lambda_{i} \lambda_{j} \operatorname{cov}\left(x_{i}-x_{j}\right)-2 \mu_{0}\left(\sum_{i=1}^{n} \lambda_{i}-1\right)
$$

Derivando-se o Lagrangiano com relação a cada um dos ponderadores $\mathrm{Xi}$ e em relação a $\mu_{0}$, tem-se :

$$
\left\{\begin{array}{l}
2 \sum_{j=1}^{n} \lambda_{j} C\left(x_{i}-x_{j}\right)-2 \mu=0 \\
\sum_{j=1}^{n} \lambda_{j}=1
\end{array} \quad \text { para } i=1, n\right.
$$

que corresponde ao sistema normal das equações da krigagem da média.

A variância da krigagem da média, a partir dos pesos da $\mathrm{KM}$, é conhecida como:

$$
\operatorname{var}\left[m^{*}-m\right]=\sigma_{K M}^{2}=\sum_{i=1}^{n} \sum_{j=1}^{n} \lambda_{i} \lambda_{i} C\left(x_{i}-x_{j}\right)=\mu
$$


Portanto, a variância da $\mathrm{KM}$ é o próprio multiplicador de Lagrange que, neste caso, é sempre positivo.

Substituindo-se o estimador da KM na equação da krigagem simples, tem-se:

$$
\begin{aligned}
& Z_{S K M}^{*}\left(X_{0}\right)=\sum_{i=1}^{n} \lambda_{i}^{K M} Z\left(X_{i}\right)+\sum_{i=1}^{n} \lambda_{i}^{K S} Z\left(X_{i}\right)-\sum_{i=1}^{n} \lambda_{i}^{K S} \sum_{j=1}^{n} \lambda_{i}^{K M} Z\left(X_{j}\right) \\
& =\sum_{i=1}^{n} \lambda_{i}^{K S} Z\left(X_{i}\right)+\sum_{i=1}^{n} \lambda_{i}^{K M} Z\left(X_{i}\right)-\sum_{i=1}^{n} \lambda_{i}^{K M} Z\left(X_{i}\right) \sum_{i=1}^{n} \lambda_{i}^{K S} \\
& =\sum_{i=1}^{n}\left[\lambda_{i}^{K S}+\lambda_{i}^{K M}\left(1-\sum_{j=1}^{n} \lambda_{j}^{K S}\right)\right] Z\left(X_{i}\right)
\end{aligned}
$$

Na realidade, chega-se ao resultado da krigagem ordinária, pois:

$$
\left[\lambda_{i}^{K S}+\lambda_{i}^{K M}\left(1-\sum_{j=1}^{n} \lambda_{j}^{K S}\right]=\lambda_{i}^{K O}\right.
$$

Deste modo, não se utiliza rotineiramente a krigagem simples, pois esta requer uma média conhecida. Por outro lado, a krigagem simples é o melhor estimador de todos os estimadores dos mínimos quadrados somente quando uma distribuição multinormal é usada como modelo para a função aleatória (Olea, 1991).

Existe, desta forma, uma possibilidade de realizar a krigagem com a média local determinada automaticamente. A esta modalidade de krigagem denomina-se krigagem ordinária, cujo estimador pode ser obtido como segue:

$$
Z^{*}\left(x_{0}\right)=\sum_{i=1}^{n} \lambda_{i} Z\left(x_{i}\right)
$$

Os ponderadores $\left(\lambda_{i}, i=1, n\right)$ podem ser obtidos diretamente do sistema de equações de krigagem ordinária. Como será demostrado no desenvolvimento a seguir, a média local é introduzida pela condição de não enviesamento. 
Para que o estimador $Z^{*}\left(x_{0}\right)$ não seja enviesado, segundo Journel \& Huijbregts (1978), basta garantir que:

$E\left[Z\left(x_{0}\right)-Z^{*}\left(x_{0}\right)\right]=0$

fazendo $E\left[Z\left(x_{\circ}\right)\right]=m$ e tendo que:

$E\left[Z^{*}\left(x_{o}\right)\right]=E\left[\sum_{i=1}^{n} \lambda_{i} Z\left(x_{i}\right)\right]=\sum_{i=1}^{n} \lambda_{i} E\left[Z\left(x_{i}\right)\right]$

$E\left[Z^{*}\left(x_{0}\right)\right]=m \sum_{i=1}^{n} \lambda_{i}$

assim, a condição de não enviesamento para $Z^{*}\left(x_{0}\right)$ fica:

$\sum_{i=1}^{n} \lambda_{i}=1$

Como toda técnica de estimativa, a krigagem procura fazê-la com mínima variância.

A variância do erro da krigagem é dada pela equação a seguir:

$\sigma_{E}^{2}=\operatorname{Var}\left\{Z\left(x_{0}\right)-Z^{*}\left(x_{0}\right)\right\}$

Expandindo a variância do erro, de acordo com Isaaks \& Srivastava (1989), temse:

$\sigma_{E}^{2}=\operatorname{Cov}\left\{Z\left(x_{0}\right) Z\left(x_{0}\right)\right\}-2 \operatorname{Cov}\left\{Z^{*}\left(x_{0}\right) Z\left(x_{0}\right)\right\}+\operatorname{Cov}\left\{Z^{*}\left(x_{0}\right) Z^{*}\left(x_{0}\right)\right\}$

Desenvolvendo cada termo do lado direito de (5.2), conforme Isaak \& Srivastava (1989), tem-se: 
$\operatorname{Cov}\left\{z\left(x_{0}\right) Z\left(x_{0}\right)\right\}=\operatorname{Var}\left\{z\left(x_{0}\right)\right\}=c(0)$

$$
\begin{aligned}
2 \operatorname{Cov}\left\{Z^{*}\left(x_{0}\right) Z\left(x_{0}\right)\right\} & =2 \operatorname{Cov}\left\{\left[\sum_{i} \lambda_{i} Z\left(x_{i}\right)\right] Z\left(x_{0}\right)\right\} \\
& =2 E\left\{\sum_{i} \lambda_{i} Z\left(x_{i}\right) Z\left(x_{0}\right)\right\}-2 E\left\{\sum_{i} \lambda_{i} Z\left(x_{i}\right)\right\} E\left\{Z\left(x_{0}\right)\right\} \\
& =2 \sum_{i} \lambda_{i} E\left\{Z\left(x_{i}\right) Z\left(x_{0}\right)\right\}-2 \sum_{i} \lambda_{i} E\left\{Z\left(x_{i}\right)\right\} E\left\{Z\left(x_{0}\right)\right\} \\
& \left.=2 \sum_{i} \lambda_{i} E\left\{Z\left(x_{i}\right) Z\left(x_{0}\right)\right\}-E\left\{Z\left(x_{i}\right)\right\} E\left\{Z\left(x_{0}\right)\right\}\right] \\
& =2 \sum_{i} \lambda_{i} C\left(x_{0}-x_{i}\right)
\end{aligned}
$$

$$
\begin{aligned}
\operatorname{Cov}\left\{Z^{*}\left(x_{0}\right) Z^{*}\left(x_{0}\right)\right\} & =\operatorname{Var}\left\{Z^{*}\left(x_{0}\right)\right\} \\
& =\operatorname{Var}\left\{\sum_{i} \lambda_{i} Z\left(x_{i}\right)\right\} \\
& =\sum_{i} \sum_{i} \lambda_{i} \lambda_{j} C\left(x_{i}-x_{j}\right)
\end{aligned}
$$

Assim, a expressão da variância do erro torna-se:

$$
\sigma_{E}^{2}=C(0)-2 \sum_{i} \lambda_{i} C\left(x_{0}-x_{i}\right)+\sum_{i} \sum_{j} \lambda_{i} \lambda_{j} C\left(x_{i}-x_{j}\right)
$$

O objetivo da krigagem é buscar o melhor conjunto de ponderadores, de tal modo que a variância do erro seja a mínima possível. Trata-se, portanto, de encontrar o mínimo da função variância do erro. Entretanto, como tal função tem $n$ variáveis, o ponto de mínimo poderá ser determinado após aplicação da técnica dos multiplicadores de Lagrange, conforme colocação do problema a seguir:

- minimizar a função:

$$
\sigma_{E}^{2}=C(0)-2 \sum_{i} \lambda_{i} C\left(x_{o}-x_{i}\right)+\sum_{i} \sum_{j} \lambda_{i} \lambda_{i} C\left(x_{i}-x_{j}\right)
$$


- restrito a:

$\sum_{j} \lambda_{j}=1$ ou $\sum_{j} \lambda_{j}-1=0$

Forma-se o lagrangiano:

$L\left(\lambda_{1}, \lambda_{2}, \ldots, \lambda_{n}, \mu\right)=C(0)-2 \sum_{i} \lambda_{i} C\left(x_{0}-x_{i}\right)+\sum_{i} \sum_{j} \lambda_{i} \lambda_{i} C\left(x_{i}-x_{i}\right)-2 \mu\left(\sum_{i} \lambda_{j}-1\right)$

onde: $\mathrm{L}\left(\lambda_{1}, \lambda_{2}, \ldots, \lambda_{n}, \mu\right)$ é o lagrangiano; $\mu$ é o multiplicador de Lagrange.

Para minimizar o lagrangiano, faz-se cada uma das derivadas parciais $\mathrm{dL} / \mathrm{d} \lambda_{\mathrm{i}}$ iguais a zero:

$\frac{d L}{d \lambda_{i}}=-2 C\left(x_{0}-x_{i}\right)+2 \sum_{j} \lambda_{j} C\left(x_{i}-x_{j}\right)-2 \mu=0 \quad$ para $i=1, n$

e fazendo dL/du igual a zero:

$\frac{d L}{d \mu}=\sum_{j} \lambda_{j}-1=0$

Assim, a minimização da variância do erro, sujeita à condição de não enviesamento, resulta nas equações de krigagem ou sistema de krigagem:

$\left\{\begin{array}{l}\sum_{i} \lambda_{j} C\left(x_{i}-x_{j}\right)-\mu=c\left(x_{o}-x_{i}\right) \text { para } i=1, n \\ \sum_{j} \lambda_{j}=1\end{array}\right.$

Em termos matriciais, as equações de krigagem são representadas como segue: 


$$
\left[\begin{array}{ccccc}
C\left(x_{1}-x_{1}\right) & C\left(x_{1}-x_{2}\right) & \cdots & C\left(x_{1}-x_{n}\right) & 1 \\
C\left(x_{2}-x_{1}\right) & C\left(x_{2}-x_{2}\right) & \cdots & C\left(x_{2}-x_{n}\right) & 1 \\
\vdots & \vdots & \cdots & \vdots & \vdots \\
C\left(x_{n}-x_{1}\right) & C\left(x_{n}-x_{2}\right) & \cdots & C\left(x_{n}-x_{n}\right) & 1 \\
1 & 1 & \cdots & 1 & 0
\end{array}\right] \cdot\left[\begin{array}{c}
\lambda_{1} \\
\lambda_{2} \\
\vdots \\
\lambda_{n} \\
\mu
\end{array}\right]=\left[\begin{array}{c}
C\left(x_{0}-x_{1}\right) \\
C\left(x_{0}-x_{2}\right) \\
\vdots \\
C\left(x_{0}-x_{n}\right) \\
1
\end{array}\right]
$$

A minimização da variância do erro resulta na variância de estimativa ou de krigagem ordinária, conforme segue:

$$
\sigma_{K O}^{2}=C(0)-2 \sum_{i} \lambda_{i} C\left(x_{0}-x_{i}\right)+\sum_{i} \sum_{j} \lambda_{i} \lambda_{j} C\left(x_{i}-x_{j}\right)
$$

o termo $\sum_{i} \sum_{j} \lambda_{i} \lambda_{j} C\left(x_{i}-x_{j}\right)$ pode ser derivado do primeiro conjunto de equações, conforme Isaak \& Srivastava (1989):

$$
\sum_{j} \lambda_{j} C\left(x_{i}-x_{i}\right)-\mu=C\left(x_{0}-x_{i}\right) \quad \text { para } i=1, n
$$

Escrevendo as $n$ equações para $i=1, n$, somando:

$$
\sum_{i} \sum_{j} \lambda_{i} \lambda_{j} C\left(x_{i}-x_{j}\right)-\mu \sum_{i} \lambda_{i}=\sum_{i} \lambda_{i} C\left(x_{0}-x_{i}\right)
$$

e lembrando que $\sum_{i} \lambda_{i}=1$, tem-se:

$$
\sum_{i} \sum_{i} \lambda_{i} \lambda_{i} C\left(x_{i}-x_{i}\right)=\sum_{i} \lambda_{i} C\left(x_{0}-x_{i}\right)+\mu
$$

Substituindo este resultado na expressão da variância de krigagem ordinária, tem-se:

$$
\sigma_{\mathrm{KO}}^{2}=\mathrm{C}(0)-\sum_{i} \lambda_{i} \mathrm{C}\left(\mathrm{x}_{0}-\mathrm{x}_{i}\right)+\mu
$$


O sistema de equações também pode ser escrito em termos da função semivariograma:

$$
\left\{\begin{array}{l}
\sum_{i} \lambda_{j} y\left(x_{i}-x_{i}\right)+\mu=\gamma\left(x_{0}-x_{i}\right) \text { para } i=1, n \\
\sum_{i} \lambda_{i}=1
\end{array}\right.
$$

Nesses termos, a variância de krigagem torna-se:

$$
\sigma_{\mathrm{KO}}^{2}=\sum_{\mathrm{i}} \lambda_{\mathrm{i}} \mathrm{\gamma}\left(\mathrm{x}_{0}-\mathrm{x}_{\mathrm{i}}\right)+\mu
$$

As equações de krigagem permitem determinar o conjunto de ponderadores $\left\{\lambda_{\mathrm{i}}\right.$, $i=1, n\}$ associados ao conjunto de dados disponiveis $\left\{Z\left(x_{i}\right), i=1, n\right\}$, resultando na estimativa do valor desconhecido $Z^{\prime \prime}\left(x_{0}\right)$.

Pode-se perceber, a seguir, porque a krigagem ordinária é o interpolador mais utilizado em estimativas.

Pela equação da krigagem da média, tem-se:

$$
Z_{S K M}^{*}\left(X_{0}\right)=\sum_{i=1}^{n}\left[\lambda_{i}^{K S}+\lambda_{i}^{K M}\left(1-\sum_{j=1}^{n} \lambda_{j}^{K S}\right)\right] Z\left(X_{i}\right)
$$

Introduzindo um peso $\bar{w}=1-\sum_{i=1}^{n} \lambda_{i}^{K S}$ chamado peso da média, tem-se :

$$
Z_{\text {SKM }}^{*}\left(X_{0}\right)=\sum_{i=1}^{n}\left[\lambda_{i}^{K S}+\bar{W} \lambda_{i}^{K M}\right] Z\left(X_{i}\right)=\sum_{i=1}^{n} \lambda_{i}^{\prime} Z\left(X_{i}\right)
$$

que se assemelha com o estimador utilizado na KO.

Deve-se checar se os pesos $\lambda_{i}$ nesta combinação linear somam 1 : 
$\sum_{i=1}^{n} \lambda_{i}^{\prime}=\sum_{i=1}^{n} \lambda_{i}^{K S}+\bar{w} \sum_{i=1}^{n} \lambda_{i}^{K M}=\sum_{i=1}^{n} \lambda_{i}^{K S}+1-\sum_{i=1}^{n} \lambda_{i}^{K S}=1$

Examinando-se a possibilidade de que os pesos $\lambda_{i}$ possam ser obtidos de um sistema de KO, tem-se :

$$
\begin{aligned}
& \sum_{j=1}^{n} \lambda_{j} C\left(X_{i}-X_{j}\right)=\sum_{j=1}^{n} \lambda_{j}^{K S} C\left(X_{i}-X_{j}\right)+\bar{w} \sum_{j=1}^{n} \lambda_{j}^{K M} C\left(X_{i}-X_{j}\right) \\
& =C\left(X_{i}-X_{0}\right)+\bar{w} \mu_{K M}
\end{aligned}
$$

Chamando de $\mu_{i}^{\prime}$ o produto dos pesos da média com a variância da krigagem simples e colocando as equações de $\lambda_{i}$ juntas, tem-se um sistema de krigagem ordinária :

$$
\left\{\begin{array}{l}
\sum_{j=1}^{n} \lambda_{j}^{\prime} C\left(X_{i}-X_{j}\right)=C\left(X_{i}-X_{0}\right)+\mu^{\prime} \\
\sum_{j=1}^{n} \lambda_{j}^{\prime}=1
\end{array} \quad \text { para } i=1, n,\right.
$$

que mostra que a krigagem ordinária é igual a krigagem simples, baseada na média estimada $Z_{\mathrm{SKM}}^{*}\left(\mathrm{X}_{0}\right)=Z_{\mathrm{KO}}^{*}\left(\mathrm{X}_{0}\right)$.

A variância da krigagem ordinária tem a seguinte composição:

$$
\sigma_{\mathrm{KO}}^{2}=\sigma_{\mathrm{KS}}^{2}+\bar{w} \cdot \sigma_{\mathrm{KM}}^{2}
$$

A variância da KO é a soma da variância da KS (assumindo-se uma média conhecida) com a variância devida à incerteza sobre o verdadeiro valor da média. Quando o peso da média é pequeno, a soma dos pesos da KS é igual a 1 e a KO é semelhante à solução da KS, devido à variância da KM também ser pequena. 


\subsubsection{1 - Variância de Interpolação}

A variância de krigagem é baseada em um semivariograma global, não medindo dispersões locais dos dados. Segundo Isaaks \& Srivastava (1989), deve-se reconhecer que a natureza dos fenômenos em estudo pode variar de um local a outro. Deste modo, utilizando-se os mesmos dados, a variância de krigagem produz o mesmo valor, independente da posição dos mesmos. Isto ocorre porque os ponderadores da krigagem ordinária e a variância são independentes. Segundo Olea (1991), a variância de krigagem é homoscedástica, ou seja, é independente dos dados utilizados na obtenção de $Z^{*}\left(X_{0}\right)$.

Sob este problema, Yamamoto (2000b) propõe a utilização da chamada variância de interpolação, assim definida:

$s_{0}^{2}=\sum_{i=1}^{n} \lambda_{i}\left[Z\left(X_{i}\right)-Z^{*}\left(X_{0}\right)\right]^{2}$



Pode-se notar que esta expressão é dependente dos dados. Por esta definição, todos os pesos devem ser positivos, já que se algum peso for negativo, a variância de interpolação pode ser negativa.

O mesmo autor define ainda algumas propriedades desta variância:

- é uma medida exata, pois se o ponto a ser estimado coincidir com um ponto de dados, seu peso será igual a 1 , sendo todos os outros iguais a zero. Deste modo, o valor de $\mathrm{s}_{0}^{2}$ será zero;

- $\quad$ é incrementada com a dispersão dos dados;

- utiliza, indiretamente, a estrutura do semivariograma através dos ponderadores $\lambda_{\mathrm{i}}$. Os pontos com maiores influências recebem os maiores pesos.

Para corrigir a possibilidade da existência de pesos negativos, Yamamoto (2000b) propõe a utilização de algoritmos específicos. No mesmo trabalho, o autor propõe a utilização dos algoritmos propostos por Froidevaux (1993), Journel \& Rao (1996) e Deutsch (1996). 
Segundo Froidevaux, deve-se cancelar os pesos que forem negativos, removendo da estimativa os dados associados a estes pesos. Deste modo, algumas informações seriam perdidas.

O cálculo dos novos pesos seria:

$T_{i}=\frac{\lambda_{i}}{\sum_{i=1}^{n} \lambda}$

A correção proposta por Journel \& Rao remove apenas os maiores pesos negativos. Após a resolução do sistema de krigagem, é adicionada em todos os pesos uma constante positiva e igual ao módulo do maior peso negativo:

$c=-\min \left(\lambda_{i}, i=1, n\right)$ se $\min \left(\lambda_{i}\right) \leq 0, c=0$

caso contrário

$r_{i}=\frac{\lambda_{i}+c}{\sum_{j=1}^{n} \lambda_{j}+c}$

Deutsch propôs uma aproximação que zera os pesos negativos. Além disso, este procedimento também remove as amostras que tenham pesos menores que a média absoluta dos pesos negativos e cuja covariância entre o ponto a ser estimado e o ponto amostrado seja menor que a covariância média entre o ponto estimado e os pontos com pesos negativos.

A média absoluta dos pesos negativos, dentro do conjunto destes pesos é calculada da seguinte forma:

$\bar{\lambda}=\frac{1}{n^{\prime}} \sum_{j=1}^{n^{\prime}}\left|\lambda_{j}\right|$ 
A covariância média entre o ponto a ser estimado e os pontos com pesos negativos é definida por:

$$
\overline{\mathrm{C}}=\frac{1}{\mathrm{n}^{\prime}} \sum_{\mathrm{j}=1}^{\mathrm{n}^{\prime}} \mathrm{C}\left(\mathrm{u}-\mathrm{u}_{\mathrm{j}}\right)
$$

O procedimento para a correção dos pesos negativos é como segue:

se $\lambda_{i}<0 \Rightarrow \lambda_{i}=0$

se $\lambda_{\mathrm{i}}>0$ e $\mathrm{C}\left(\mathrm{u}-\mathrm{u}_{\mathrm{i}}\right)<\overline{\mathrm{C}}$ e $\lambda_{\mathrm{i}}<\bar{\lambda} \Rightarrow \lambda_{\mathrm{i}}=0$

$T_{i}=\frac{\lambda_{i}}{\sum_{j=1}^{n} \lambda_{i}}$

Após a correção dos pesos negativos, o valor estimado pela krigagem ordinária é calculado da seguinte maneira:

$Z^{* *}\left(X_{0}\right)=\sum_{i=1}^{n} T_{i} Z\left(X_{i}\right)$

Garantindo que os pesos da krigagem ordinária são positivos, a variância de interpolação é obrigatoriamente positiva. 


\section{CAPÍTULO 6 \\ MODELAGEM TRIDIMENSIONAL DIGITAL}

A modelagem tridimensional digital de um corpo de minério tem por objetivos principais a delineação de um volume (Houlding, 1994) e o melhor entendimento de sua geometria. A partir deste volume, pode-se calcular o valor de uma variável de interesse, bem como a incerteza associada.

Um modelo geológico é definido como sendo uma representação da realidade, baseada em medidas e/ou outras observações. O tipo, a exatidão e a precisão dos modelos geológicos criados dependem da qualidade dos dados que são utilizados na sua construção.

Para a modelagem de um corpo de minério, os parâmetros críticos consistem, basicamente, na delimitação dos contatos entre as diferentes unidades de interesse, bem como nas medidas das propriedades físicas e químicas destes materiais. É essencial também que todos os pontos de amostragem devam estar corretamente referenciados em três dimensões.

A interpretação geológica convencional trabalha com a construção de planos e seções para representar a geometria e a disposição das unidades geológicas em subsuperfície. No caso de depósitos que afloram, a representação desta disposição é auxiliada pelo mapeamento das unidades em superficie, com a observação das relações de contato entre elas e sua orientação, que podem ser utilizadas para a interpretação em subsuperfície. Este conjunto de informações, por vezes auxiliado pelos dados de amostragem indireta (por exemplo, geofísica), permite o planejamento dos programas de sondagem, fornecendo o volume de dados utilizados para a modelagem dos corpos de minério e avaliação de reservas. $A$ interpretação destas informações é feita também por analogia com outros depósitos similares.

A criação do modelo geológico tridimensional de corpos de minério conta com a utilização de uma série de seções paralelas, obtidas a partir das interpretações dos dados acima citados (Figuras 6.1 e 6.2). Os dois principais métodos de modelagem existentes, segundo Sides (1997), são: método das fatias seriais (serial slice method) e método das fatias interligadas (interlinked slice method). 


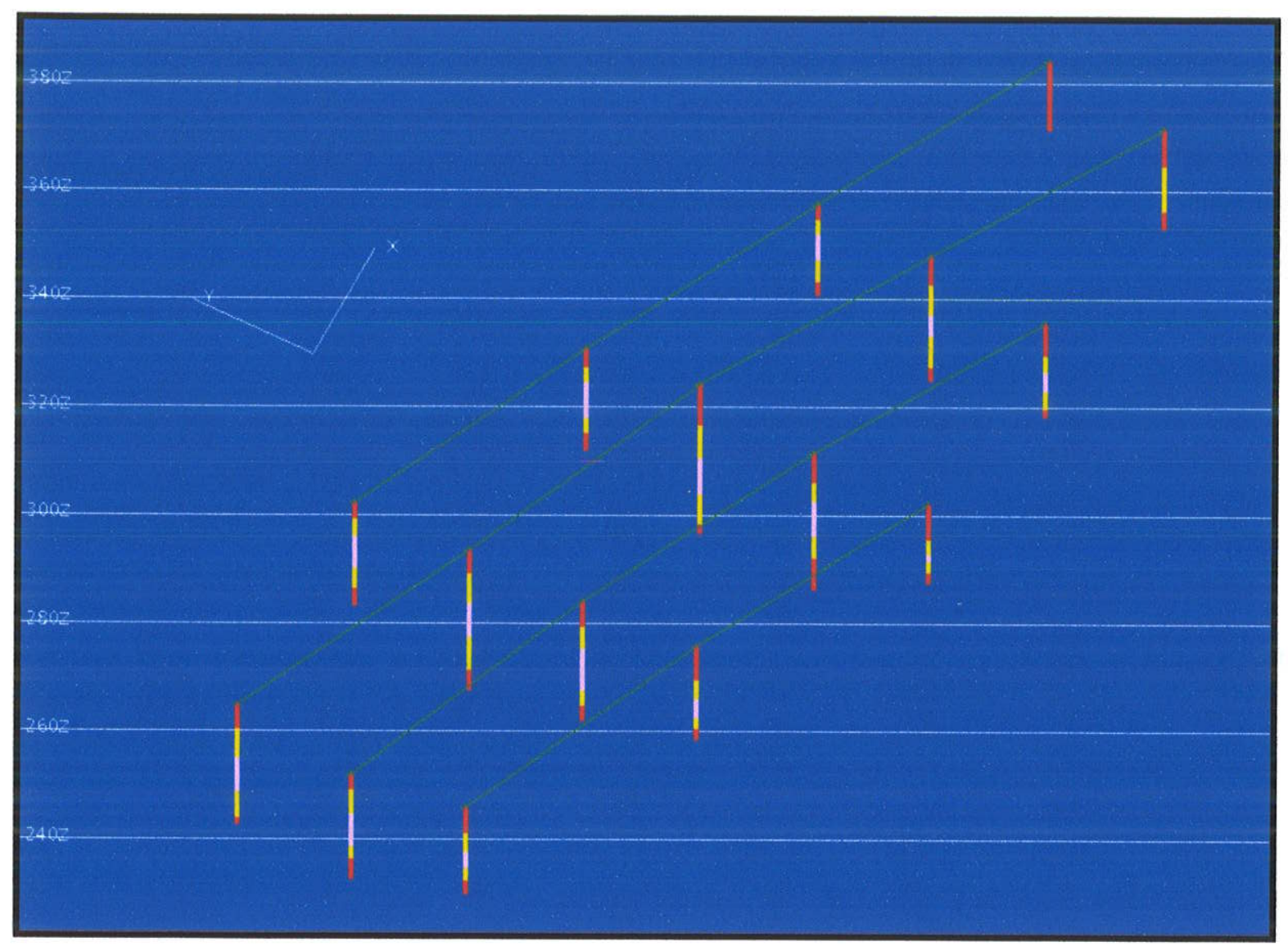

Figura 6.1 - Orientação de seções paralelas a partir da disposição de uma malha de furos de sondagem

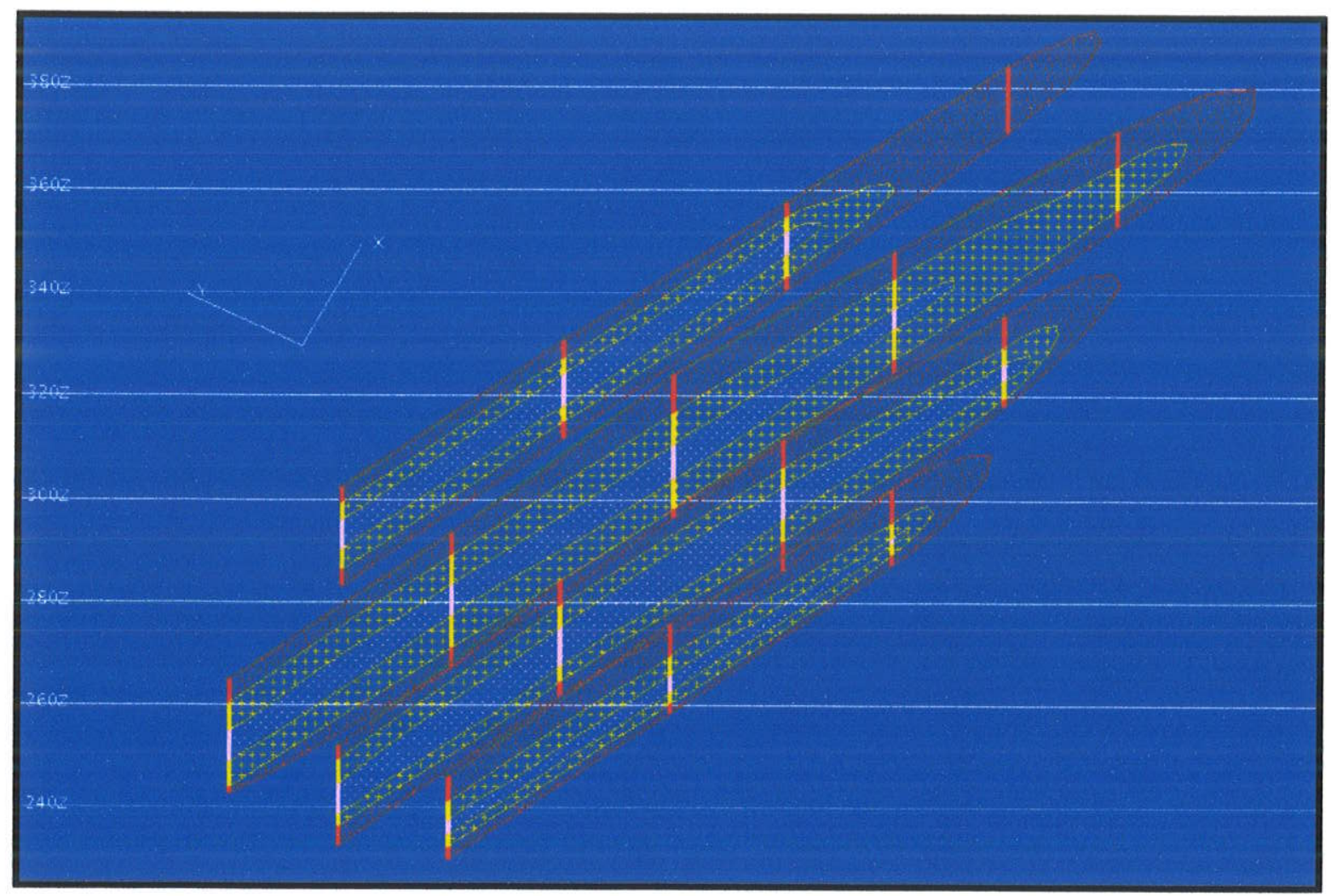

Figura 6.2 - Seções geológicas interpretadas 
O método das fatias seriais consiste em gerar uma área de influência para cada seção geológica interpretada. A partir destes volumes, procede-se a triangulação entre seções contíguas, gerando blocos tridimensionais com volume conhecido (Figura 6.3). Este método segue o princípio dos pontos mais próximos, que determina áreas de influência. A desvantagem apresentada por este método é o fato de que mudanças abruptas podem ocorrer nas formas dos corpos entre os limites de influência de seções adjacentes (Sides, 1997).

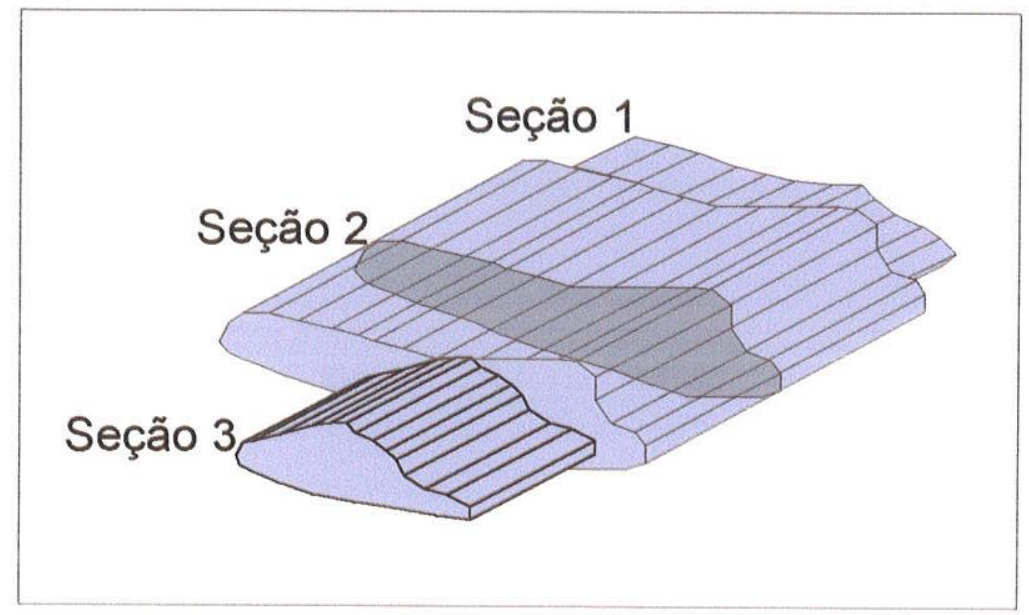

Figura 6.3 - Modelagem tridimensional utilizando o método das fatias seriais (modificado de Sameshima, 1995)

O método das fatias interligadas consiste na ligação direta de uma seção a outra, resultando, por triangulação, em um corpo com volume conhecido (Figura 6.4). Este método utiliza o princípio da variação gradual.

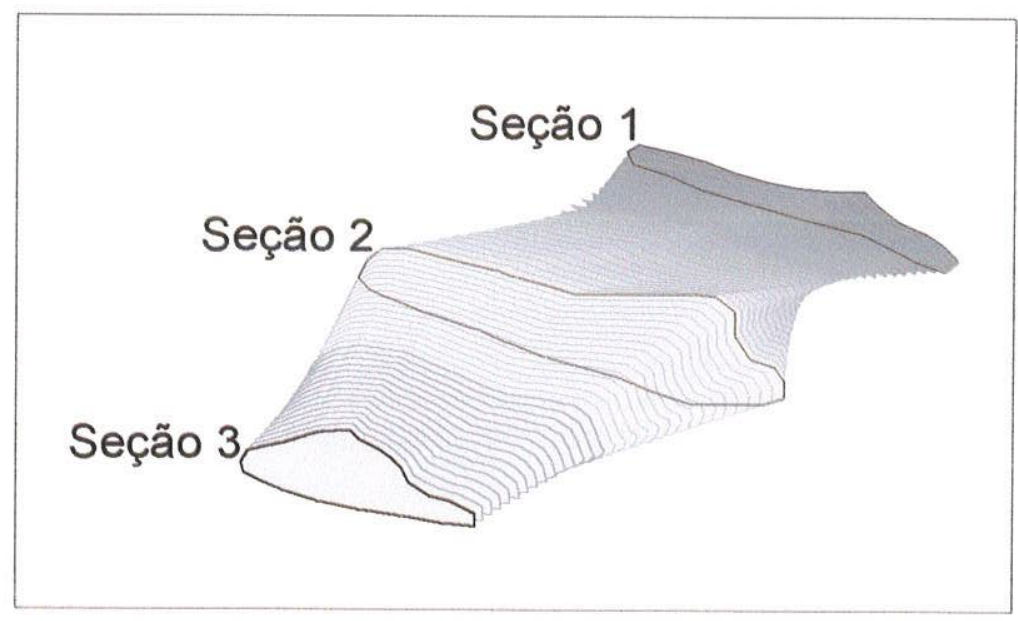

Figura 6.4 - Modelagem tridimensional utilizando o método das fatias interligadas (modificado de Sameshima, 1995) 
A triangulação entre uma seção e outra é baseada no princípio das mudanças graduais entre duas seções adjacentes, gerando uma malha triangular. Para evitar que os pontos de uma seção sejam ligados ao acaso com os pontos de uma seção à frente, existem algoritmos computacionais que, segundo regras preestabelecidas, resultam em uma malha triangular. O algoritmo mais utilizado para este fim é a chamada Triangulação de Delaunay. Por este algoritmo, os pontos de uma seção são ligados aos pontos da seção adjacente, respeitando uma seqüência numérica, de maneira que a ligação entre dois pontos seja a mais curta possível e que esta ligação não cruze nenhuma outra ligação de quaisquer outros pontos do conjunto (Figura 6.5). O resultado desta triangulação consiste em uma malha de triângulos que representa o arcabouço tridimensional do corpo interpretado (Figura 6.6).
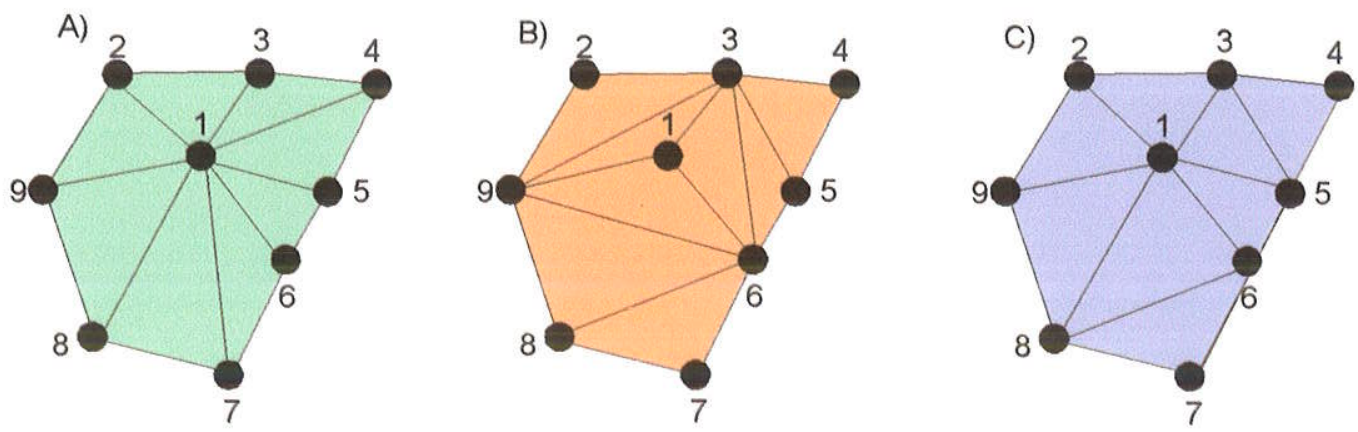

Figura 6.5 - (A) e (B) Tipos de triangularização utilizando uma mesma malha de pontos; (C) Triangularização da malha de pontos utilizando o Algoritmo de Delaunay (modificado de Popoff, 1966) 


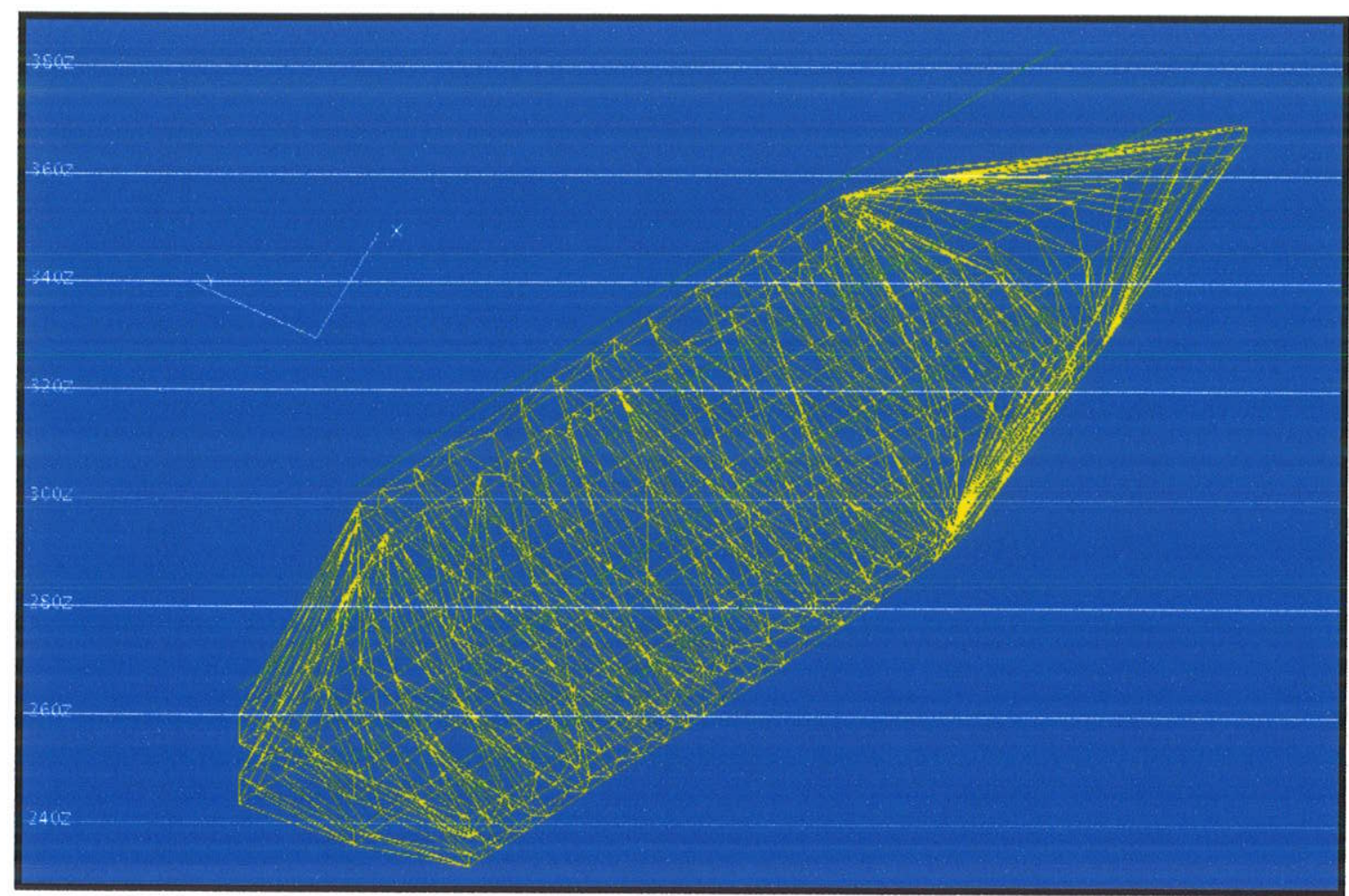

Figura 6.6 - Modelo triangularizado de uma unidade geológica

Para a obtenção do sólido que representa o produto final da modelagem tridimensional, é aplicada a técnica da renderização, que consiste no preenchimento de cada um dos triângulos gerados na triangulação anterior. Deste modo, cada triângulo torna-se uma face do sólido que representa o modelo geológico tridimensional (Figura $6.7)$. 




Figura 6.7 - Modelo geológico renderizado

A elaboração do modelo geológico tridimensional do depósito permite a construção de um modelo de blocos do depósito, a partir do qual pode ser realizada a estimativa de teores pela krigagem ordinária de blocos. 


\section{CAPÍTULO 7 \\ RESULTADOS OBTIDOS E DISCUSSÕES}

Neste capitulo serão apresentados os resultados obtidos neste trabalho. Para isso, procurou-se analisar o banco de dados completo, separando-se, com o decorrer do projeto, populações de amostras.

\section{1 - Análise Estatística}

A Figura 7.1 apresenta o histograma de distribuição de freqüências dos dados sem a regularização, bem como as estatísticas.


Figura 7.1 - Histograma de distribuição de freqüência e estatísticas das variáveis $\mathrm{P}_{2} \mathrm{O}_{5}(\mathrm{~A})$ e $\mathrm{MgO}(\mathrm{B})$ dos dadós não regularizados.

Após a regularização da amostras utilizando-se o valor de 10 metros, foram obtidos novos histogramas de distribuição de freqüências, conforme observados na Figura 7.2, juntamente com as novas estatísticas. 

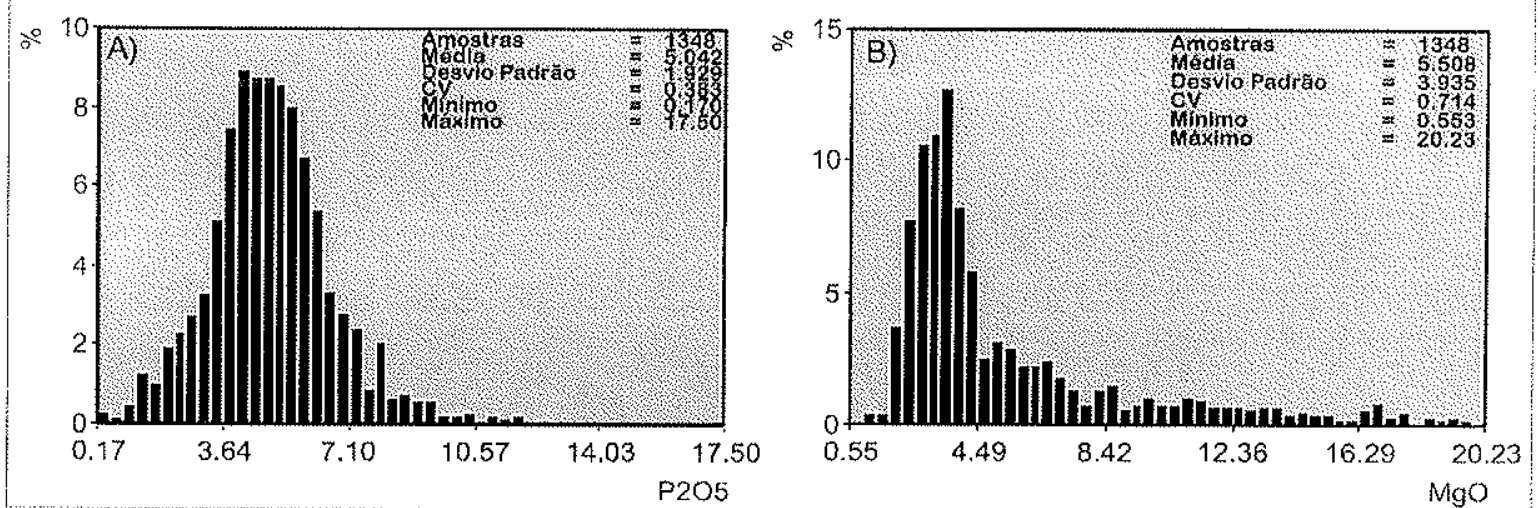

Figura 7.2 - Histograma de distribuição de freqüência e estatísticas das variáveis $\mathrm{P}_{2} \mathrm{O}_{5}(A)$ e $\mathrm{MgO}(\mathrm{B})$ dos dados após a regularização.

Nota-se que, após a regularização das amostras, tem-se um pequeno aumento no valor da média da variável $\mathrm{P}_{2} \mathrm{O}_{5}$. Em relação ao $\mathrm{MgO}$, nota-se uma pequena diminuição no valor da média. Os valores de desvio padrão para ambas as variáveis sofreram uma diminuição, que pode ser explicada pelo fato da regularização tender a atenuar as variações que ocorrem devido a diferentes suportes.

Conforme a Figura 7.3 , não existe correlação entre as duas variáveis, pois o coeficiente de correlação é praticamente nulo, com valor de 0,026 .

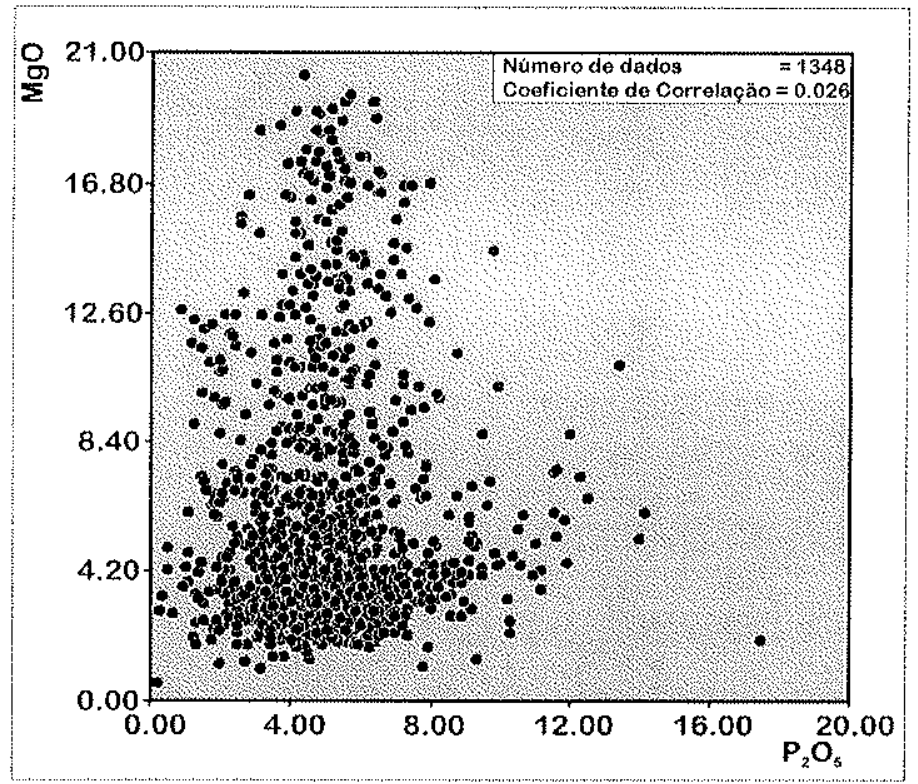

Figura 7.3 - Diagrama de dispersão entre as variáveis $\mathrm{P}_{2} \mathrm{O}_{5}$ e $\mathrm{MgO}$.

Observando-se os histogramas da Figura 7.2, pode-se dizer que a variável $\mathrm{P}_{2} \mathrm{O}_{5}$ apresenta uma distribuição aproximadamente normal. Os poucos valores altos 
presentes no gráfico (cerca de $2 \%$ do total das amostras) podem ser explicados por existirem intervalos amostrados em material muito intemperizado, onde ocorreria um enriquecimento relativo do teor de fósforo nestes intervalos. A existência de sondagens verticais, paralelas à orientação das apatitas na rocha também pode ser uma outra explicação para a existência destes teores anômalos.

O histograma de distribuição dos teores de magnésio apresenta uma certa assimetria positiva. Outra característica marcante desta distribuição corresponde à presença de mais de uma população de $\mathrm{MgO}$. Pode-se dizer que existe uma população com teores abaixo de 4,3\%, uma segunda população entre $4,3 \%$ e $16,0 \%$ e uma terceira população com teores acima de $16 \%$ de MgO (Figura 7.4). A explicação para este fato está na gênese do corpo de minério. $O$ corpo de minério lavrado é resultado de cinco intrusões, cada uma delas apresentando características químicas e mineralógicas distintas, existindo intrusões com características mais calcíticas ou mais dolomíticas. Uma possível quarta população poderia ser sugerida apresentando teores abaixo de $2 \%$ de $\mathrm{MgO}$. Porém, devido à pequena quantidade de amostras, está possivel população foi englobada na população com teores de até $4,3 \%$.

A partir destes fatos, procurou-se dividir o banco de dados em três partes, de acordo com as populações de magnésio. A disposição das amostras em relação aos três novos bancos de dados foi possivel porque se observou que cada população localizava-se em uma determinada região do depósito, indo de acordo com a idéia dos teores de magnésio dependerem da geologia do corpo. A Figura 7.5 mostra a disposição das amostras com a separação das três populações, denominadas Área Sul, Área Central e Área Norte. 


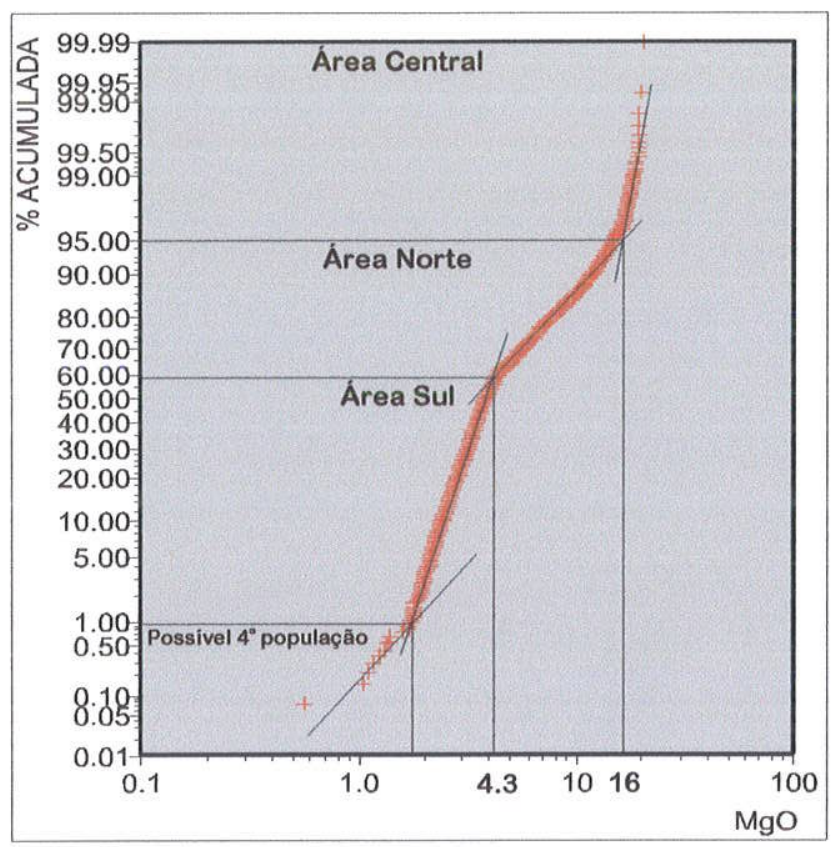

Figura 7.4 - Curva de freqüência acumulada em escala logarítmica da variável MgO indicando três populações.

Por este gráfico, pode-se observar que ocorre uma possível população com valores abaixo de $2 \%$. Porém, como este conjunto apresentou poucas amostras em comparação às demais áreas, optou-se pela sua inclusão no conjunto de dados da chamada Área Sul. 


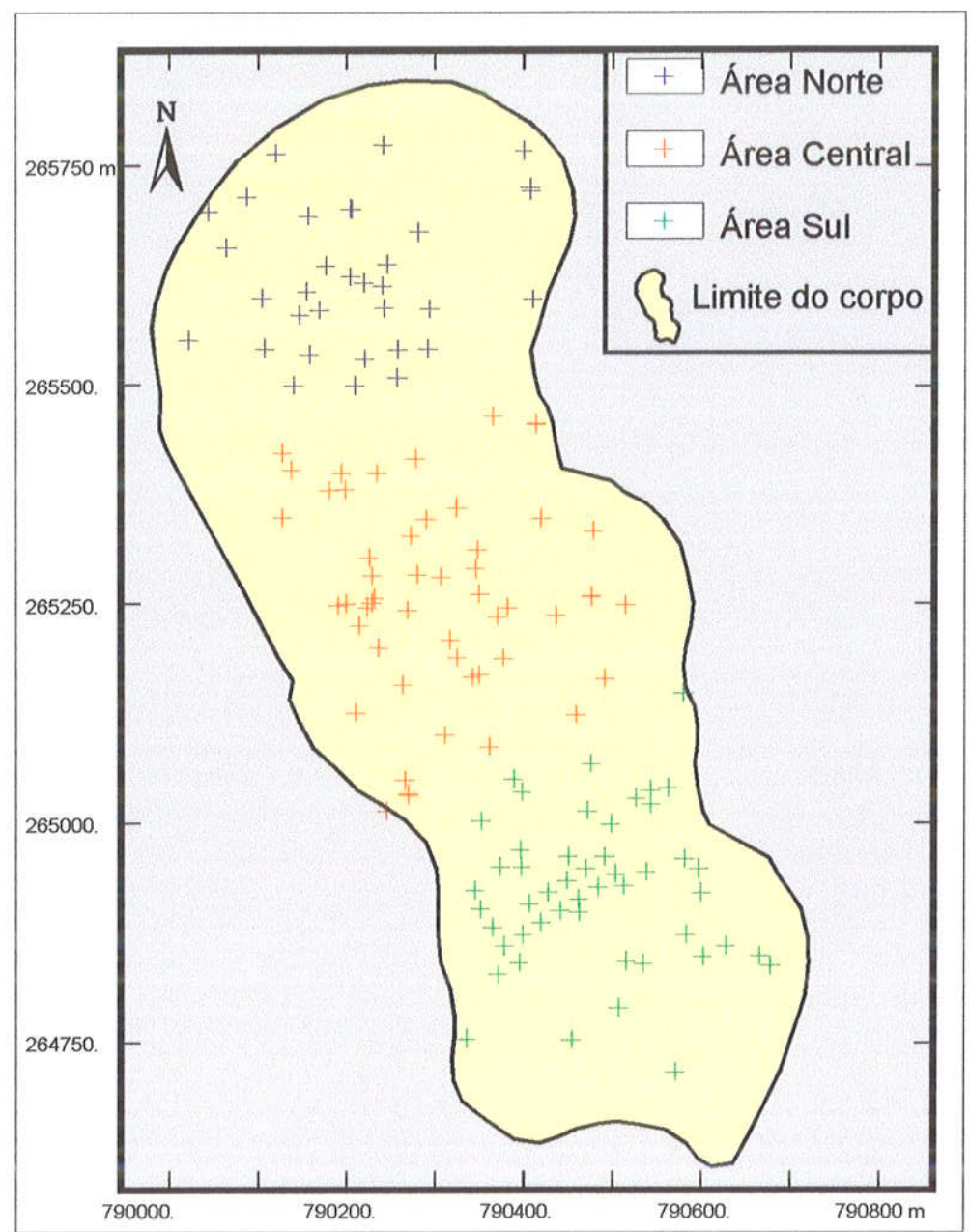

Figura 7.5 - Mapa de localização das três populações observáveis no conjunto de dados.

A partir desta divisão, procedeu-se aos estudos estatísticos para cada população, conforme se pode observar nas Figuras 7.6 a 7.8 .
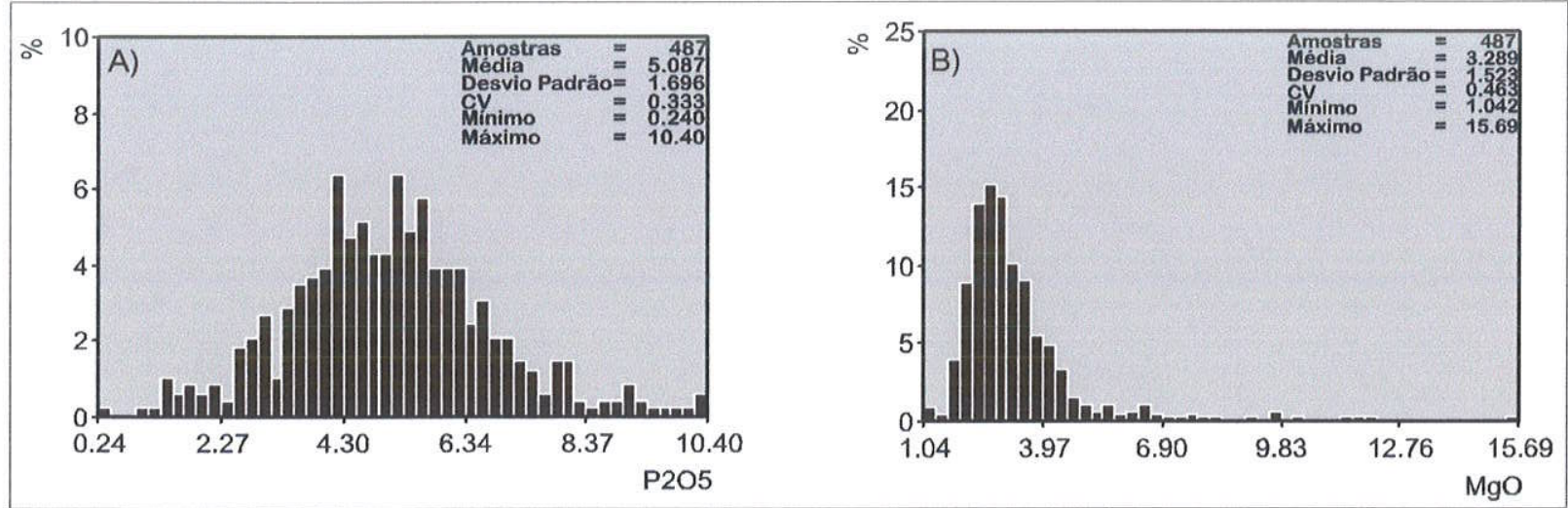

Figura 7.6 - Histograma de distribuição de freqüência e estatísticas das variáveis $\mathrm{P}_{2} \mathrm{O}_{5}(\mathrm{~A})$ e $\mathrm{MgO}(\mathrm{B})$ da Área Sul. 

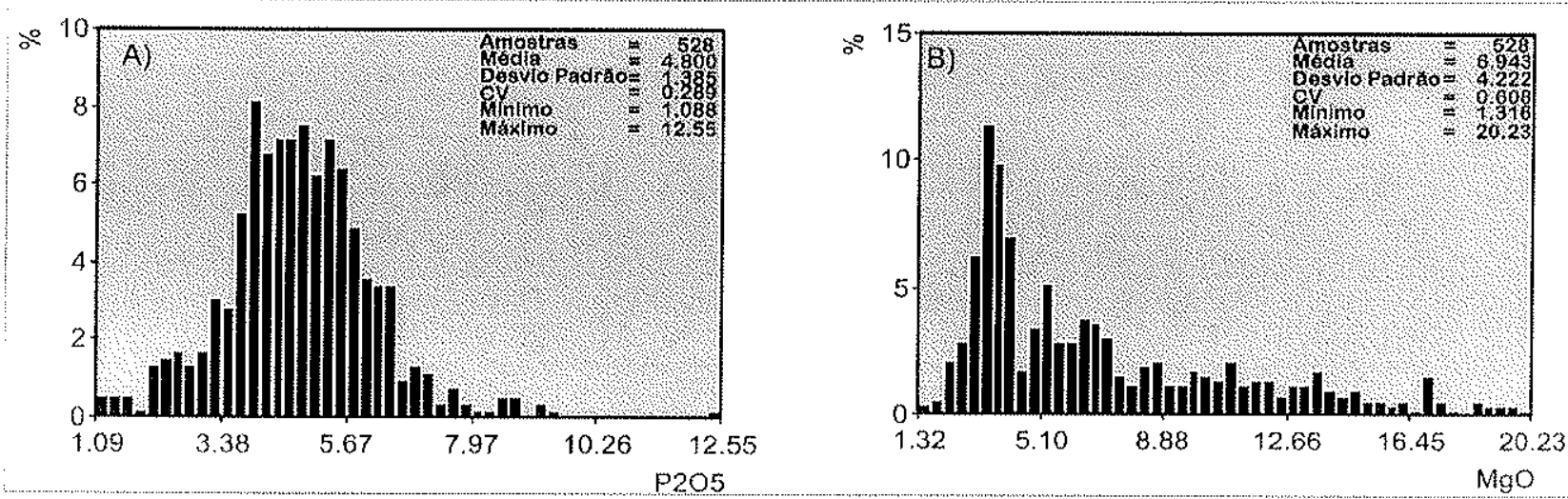

Figura 7.7 - Histograma de distribuição de freqüência e estatísticas das variáveis $\mathrm{P}_{2} \mathrm{O}_{5}(\mathrm{~A})$ e $\mathrm{MgO}(\mathrm{B})$ da Área Central.
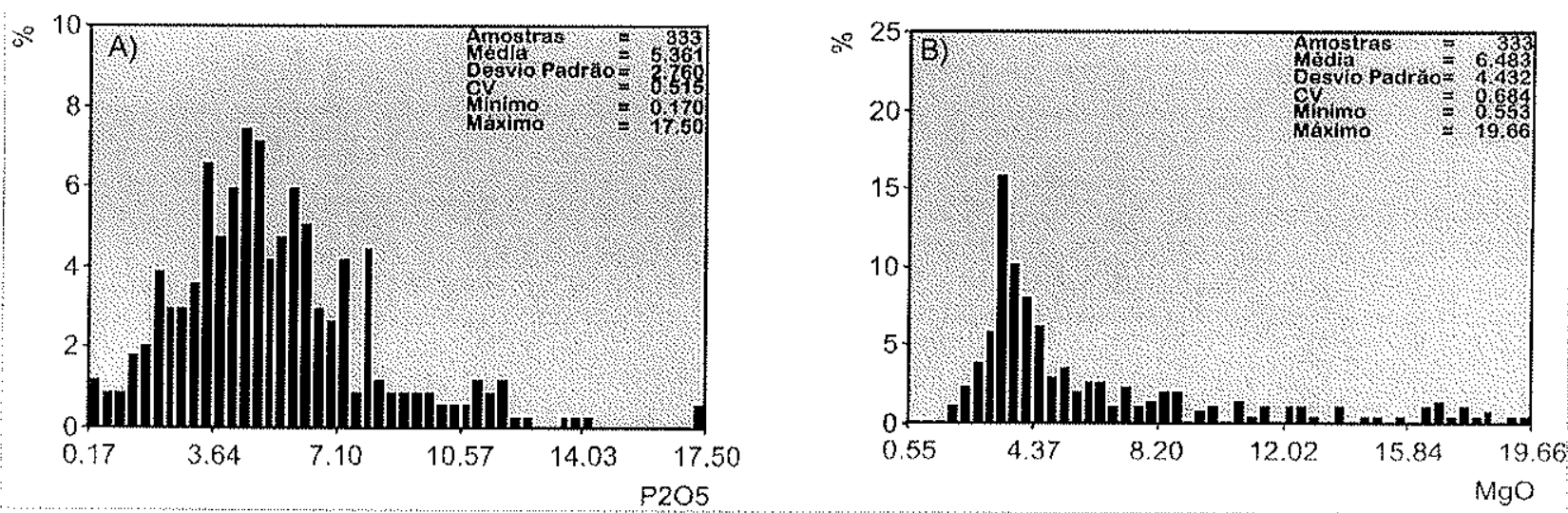

Figura 7.8 - Histograma de distribuição de freqüencia e estatísticas das variáveis $\mathrm{P}_{2} \mathrm{O}_{5}(\mathrm{~A})$ e $\mathrm{MgO}(\mathrm{B})$ da Area Norte.

Por estes gráficos, percebe-se que nas três áreas o $\mathrm{P}_{2} \mathrm{O}_{5}$ apresenta uma distribuição praticamente normal. Já o MgO apresenta uma distribuição com uma assimetria positiva. Os maiores teores de $\mathrm{P}_{2} \mathrm{O}_{5}$ encontram-se na Área Norte $(5,4 \%)$, seguida da Área Sul $(5,1 \%)$. Em relação ao $\mathrm{MgO}$, a Área Sul apresenta os menores teores $(3,3 \%)$, seguida da Area Norte $(6,5 \%)$. Ressalta-se nesta análise os altos valores de desvio padrão calculados para a variável magnésio nas Áreas Central e Norte. Analisando-se estes valores juntamente com os respectivos histogramas de distribuição de freqüências, nota-se que ainda existe mistura de populações nestas áreas, mas que neste estudo não foram possiveis de serem identificadas. A Área Sul apresentou os melhores resultados em relação à delimitação de sua ocorrência. Notase pelo valor do coeficiente de variação, principalmente para a variável MgO, que este se encontra muito baixo $(0,46)$, em comparação com as outras áreas. 
As Figuras 7.9 a 7.11 apresentam os diagramas de dispersão das variáveis para cada uma das áreas definidas. Novamente percebe-se que não existe correlação entre as variáveis, com os coeficientes de correlação muito baixos.

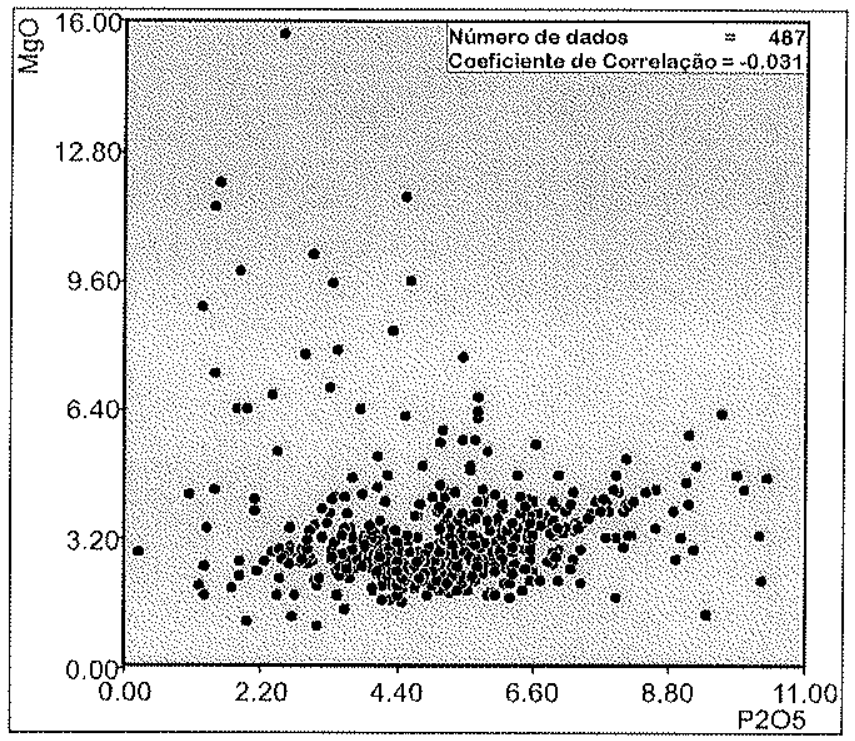

Figura 7.9- Diagrama de dispersão entre as variáveis $\mathrm{P}_{2} \mathrm{O}_{5}$ e $\mathrm{MgO}$ (Area Sul).

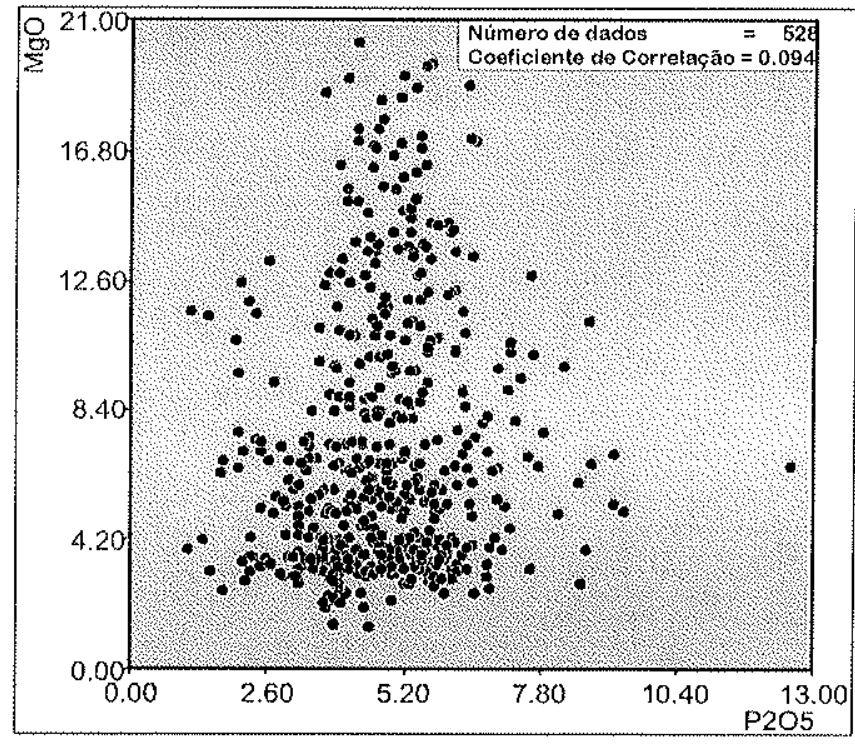

Figura 7.10 - Diagrama de dispersão entre as variáveis $\mathrm{P}_{2} \mathrm{O}_{5}$ e MgO (Área Central). 




Figura 7.11 - Diagrama de dispersão entre as variáveis $\mathrm{P}_{2} \mathrm{O}_{5}$ e $\mathrm{MgO}$ (Área Norte).

A baixa correlação entre as duas variáveis estudadas, tanto no conjunto global de amostras quanto nas sub-populações definidas, pode ser explicada pelo fato que, enquanto a distribuição dos teores de $\mathrm{MgO}$ varia ao longo do depósito, definindo minérios calcíticos e dolomíticos, a distribuição do $\mathrm{P}_{2} \mathrm{O}_{5}$ ocorre de forma mais homogênea, caracterizada pela distribuição normal das suas freqüências (Figuras 7.6 a 7.8). Este fator deve estar ligado à mineralogia da rocha, já que os carbonatos possuem variações nas suas composições (calcita ou dolomita), enquanto que a apatita constitui-se em um mineral acessório no carbonatito, sendo encontrando, por assim dizer, disseminado por todo o depósito.

\section{2 - Análise Geoestatística}

Primeiramente, procedeu-se à análise geoestatística estrutural do depósito, para a obtenção de semivariogramas direcionais experimentais.

Para isso, foram construídos semivariogramas em duas direções, uma contida no plano horizontal, e outra contida no plano vertical. No plano horizontal não foi encontrada nenhuma direção preferencial para a análise semivariográfica em nenhuma área estudada. Apenas na Área Sul, a análise determinou o melhor semivariograma na direção N10E, pois a maioria dos furos inclinados possui esta direção.

Foram considerados para o cálculo dos semivariogramas a tolerância angular, o tamanho do passo e a sua tolerância e o número de passos. Estes parâmetros 
definiram a busca de pares de pontos, utilizados para a construção do semivariograma. Procedeu-se a uma busca com uma determinada abertura (tolerância angular) selecionando pontos separados por uma determinada distância (tamanho do passo \pm tolerância do passo). O número de passos indica qual a distância máxima da busca. Essa distância, normalmente, corresponde à metade do campo geométrico estudado. Na prática, costuma-se utilizar como tamanho do passo a distância média entre os furos de sonda.

Obtidos os semivariogramas experimentais, ajustaram-se modelos teóricos que melhor os caracterizariam, analisando-se o número de pares de amostras utilizadas para o cálculo dos pontos próximos à origem. Se este número fosse muito baixo em relação aos seguintes, optava-se pelo descarte do ponto, considerado não significativo para a análise.

Para o ajuste do modelo teórico, determinaram-se os parâmetros dos semivariogramas teóricos, que correspondem ao efeito pepita, patamar e amplitude. Nas Figuras 7.12 a 7.17, pode-se observar os semivariogramas experimentais obtidos, bem como os modelos teóricos ajustados.

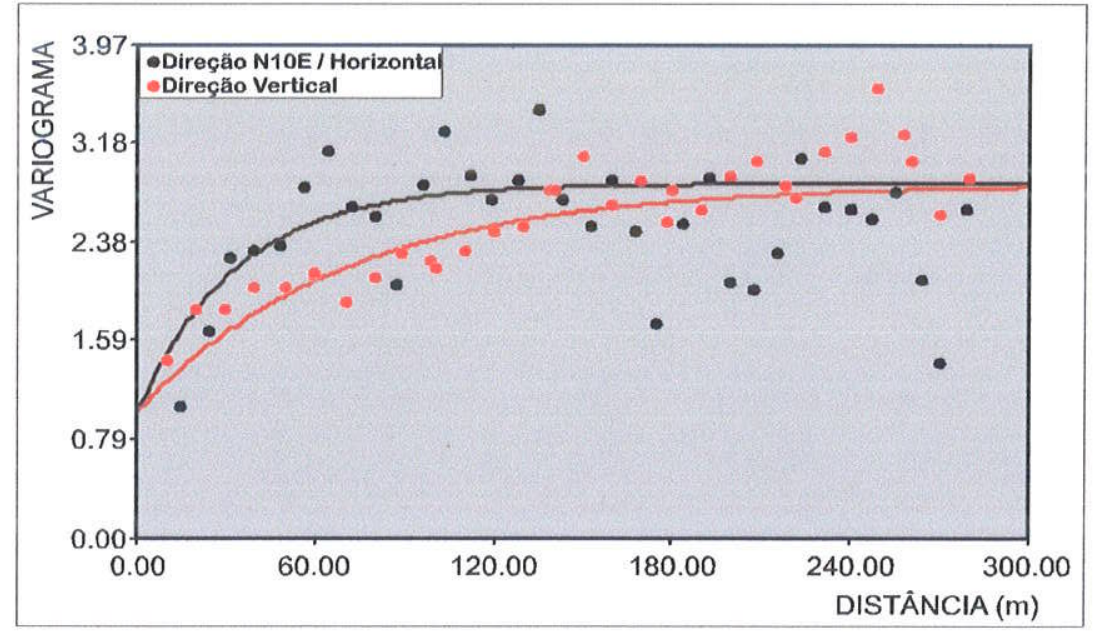

Figura 7.12 - Semivariograma experimental da variável $\mathrm{P}_{2} \mathrm{O}_{5}$ e seu respectivo modelo teórico ajustado (Área Sul). 


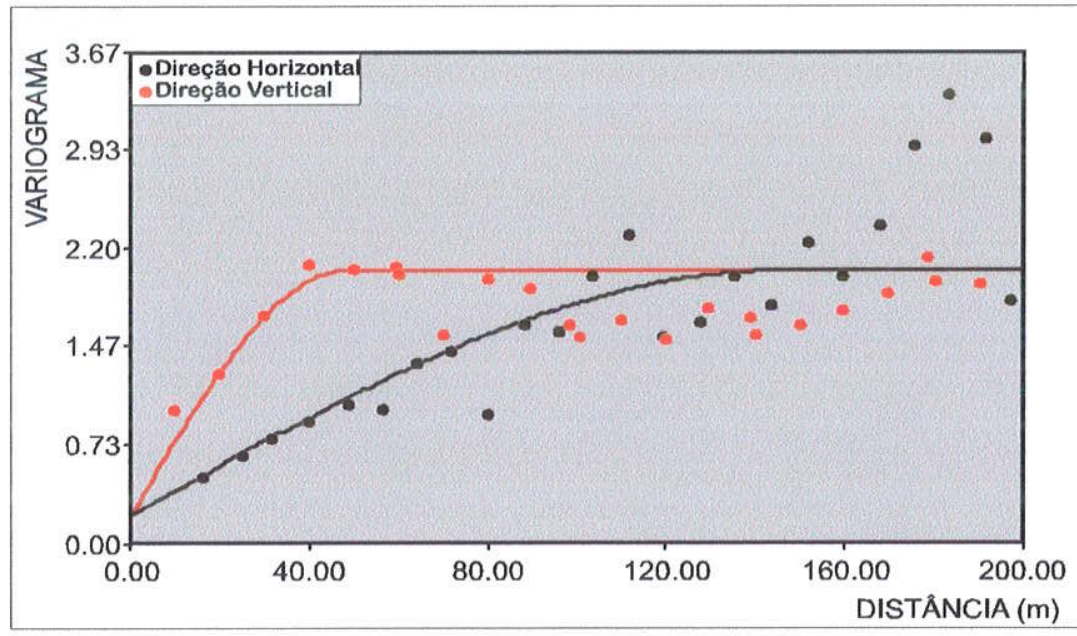

Figura 7.13 - Semivariograma experimental da variável MgO e seu respectivo modelo teórico ajustado (Área Sul).



Figura 7.14 - Semivariograma experimental da variável $\mathrm{P}_{2} \mathrm{O}_{5}$ e seu respectivo modelo teórico ajustado (Área Central).

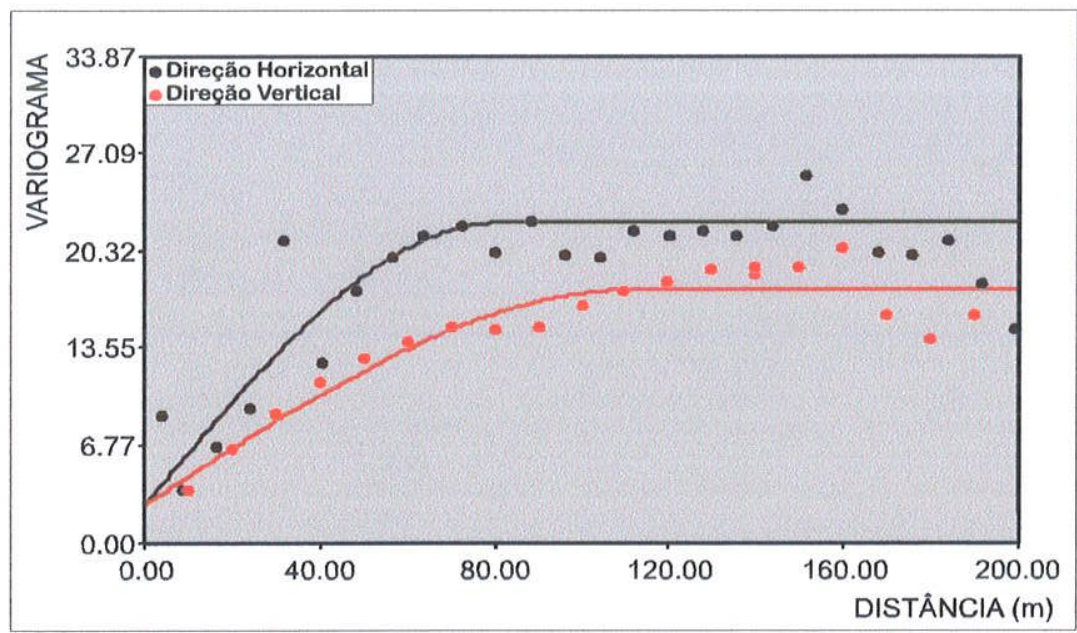

Figura 7.15 - Semivariograma experimental da variável MgO e seu respectivo modelo teórico ajustado (Área Central). 


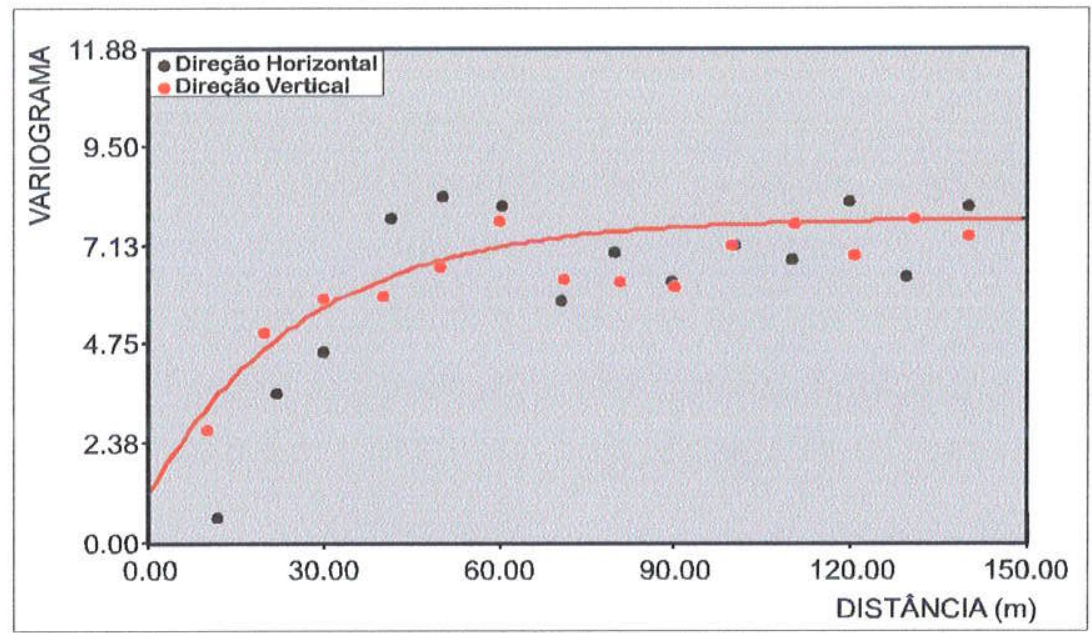

Figura 7.16 - Semivariograma experimental da variável $\mathrm{P}_{2} \mathrm{O}_{5}$ e seu respectivo modelo teórico ajustado (Área Norte).

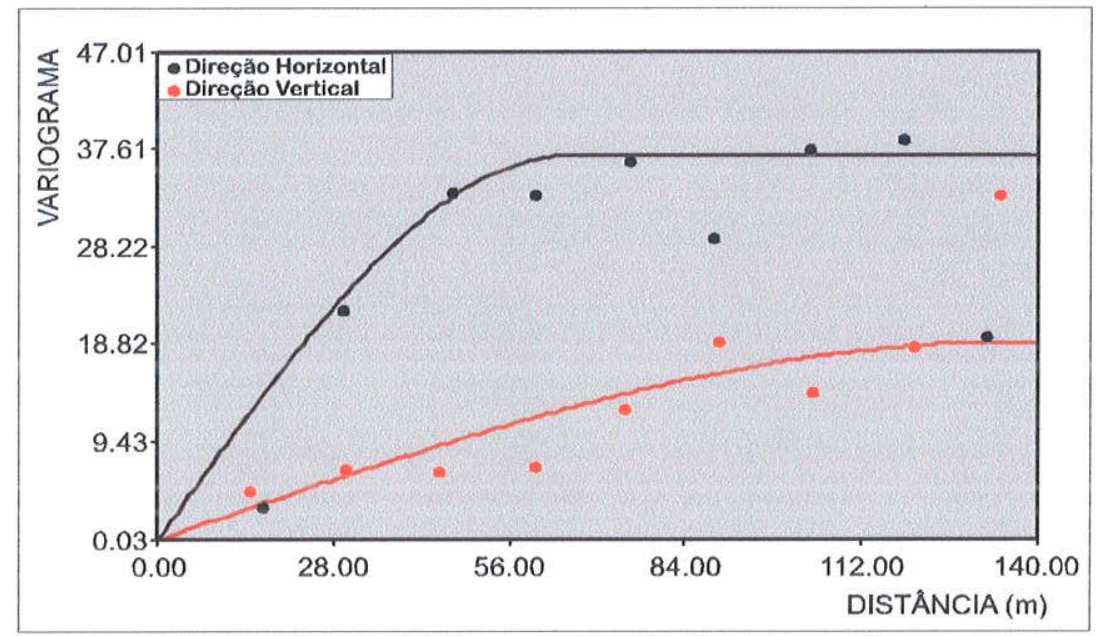

Figura 7.17 - Semivariograma experimental da variável MgO e seu respectivo modelo teórico ajustado (Área Norte).

A análise dos semivariogramas obtidos permite verificar, em praticamente todas as áreas, que o valor dos patamares dos semivariogramas calculados no plano horizontal foi maior que os valores dos patamares dos semivariogramas calculados no plano vertical. A natureza intrusiva do depósito, bem como as estruturas verticalizadas da rocha, principalmente a foliação de fluxo acarretam uma maior variabilidade lateral do corpo, em relação à direção da intrusão.

O mesmo fato pode explicar a melhor estruturação obtida nos semivariogramas verticais. Nota-se em todas as áreas que os pontos dos semivariogramas experimentais calculados no plano horizontal apresentam-se mais erráticos, sendo difícil o ajuste de um modelo teórico. 
A Área Sul, que segundo a análise estatística foi a área melhor delimitada, apresentou para a variável $\mathrm{P}_{2} \mathrm{O}_{5}$, a maior amplitude na direção vertical, o que vai ao encontro com a direção da foliação da rocha. Por outro lado, a variável MgO apresentou maior continuidade na direção horizontal, evidenciando a homogeneidade composicional da intrusão em relação aos carbonatos, principalmente a calcita. Esta área foi a única que apresentou anisotropia geométrica.

Para as demais áreas, fica evidenciada a presença de mais de uma população, já observada na análise estatística. Percebe-se uma maior variabilidade dos dados em relação à Área Sul, com altos valores do patamar.

A Área Norte foi a que apresentou os semivariogramas mais erráticos, principalmente na direção horizontal. Esta área, por estar localizada na porção mais elevada do depósito, possui algumas amostras em material intemperizado, além de possuir xenólitos de jacupiranguito em seu interior. Todos estes fatores não favorecem a continuidade espacial das amostras, conforme pode ser observado principalmente para a variável $\mathrm{MgO}$. As presenças de xenólitos de jacupiranguito, compostos por minerais silicáticos ferro-magnesianos e de zonas de reação relacionadas ao contato destes corpos com a rocha carbonatítica, zonas estas ricas em minerais silicáticos, devem ser consideradas quando da análise dos semivariogramas desta área.

Cada elemento apresentou o mesmo tipo de modelo de semivariograma, independente da área de estudo.

$O \mathrm{P}_{2} \mathrm{O}_{5}$ apresentou o modelo exponencial nas três áreas, sendo sua amplitude máxima ocorrendo na Área Sul (240 metros na direção vertical), e sua amplitude mínima ocorrendo na Área Norte (90 metros na direção vertical). Nas Áreas Central e Norte, optou-se por não modelar os semivariogramas experimentais calculados para a direção horizontal, por considerá-los não estruturados. Considerando as contaminações presentes nestas duas áreas, esta interpretação pode ser considerada válida.

Em relação ao $\mathrm{MgO}$, verifica-se que, excetuando a Área Sul, as demais áreas apresentaram anisotropia mista (Figuras 7.15 e 7.17), sempre com a direção vertical apresentando maior continuidade e menor variabilidade dos dados. Na Área Sul, que apresentou anisotropia geométrica, a maior continuidade pode ser observada na direção horizontal. Isto pode ser explicado pelo fato desta área englobar apenas uma única intrusão carbonatítica, constituindo-se assim, em uma área mais homogênea do 
ponto de vista dos carbonatos, Deste modo, ocorreu uma maior continuidade das amostras no plano horizontal, continuidade esta que não se observa nas demais áreas, associadas a mais de uma intrusão e, conforme observado, com composições diferentes. (Área Central englobando C2 e parte de C3; Área Norte englobando C4, C5 e parte de C3).

Para aferir a exatidão dos modelos ajustados, procedeu-se à técnica de validação cruzada, que consiste na estimativa de um ponto conhecido e retirado do conjunto, utilizando para esta estimativa os parâmetros dos semivariogramas teóricos ajustados. A análise da dispersão dos valores estimados com os valores reais permite julgar se o ajuste variográfico pode ser considerado satisfatório.

A validação cruzada foi realizada utilizando-se os chamados parâmetros de vizinhança, que correspondem às condições de seleção de amostras que serão utilizadas para estimar um determinado ponto. Estes parâmetros podem ser observados na Tabela 7.1.

Tabela 7.1 - Parâmetros de vizinhança utilizados na validação cruzada dos modelos de semivariogramas.

\begin{tabular}{|c|c|c|c|c|c|c|}
\hline Variavel & $\begin{array}{l}\text { Setores } \\
\text { angulares }\end{array}$ & $\begin{array}{l}\text { Minimio de } \\
\text { amostras }\end{array}$ & $\begin{array}{l}\text { No ldeal de } \\
\text { Amostras } \\
\text { por setor }\end{array}$ & $\begin{array}{l}\text { Raio de } \\
\text { Busca } \\
\text { (Direcâo X) }\end{array}$ & $\begin{array}{c}\text { Ralio de } \\
\text { Busca } \\
\text { (Direcáo Y) }\end{array}$ & $\begin{array}{c}\text { Raio de } \\
\text { Busca } \\
\text { (Direça } z \text { ) }\end{array}$ \\
\hline $\mathrm{P}_{2} \mathrm{O}_{5}-\mathrm{SUI}$ & 8 & 5 & 2 & 120 & 120 & 200 \\
\hline $\mathrm{MgO}$ - Sul & 8 & 5 & 2 & 100 & 100 & 50 \\
\hline $\mathrm{P}_{2} \mathrm{O}_{5}$ - Central & 8 & 5 & 2 & 0 & 0 & 100 \\
\hline MgO - Central & 8 & 5 & 2 & 70 & 70 & 100 \\
\hline $\mathrm{P}_{2} \mathrm{O}_{5}-\mathrm{Norte}$ & 8 & 5 & 2 & $0 \mathrm{~m}$ & $0 \mathrm{~m}$ & $70 \mathrm{~m}$ \\
\hline $\mathrm{MgO}$ - Norte & 8 & 5 & 2 & $50 \mathrm{~m}$ & $50 \mathrm{~m}$ & $100 \mathrm{~m}$ \\
\hline
\end{tabular}

Estes parâmetros indicam que, para se estimar um ponto, são necessárias no mínimo cinco amostras localizadas dentro dos raios de busca. Estes raios foram definidos a partir das informações dos semivariogramas, de modo que os raios escolhidos não ultrapassassem os valores de amplitude obtidos nas diferentes direções de semivariografia.

Nas Figuras 7.18 a 7.23 são apresentados os resultados das validações cruzadas realizadas para os modelos de semivariogramas ajustados. 


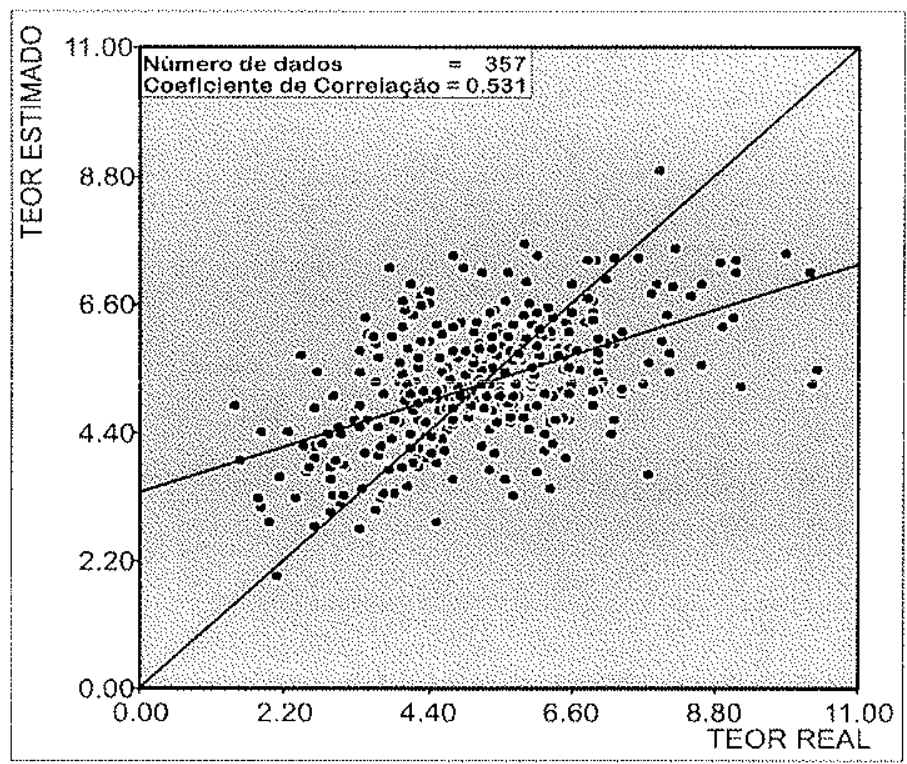

Figura 7.18 - Diagrama de Dispersão para a variável $\mathrm{P}_{2} \mathrm{O}_{5}$ (Área Sul), obtido a partir da validação cruzada.

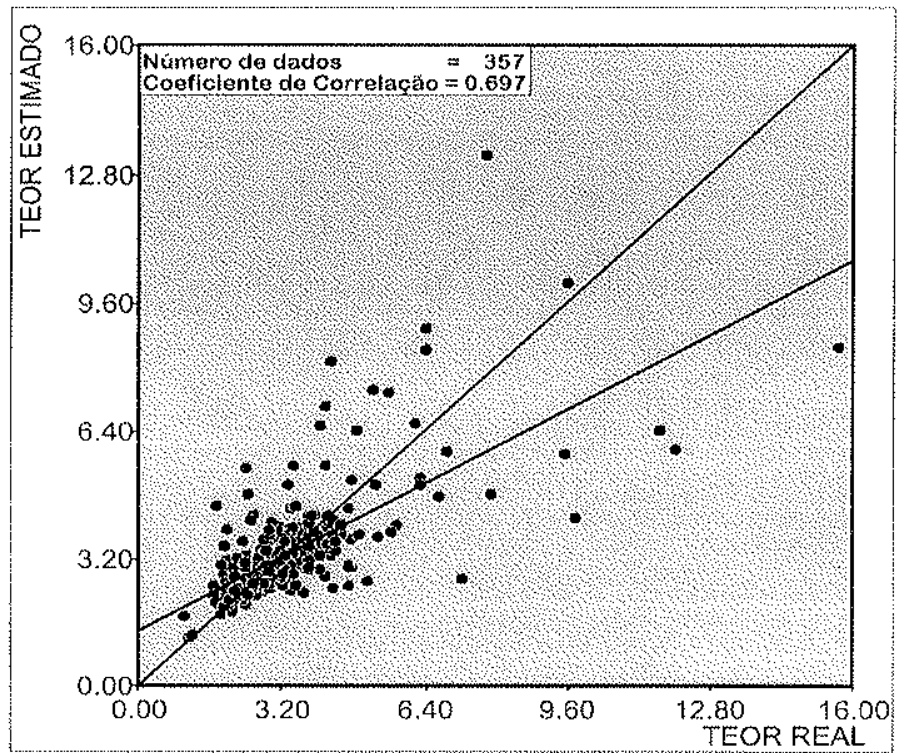

Figura 7.19 - Diagrama de Dispersão para a variável MgO (Área Sul), obtido a partir da validação cruzada. 


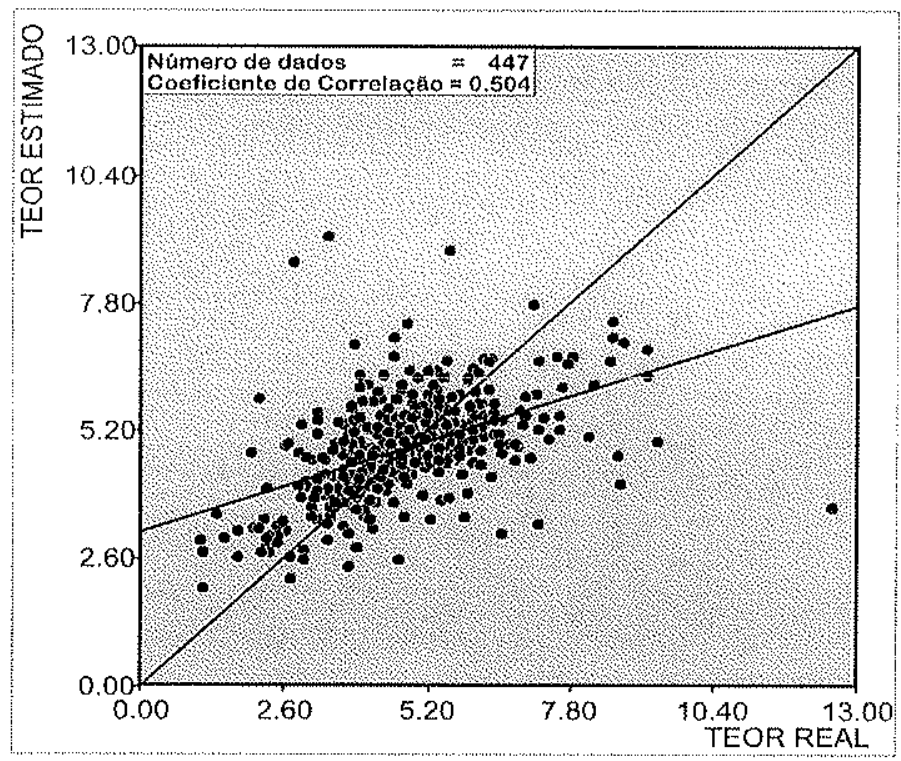

Figura 7.20 - Diagrama de Dispersão para a variável $\mathrm{P}_{2} \mathrm{O}_{5}$ (Área Central), obtido a partir da validação cruzada.

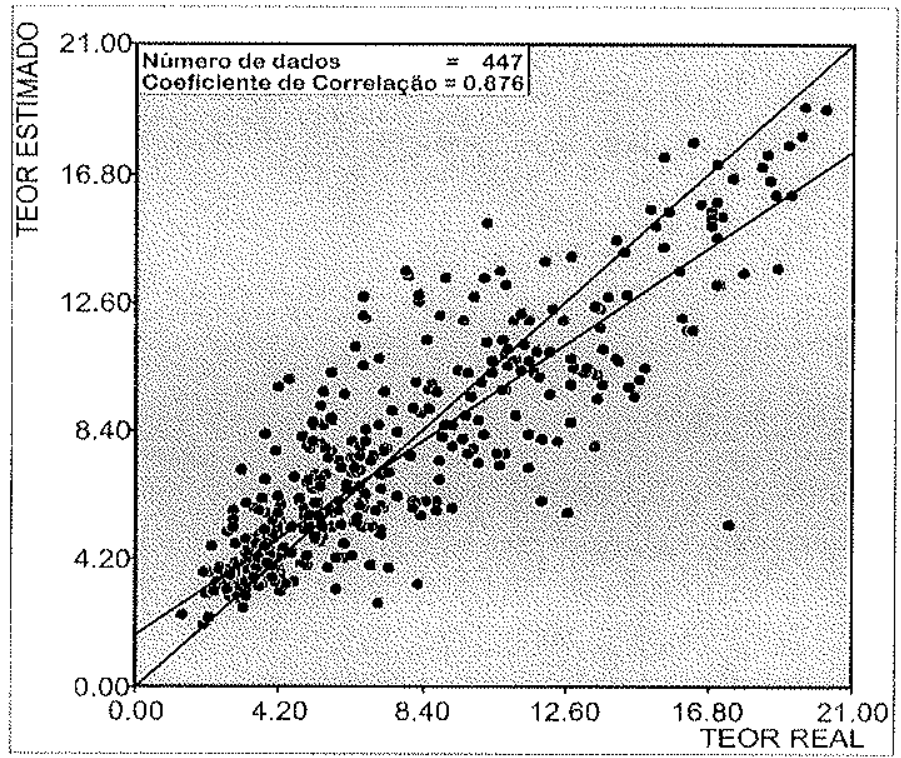

Figura 7.21 - Diagrama de Dispersão para a variável Mgo (Área Central), obtido a partir da validaçăo cruzada. 


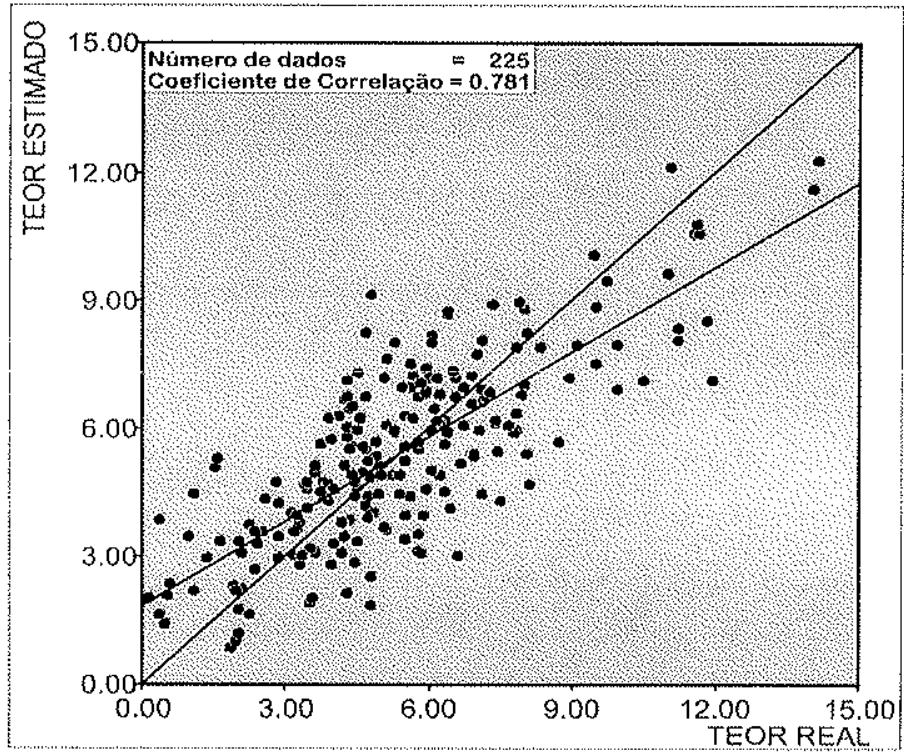

Figura 7.22 - Diagrama de Dispersão para a variável $\mathrm{P}_{2} \mathrm{O}_{5}$ (Área Norte), obtido a partir da validação cruzada.



Figura 7.23 - Diagrama de Dispersão para a variável Mgo (Área Norte), obtido a partir da validação cruzada.

A Tabela 7.2 mostra os parâmetros de erro obtidos pela validação, calculados conforme as fórmulas apresentadas no Capítulo 3. 
Tabela 7.2 - Resultado da validação cruzada para cada uma das variáveis.

\begin{tabular}{|c|c|c|c|c|}
\hline Variável & No amostras & Erro Médio & Erro Padräo da Média & Variâncla do Erro Padrão \\
\hline $\mathrm{P}_{2} \mathrm{O}_{5}-\mathrm{SuI}$ & 357 & 0,0283 & 0,0214 & 1,307 \\
\hline MgO-Sul & 357 & 0,0058 & 0,0074 & 1,667 \\
\hline $\mathrm{P}_{2} \mathrm{O}_{6}$ - Contral & 447 & 0,0025 & 0,0009 & 0,929 \\
\hline MgO-Gentral & 447 & 0,0016 & 0,0014 & 0,970 \\
\hline $\mathrm{P}_{2} \mathrm{O}_{5}$ - Norte & 225 & 0,0010 & 0,0012 & 0,952 \\
\hline MgO-Norte & 225 & 0,0027 & 0,0011 & 1,255 \\
\hline
\end{tabular}

Pode-se perceber uma grande correlação em todas as estimativas realizadas. Percebe-se em todos os gráficos de dispersão, a ocorrência do efeito de suavização da krigagem ordinária (smooth effect), onde os valores reais altos são subestimados e valores reais baixos são superestimados. Mesmo assim, a grande maioria dos dados foi estimada corretamente, onde se conclui que o modelo de semivariograma ajustado pode ser considerado satisfatório.

Mesmo apresentando os semivariogramas melhores estruturados, a Área Sul apresentou os maiores erros médios. Os semivariogramas apresentados para esta Área corresponderam aos menores erros calculados pela validação cruzada. Qualquer tentativa de alteração nos semivariogramas resultou em erros maiores que os obtidos com os semivariogramas aqui apresentados. Desta maneira, pode-se relacionar estes erros com a quantidade de informação e o espaçamento das sondagens realizadas nesta área.

\section{3 - Estimativa de Teores por Krigagem Ordinária}

Para a realização da estimativa de teores, foi construído um modelo de blocos tridimensional para cada área do depósito, utilizando-se os parâmetros atualmente utilizados na lavra, com blocos de dimensões de $25 \times 25 \times 10$ metros.

Os chamados parâmetros de vizinhança da estimativa foram os mesmos utilizados na validação cruzada e que estão listados na Tabela 8.1. Ressalta-se que para a estimativa de teores utilizou-se uma discretização de blocos de $2 \times 2 \times 2$. Novamente, para se realizar a estimativa de cada bloco foram necessárias, no mínimo, cinco amostras localizadas dentro dos raios de busca das direções estudadas. 
As Figuras 7.24 a 7.29 apresentam os modelos de blocos krigados para as variáveis $\mathrm{P}_{2} \mathrm{O}_{5}$ e $\mathrm{MgO}$ para as três áreas estudadas.

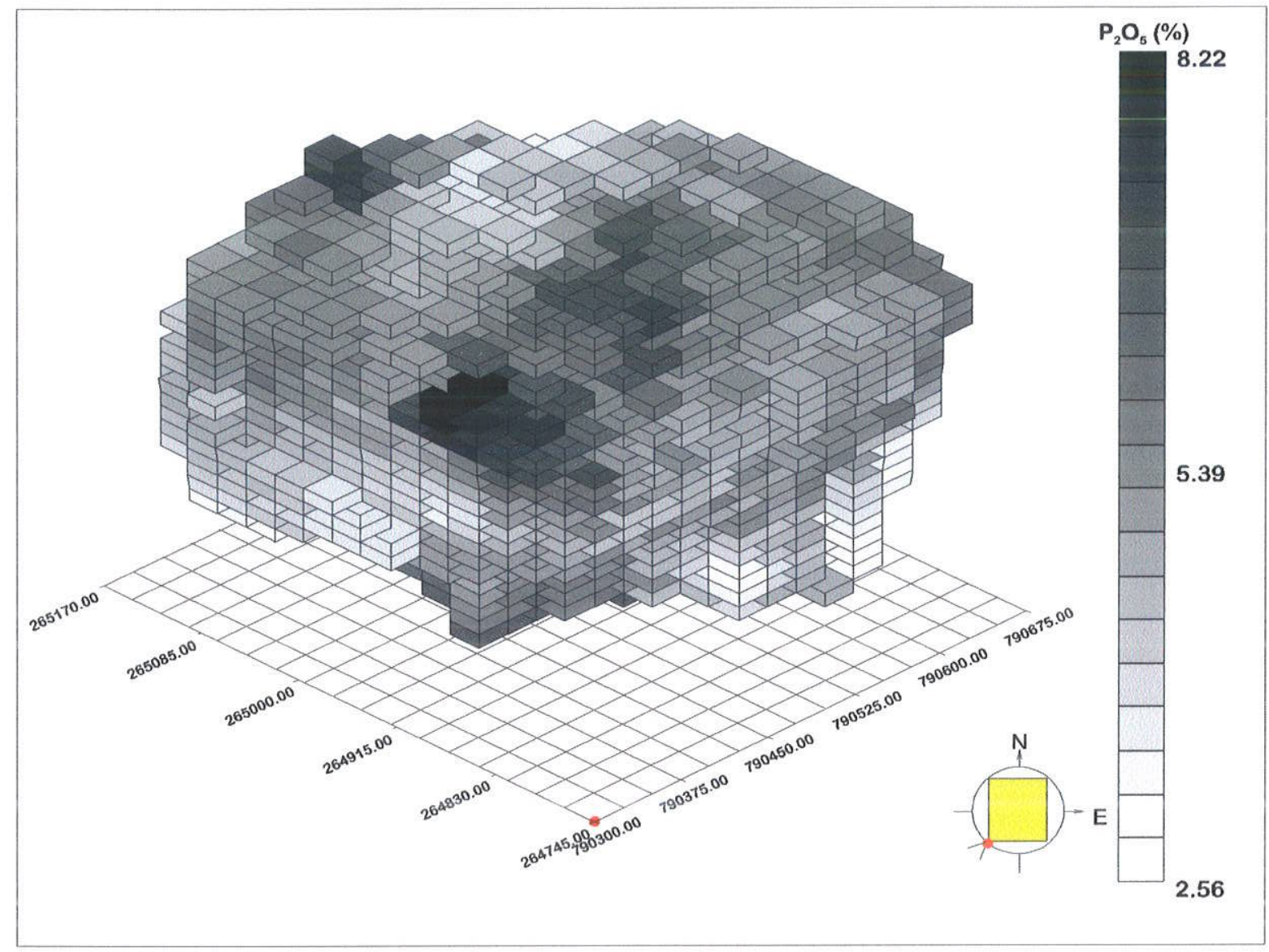

Figura 7.24 - Modelos de blocos krigados para a variável $\mathrm{P}_{2} \mathrm{O}_{5}$ (Área Sul). 


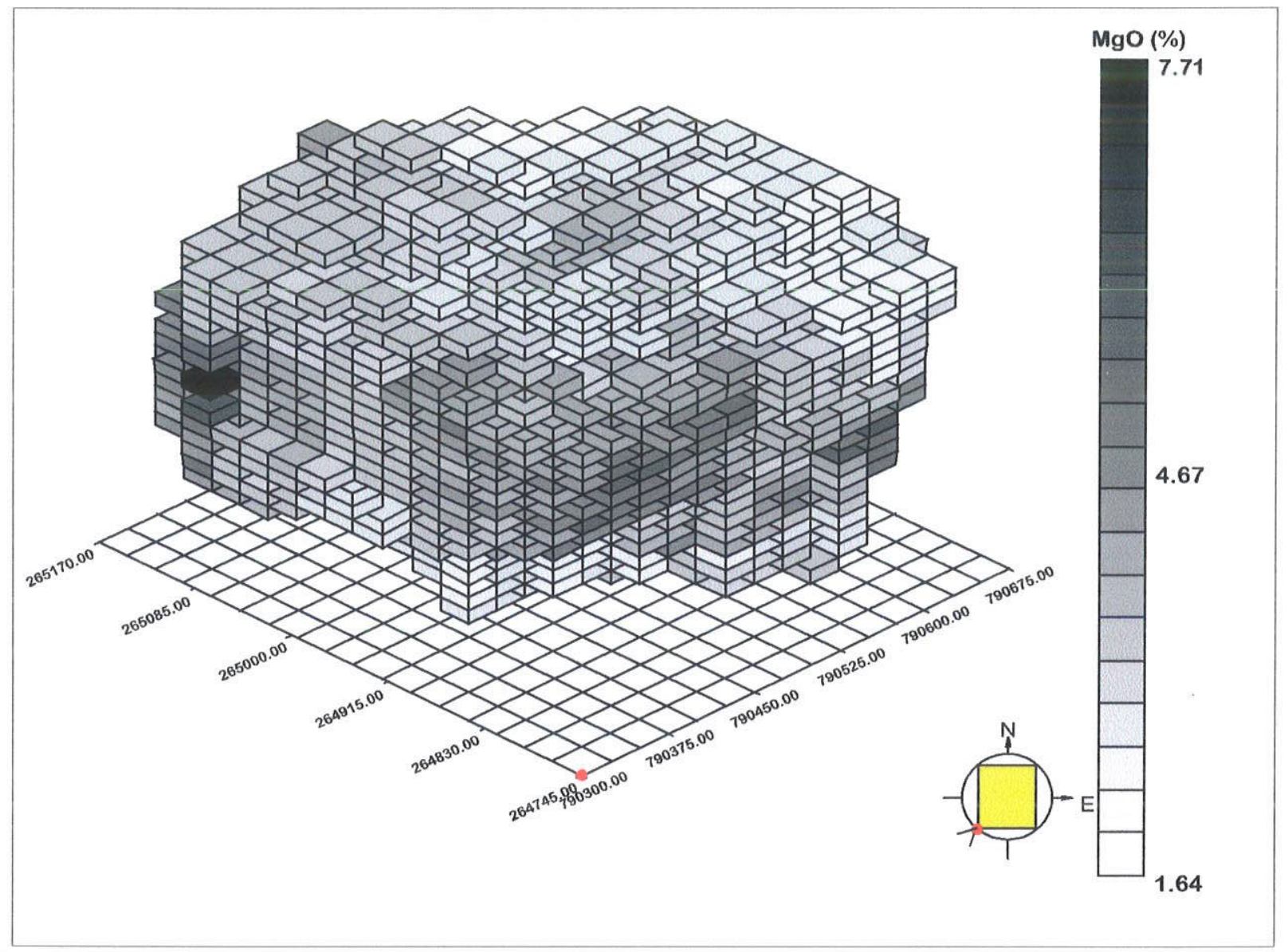

Figura 7.25 - Modelos de blocos krigados para a variável MgO (Área Sul). 




Figura 7.26 - Modelos de blocos krigados para a variável $\mathrm{P}_{2} \mathrm{O}_{5}$ (Área Central). 


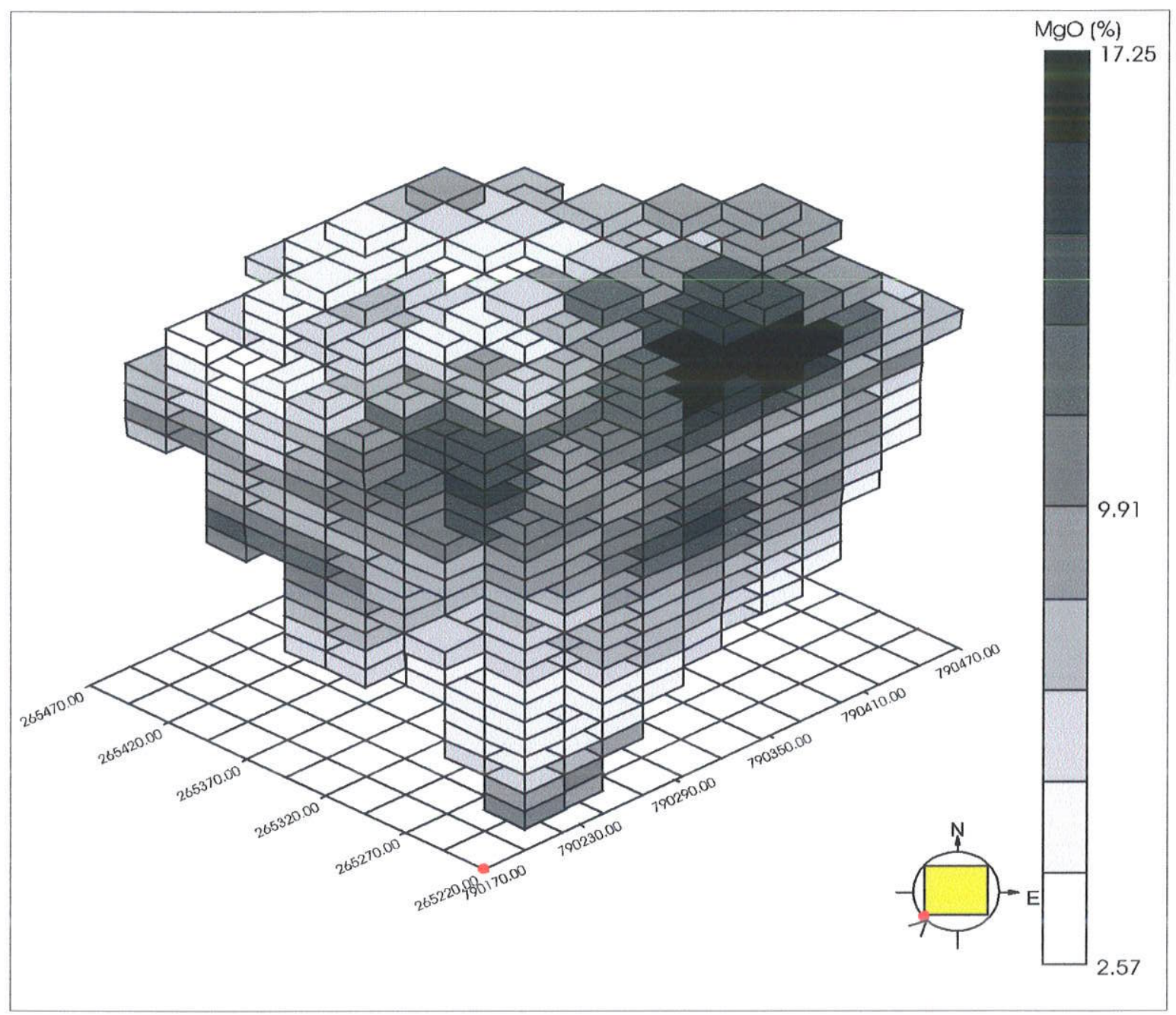

Figura 7.27 - Modelos de blocos krigados para a variável MgO (Área Central). 


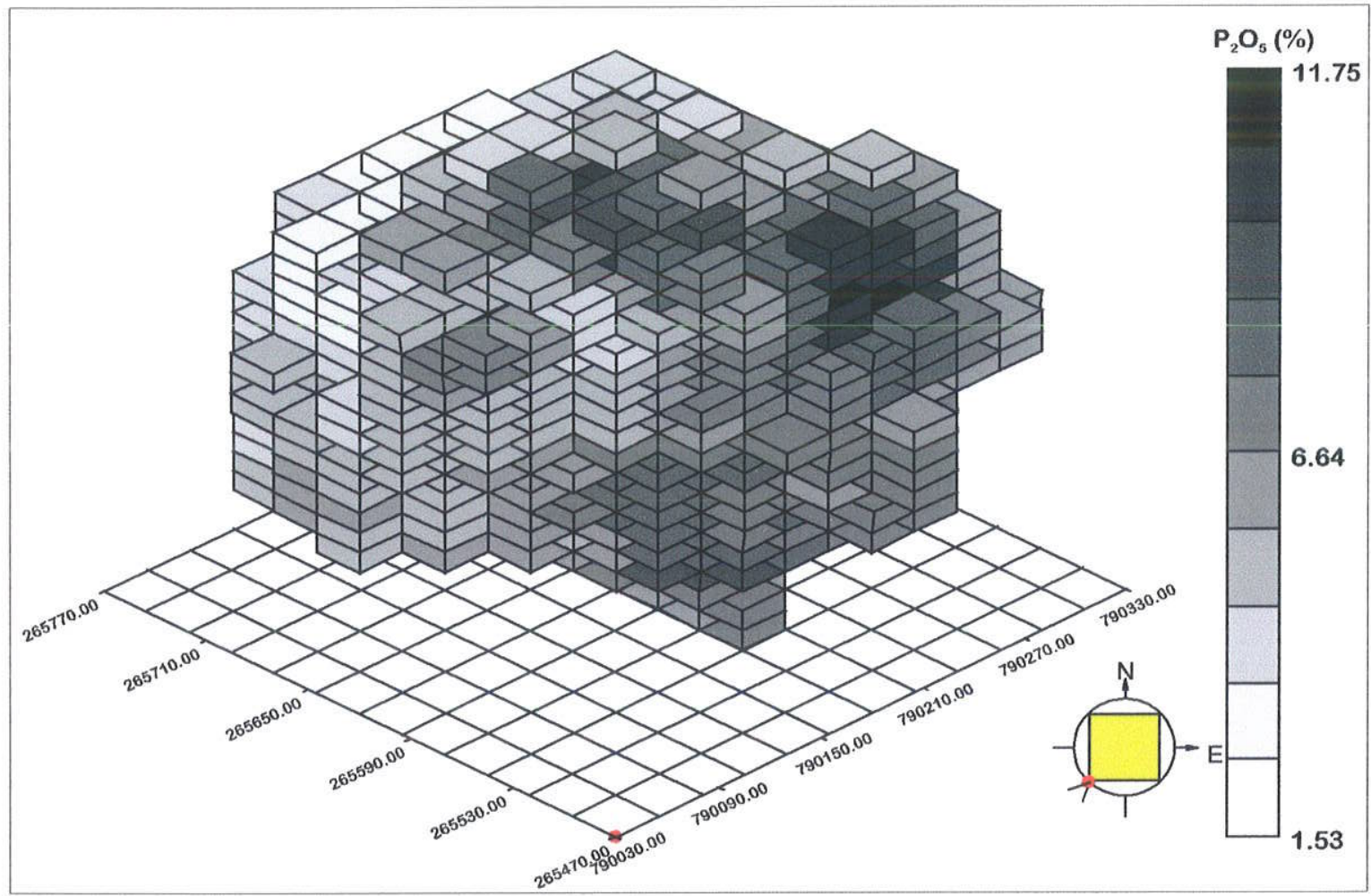

Figura 7.28 - Modelos de blocos krigados para a variável $\mathrm{P}_{2} \mathrm{O}_{5}$ (Área Norte).



Figura 7.29 - Modelos de blocos krigados para a variável MgO (Área Norte).

As Figuras 7.30 a 7.32 apresentam o resultado da estimativa de teores por níveis. Nestas figuras são apresentados apenas alguns níveis a fim de se observar a 
distribuição dos teores. A escolha dos niveis deu-se somente para efeito de visualização.

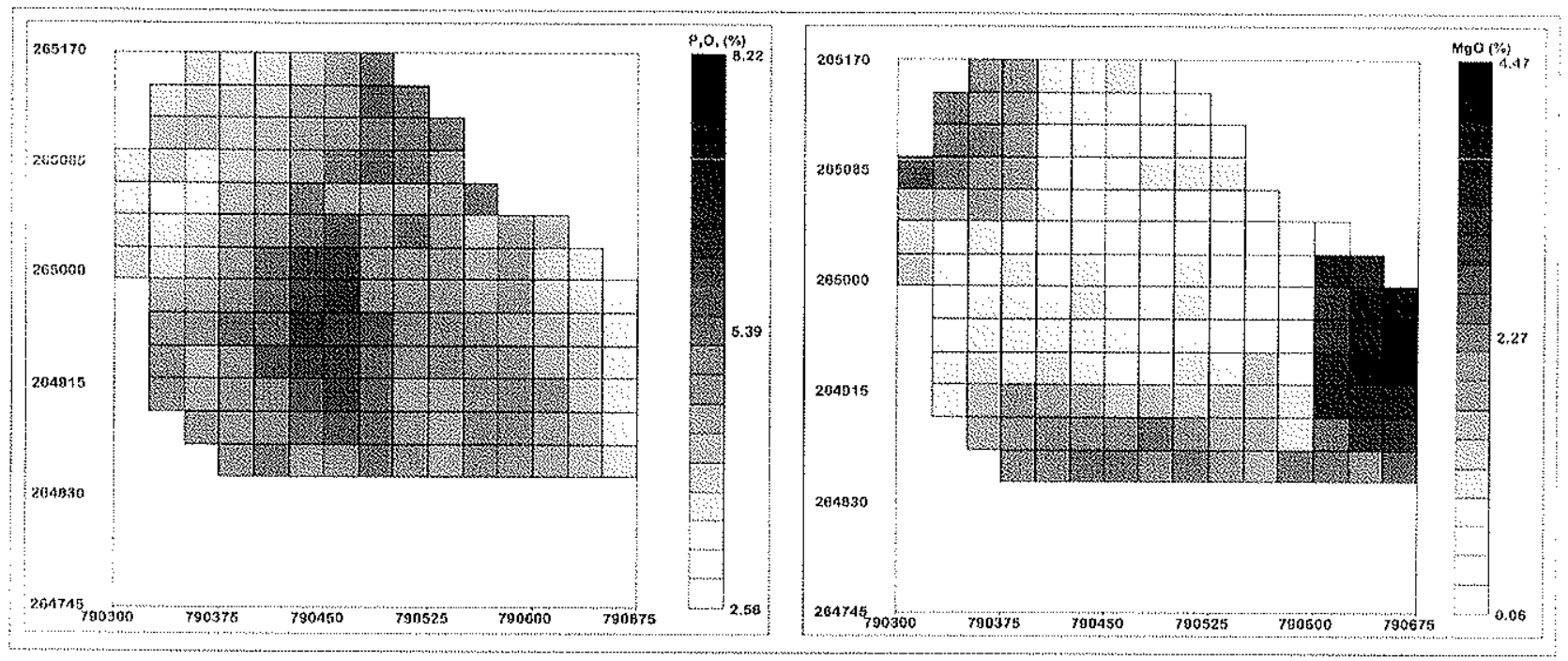

Figura 7.30 - Teores estimados para a Area Sul - Nivel - 40 .

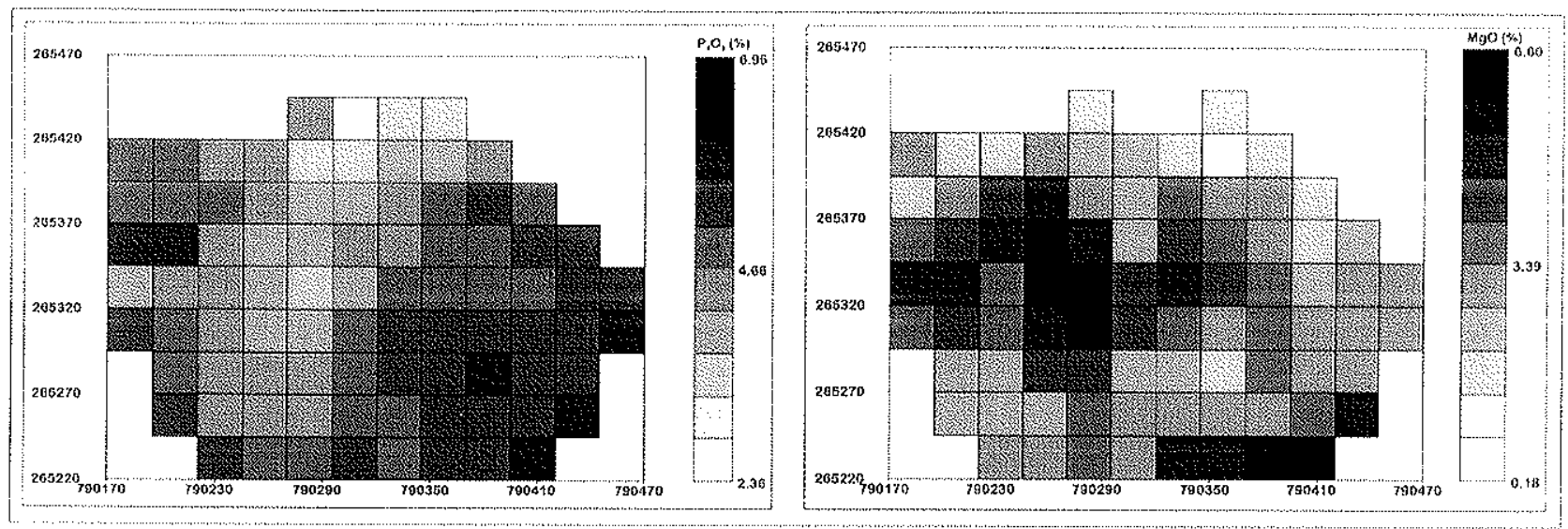

Figura 7.31 - Teores estimados para a Área Central - Nivel +80 . 




Figura 7.32 - Teores estimados para a Área Norte - Nivel +10 .

Nota-se que a Área Sul apresentou os menores teores de magnésio, pois o carbonatito constituinte é predominantemente calcítico. A Área Norte, onde predomina o carbonatito dolomítico, apresentou os maiores teores de magnésio.

Devido à falta de informação e aos critérios utilizados na seleção de amostras, não foi possível realizar a estimativa de teores para os níveis mais inferiores do depósito. Deste modo, para a Área Sul, o limite da estimativa ficou no nível -160, a Área Central foi estimada até o nível -100 e a Área Norte foi estimada até o nível -50 .

Além da estimativa dos teores, calculou-se também o desvio de interpolação, que corresponde a uma nova medida de confiabilidade das estimativas por krigagem ordinária, proposta por Yamamoto (2000b).

As Figuras 7.33 a 7.35 apresentam o mapa do desvio de interpolação para os niveis mostrados anteriormente. 




Figura 7.33 - Mapa do desvio de interpolação para a estimativa da Area Sul (Nivel -40) A) $\mathrm{P}_{2} \mathrm{O}_{5}$ - B) MgO.



Figura 7.34 - Mapa do desvio de interpolação para a estimativa da Área Central (Nível + 80) A) $\mathrm{P}_{2} \mathrm{O}_{5}-\mathrm{B}$ ) MgO.



Figura 7.35 - Mapa do desvio de interpolação para a estimativa da Área Norte (Nivel +10) A) $\mathrm{P}_{2} \mathrm{O}_{5}-\mathrm{B}$ ) $\mathrm{MgO}$ 
A análise dos mapas de desvio de interpolação juntamente com os mapas das estimativas permite caracterizar o chamado efeito proporcional, observado nas áreas que apresentam os maiores teores juntamente com as maiores incertezas associadas. Este efeito é visivel na variável $\mathrm{MgO}$, que apresenta distribuição assimétrica positiva. Variáveis com distribuição normal não apresentam o efeito proporcional, ou seja, não apresentam correlação entre os teores e as incertezas. É o que ocorre com a variável $\mathrm{P}_{2} \mathrm{O}_{5}$, que, conforme observado na análise estatística, apresenta distribuição praticamente simétrica.

Para caracterizar a ocorrência do efeito proporcional na variável $\mathrm{MgO}$, as Figuras 7.36 a 7.38 apresentam a correlação entre os teores estimados e o desvio de interpolação para as três áreas.

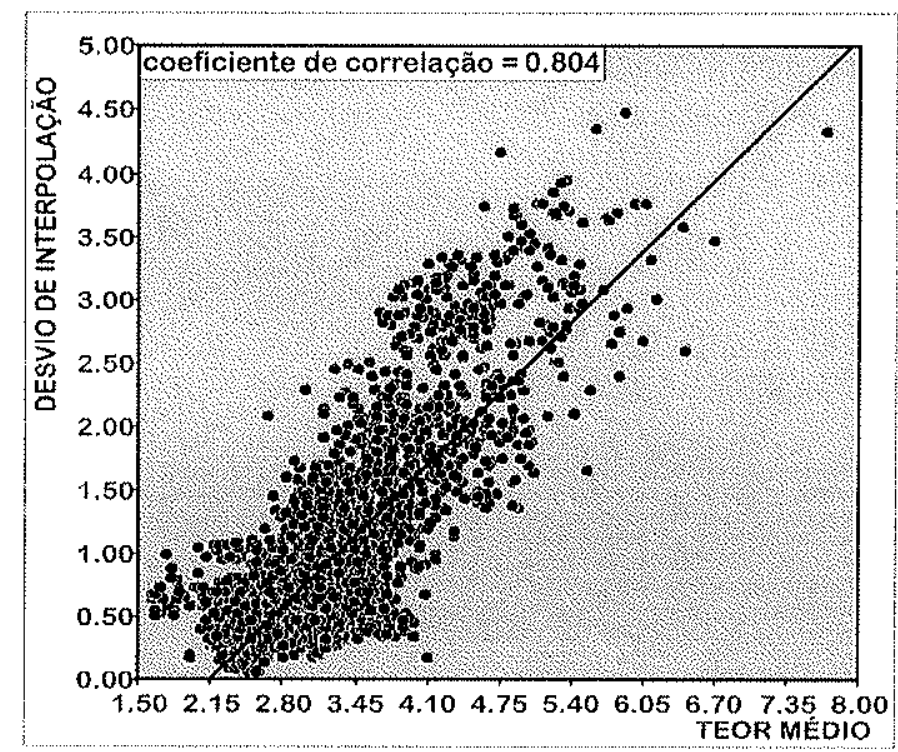

Figura 7.36 - Diagrama de dispersão entre o teor estimado e o desvio de interpolação (MgO da Área Sul). 


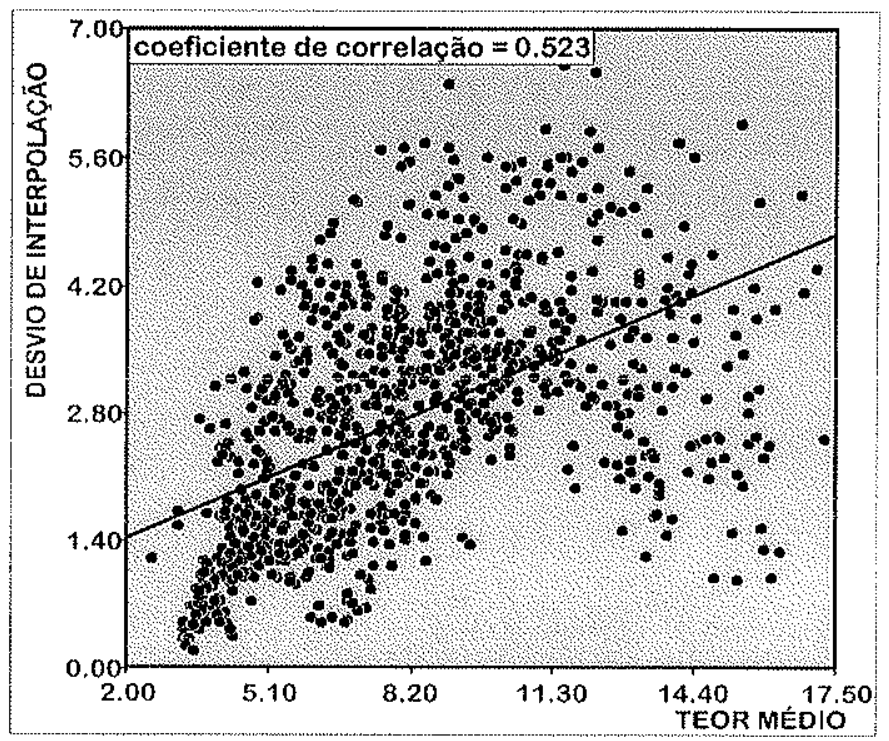

Figura 7.37 - Diagrama de dispersão entre o teor estimado e o desvio de interpolação (MgO da Area Central).

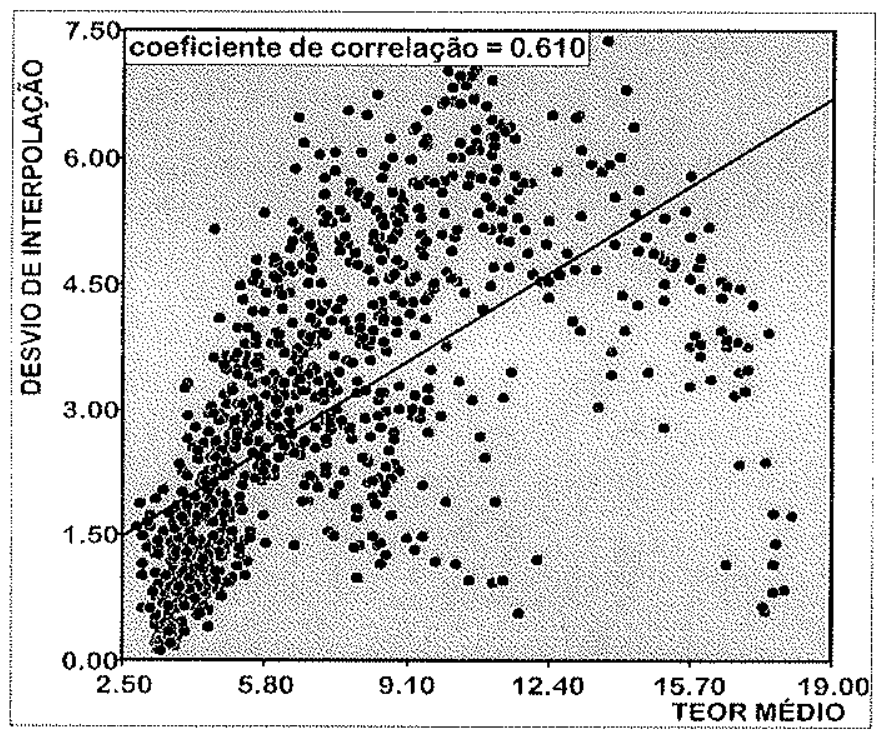

Figura 7.38 - Diagrama de dispersão entre o teor estimado e o desvio de interpolação (MgO da Área Norte).

Conforme a análise estatística (Figura 7.6B), a Área Sul foi a área melhor delimitada na separação de populações realizada neste trabalho. Nota-se que os demais histogramas, principalmente para a variável magnésio, apresentaram valores anômalos, que indicam mistura de populações. Deste modo, pode-se entender razão da dispersão obtida na Figura 7.36 apresentar melhor correlação $(0,804)$, em comparação às demais áreas. Mesmo assim, o efeito proporcional ainda pode ser caracterizado para as demais áreas (Central e Norte). 


\section{4 - Cálculo dos Recursos/Reservas}

Após a estimativa de teores realizada para as áreas do depósito, procedeu-se ao cálculo do recurso mineral do depósito. Para tanto, os teores de cada bloco krigado foram exportados para uma planilha Excel, onde se calculou o recurso de cada bloco, utilizando-se a fórmula de recurso/reserva $\mathrm{R}=\mathrm{VDT}$, sendo $\mathrm{V}$ o volume do bloco, $\mathrm{D}$ a densidade do minério e $\mathrm{T}$ o teor krigado. Para o estudo realizado, utilizou-se como dimensões dos blocos de krigagem os valores de $25 \times 25 \times 10$ metros, correspondendo às dimensões adotadas na lavra. A densidade do minério utilizada no cálculo corresponde a 2,7 ton $/ \mathrm{m}^{3}$. Assim, cada bloco krigado possui 16.875 toneladas de minério. Para o cálculo do recurso total do depósito, procedeu-se à soma dos recursos de cada bloco do modelo.

Conforme mencionado, o teor de corte adotado na lavra corresponde a $3 \%$ de $\mathrm{P}_{2} \mathrm{O}_{5}$. $\mathrm{O} \mathrm{MgO}$, por não ser considerado minério, não foi utilizado no cálculo de recursos minerais. A Tabela 7.3 apresenta os recursos avaliados para as áreas estudadas e para todo o depósito.

Tabela 7.3 - Quadro resumo da avaliação dos recursos minerais da Mina de Cajati.

\begin{tabular}{|c|c|c|c|c|}
\hline Area & No blocos & $\begin{array}{c}\text { Teor médio } \\
(\%)\end{array}$ & $\begin{array}{c}\text { Recurso } \\
\left(\mathbf{x}_{10} \mathbf{6}^{6} \text { ton) }\right.\end{array}$ & $\begin{array}{c}\text { Cota limite } \\
\text { da estimativa }\end{array}$ \\
\hline $\mathrm{P}_{2} \mathrm{O}_{5}-\mathrm{Sul}$ & 3552 & 5,041 & 3,021376 & -150 \\
\hline $\mathrm{MgO}-\mathrm{Sul}$ & 3552 & 3,163 & - & -150 \\
\hline $\mathrm{P}_{2} \mathrm{O}_{5}-$ Central & 943 & 4,730 & 0,752709 & -100 \\
\hline $\mathrm{MgO}-$ Central & 943 & 8,144 & - & -100 \\
\hline $\mathrm{P}_{2} \mathrm{O}_{5}-$ Norte & 1443 & 5,056 & 1,231236 & -50 \\
\hline $\mathrm{MgO}-$ Norte & 1443 & 7,117 & - & -50 \\
\hline Total (P $\left.\mathbf{P}_{5}\right)$ & 5938 & 4,995 & 5,005322 & \\
\hline
\end{tabular}

Por este quadro percebe-se que a Área Sul, por apresentar uma maior densidade de sondagens e por possuir maior área (Figura 7.5), apresentou o maior número de blocos estimados, estendendo-se até o nível -150. Também se pode notar que, conforme a geologia do depósito, a Área Sul apresenta composição mais calcítica, com baixos teores de magnésio, enquanto que a Área Norte apresenta composição mais dolomítica, com altos teores de magnésio. O alto valor do teor médio de magnésio da 
Área Central ocorre devido à contaminação desta área por xenólitos de jacupiranguitos, compostos por silicatos ferro-magnesianos, tais como piroxênio, olivina e flogopita. Esta contaminação também pode explicar a razão desta área apresentar o menor teor médio de $\mathrm{P}_{2} \mathrm{O}_{5}$ do depósito.

A Área Norte, por apresentar-se na região mais elevada do depósito, não possui sondagens que atinjam as cotas mais inferiores. Deste modo, realizou-se a estimativa de teores somente até a cota -50 .

Efetuou-se também o cálculo dos blocos que apresentaram teores estimados de $\mathrm{P}_{2} \mathrm{O}_{5}$ acima do valor do teor de corte. Os resultados desta seleção podem ser observados na Tabela 7.4.

Tabela 7.4 - Quadro resumo da avaliação dos recursos de $\mathrm{P}_{2} \mathrm{O}_{5}$ considerando os blocos com teores acima de $3 \%$.

\begin{tabular}{|c|c|c|c|c|}
\hline Area & $\mathrm{N}^{0}$ blocos & $\begin{array}{l}\text { Troor médio } \\
(\%)\end{array}$ & $\begin{array}{l}\text { Recurso acima de } 3 \% \\
\left(\times 10^{6} \text { ton) }\right.\end{array}$ & $\begin{array}{l}\text { Cota limite } \\
\text { da estimativa }\end{array}$ \\
\hline $\mathrm{P}_{2} \mathrm{O}_{5}-\mathrm{Sul}$ & 3535 & 5,051 & 3,013138 & -150 \\
\hline $\mathrm{P}_{2} \mathrm{O}_{5}$ - Central & 938 & 4,740 & 0,750340 & -100 \\
\hline $\mathrm{P}_{2} \mathrm{O}_{5}$ - Norte & 1258 & 5,428 & 1,152347 & -50 \\
\hline Total & 5731 & 5,083 & 4,915826 & \\
\hline
\end{tabular}

Com a seleção dos blocos apresentando teores acima de $3 \%$ de $\mathrm{P}_{2} \mathrm{O}_{5}$, apenas a Área Norte apresentou alguma alteração significativa nos resultados. Mesmo assim, cerca de $13 \%$ dos blocos desta área apresentaram teores de $\mathrm{P}_{2} \mathrm{O}_{5}$ abaixo do teor de corte. Segundo o mapa geológico apresentado na Figura 2.4, o limite norte do depósito não está bem delimitado. Deste modo, amostras consideradas como minério, mas com baixos teores de $\mathrm{P}_{2} \mathrm{O}_{5}$ poderiam corresponder a xenólitos ou zonas de reação entre o carbonatito e a encaixante, zonas estas ricas em silicatos e empobrecida em $\mathrm{P}_{2} \mathrm{O}_{5}$. Mesmo com este fator, o teor médio desta área ficou na mesma amplitude do teor médio do depósito. Como já mencionado, por posicionar-se na região mais elevada do depósito, esta área apresenta, localmente, material intemperizado, com um enriquecimento relativo de apatita em relação aos carbonatos. Se por um lado haveria zonas com baixos teores de $\mathrm{P}_{2} \mathrm{O}_{5}$ devido aos xenólitos e zonas de reação, por outro haveria zonas apresentando altos teores, relacionadas às zonas intemperizadas. 


\section{5 - Modelagem Tridimensional do Corpo de Minério}

A partir de seções horizontais digitalizadas, procedeu-se a ligação das mesmas, de modo a se obter o modelo geológico do corpo carbonatítico. Para isto, consideraram-se informações sobre a gênese do corpo, bem como suas relações de contato com a encaixante. A elaboração deste modelo foi realizada através do software Vulcan e pode ser observado nas Figuras 7.39 a 7.43 , juntamente com a topografia ao redor da mineração.

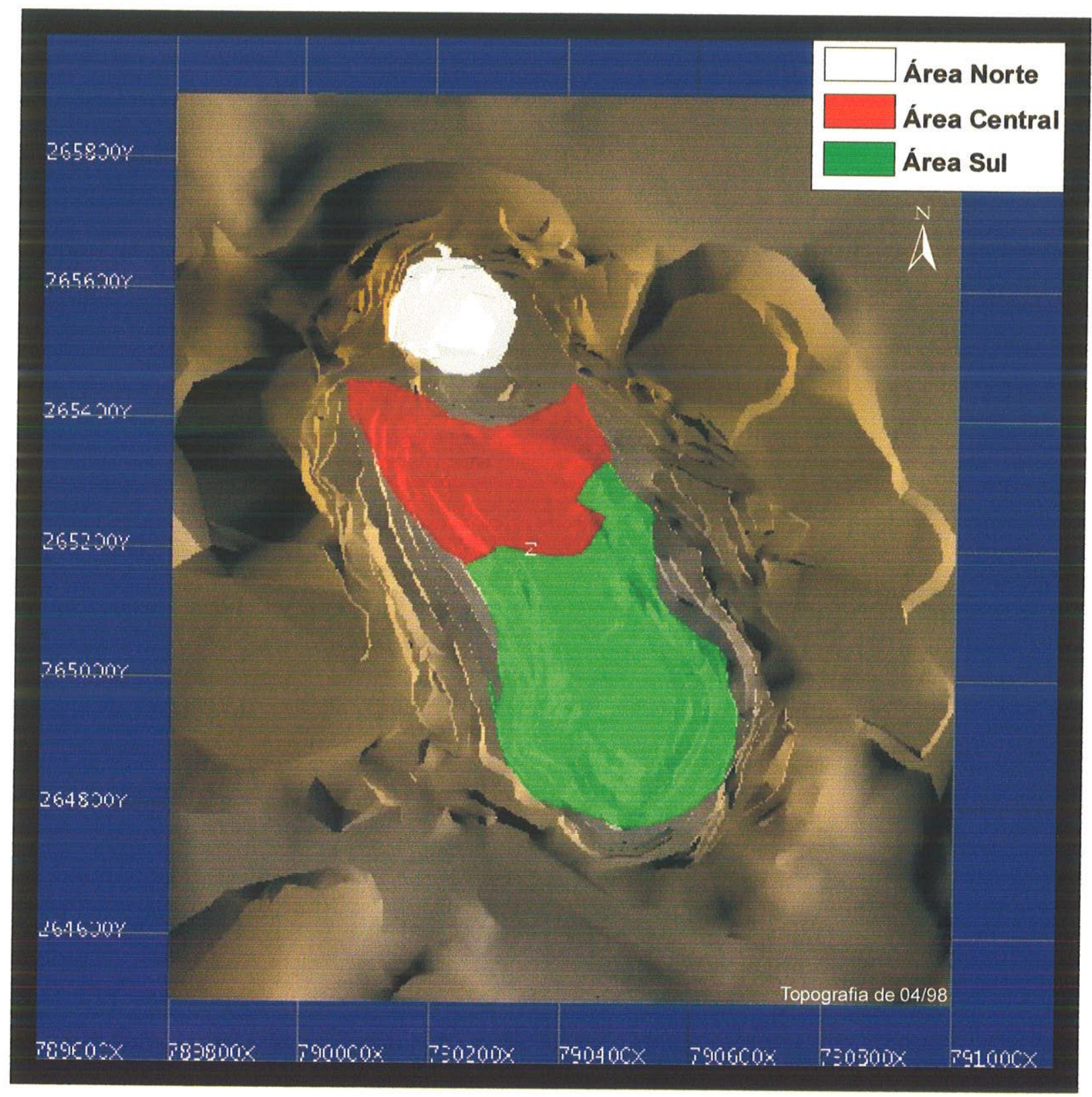

Figura 7.39 - Modelo tridimensional do corpo carbonatítico visto em planta, juntamente com a topografia. 


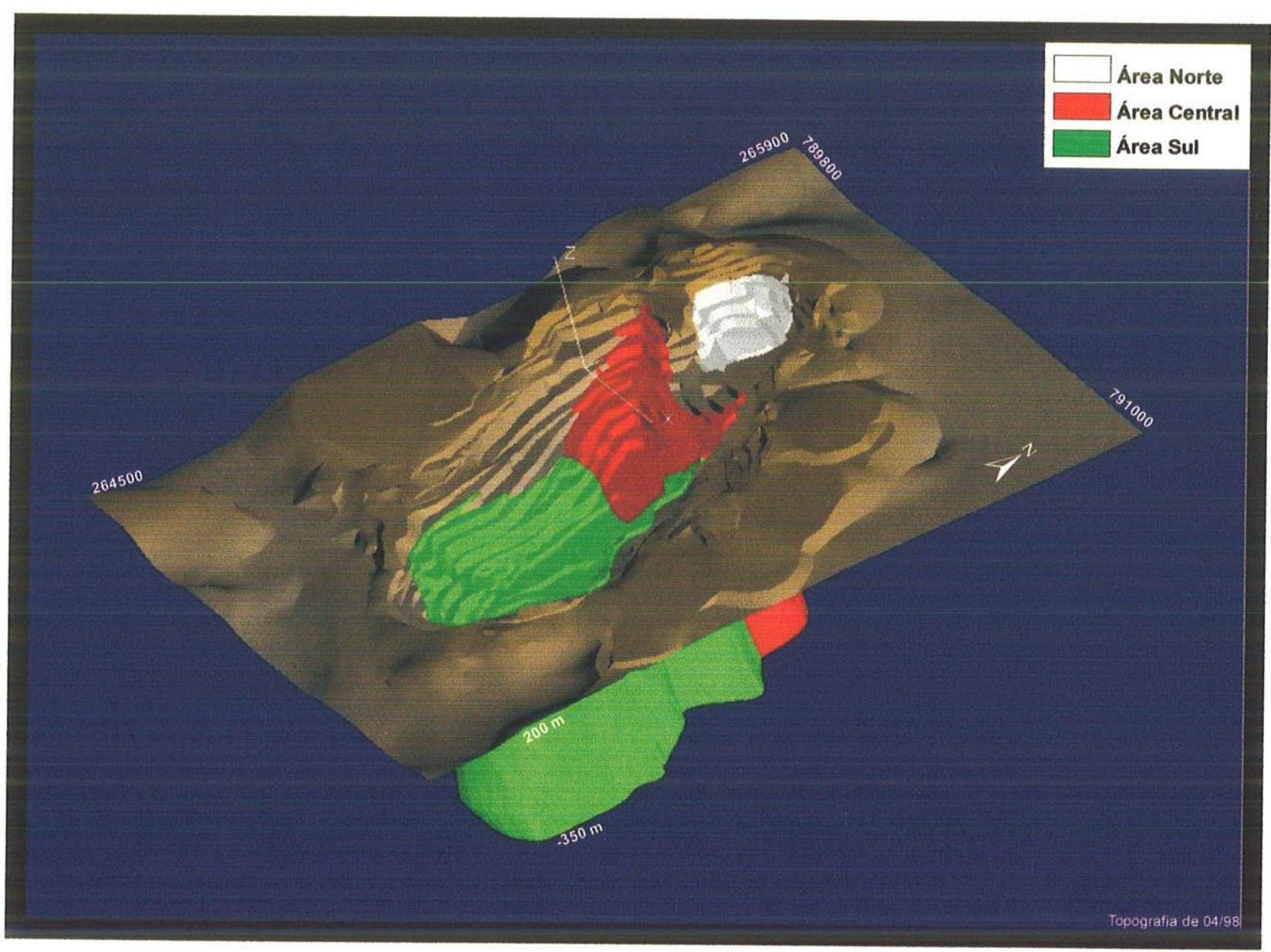

Figura 7.40 - Modelo tridimensional do corpo carbonatítico com vista para o flanco oeste. 


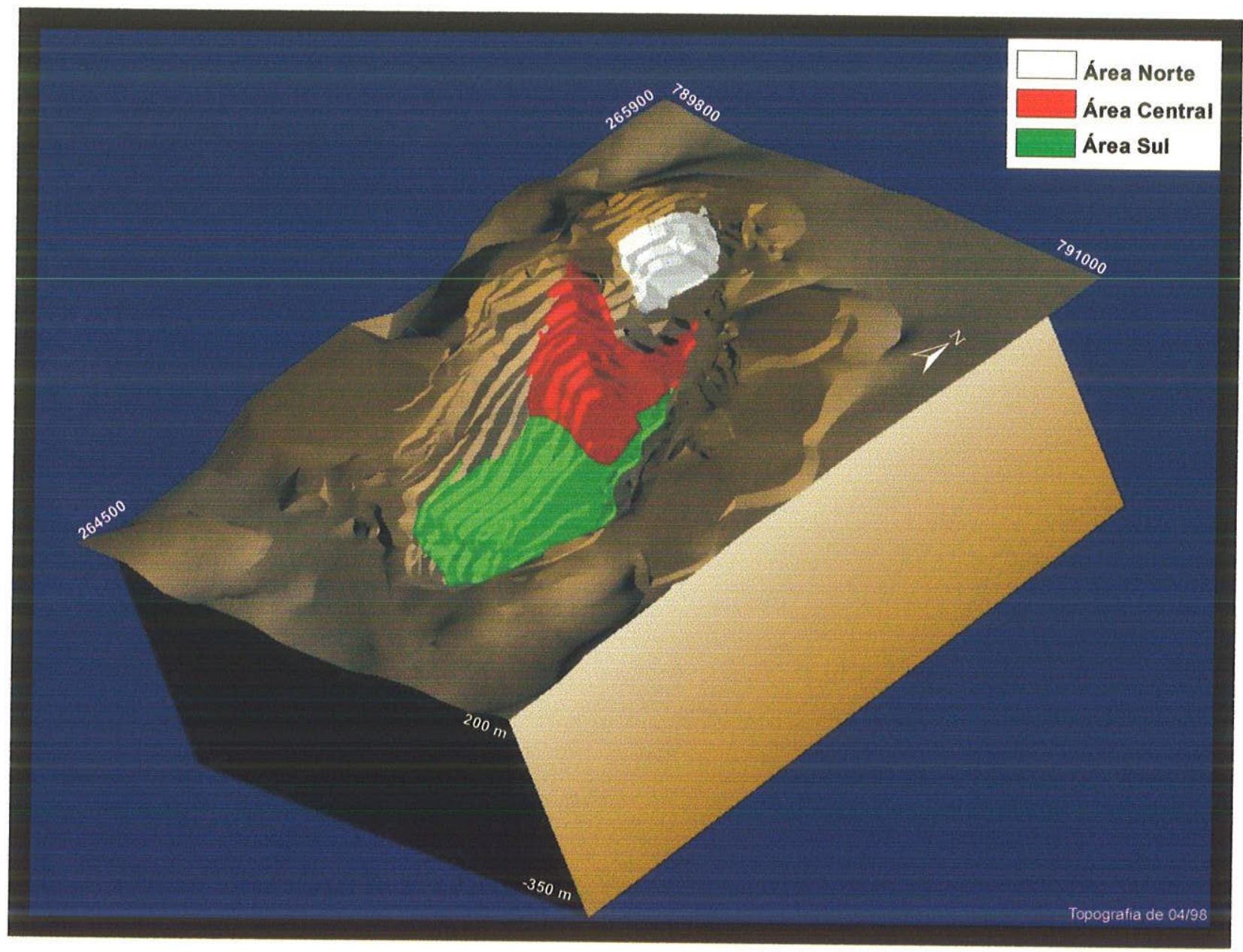

Figura 7.41 - Modelo tridimensional do corpo carbonatítico com vista para o flanco oeste. 


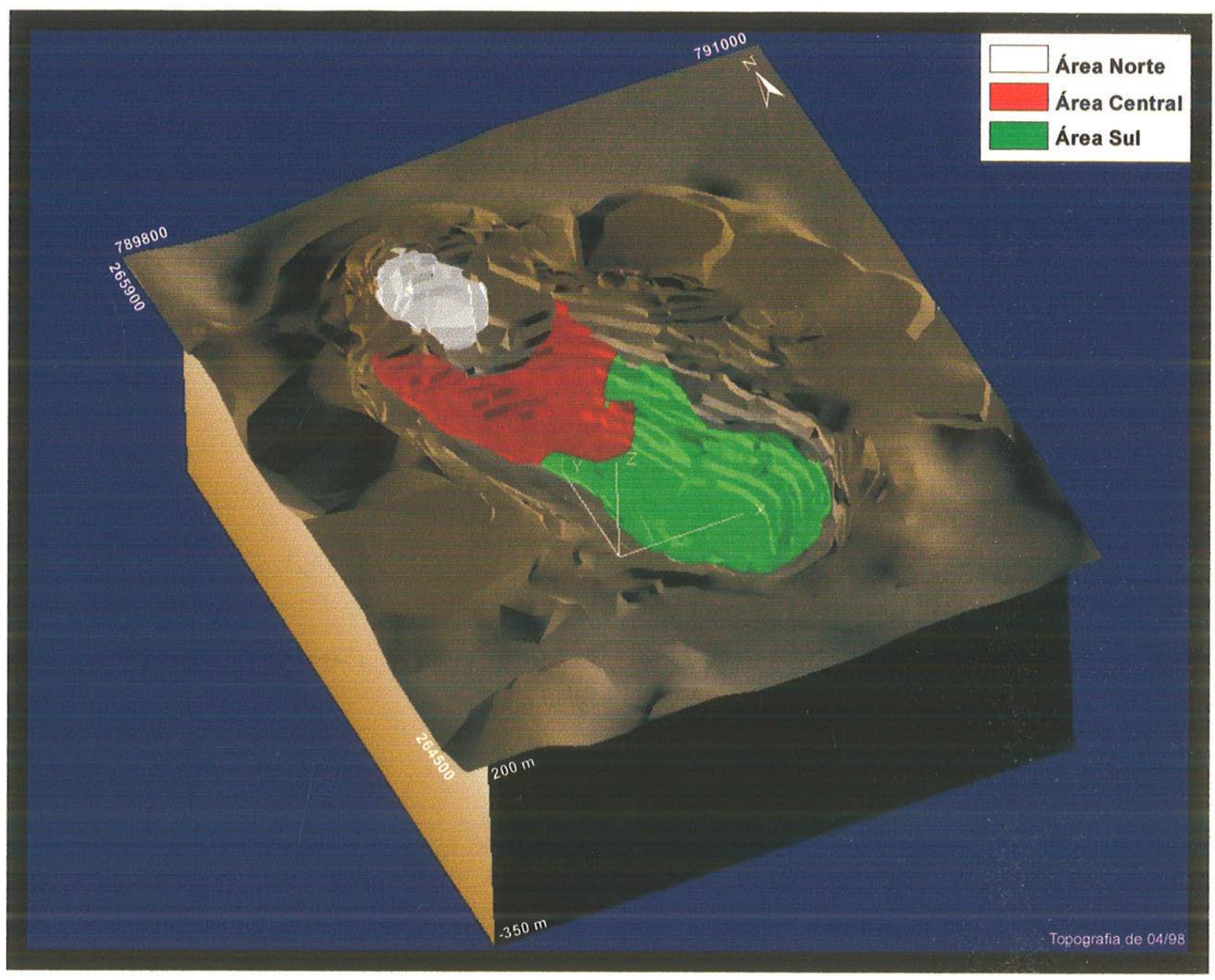

Figura 7.42 - Modelo tridimensional do corpo carbonatítico com vista para o flanco leste. 


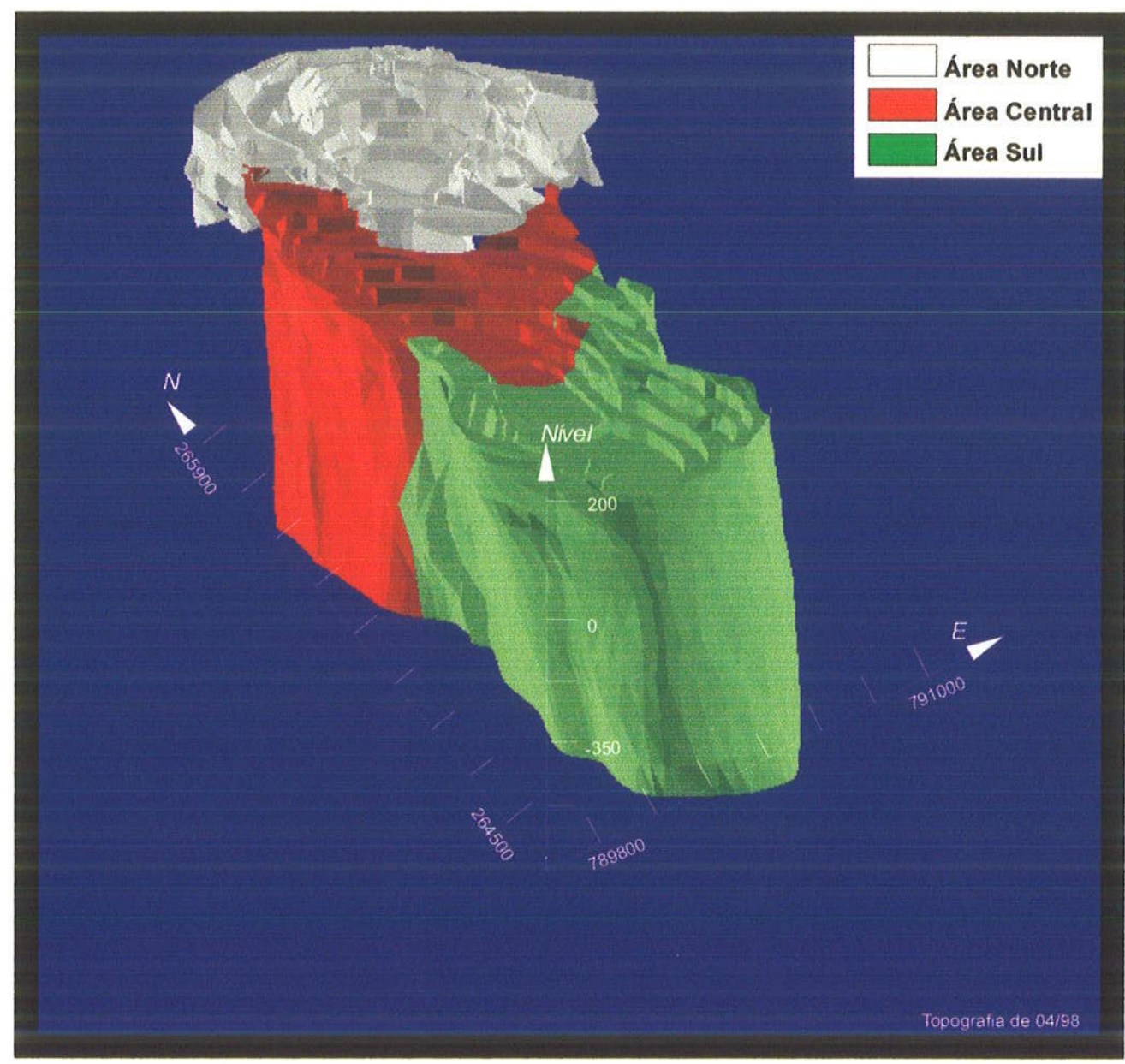

Figura 7.43 - Modelo tridimensional do corpo carbonatítico, sem a topografia.

Neste modelo, o corpo carbonatítico está interpretado até a cota -350 e que, ao que tudo indica, prossegue além desta profundidade, devido à sua natureza intrusiva. Porém, conforme mencionado, uma pequena quantidade de furos de sonda estende-se aos níveis mais inferiores do depósito. Deste modo, optou-se pela realização da estimativa dos teores até o nível -250 .

Recentemente, a empresa Bunge Fertilizantes iniciou uma nova campanha de pesquisa mineral, juntamente com um mapeamento geológico, com o objetivo de rever o modelo do depósito atualmente adotado. Infelizmente, até o término do presente projeto, os resultados destes trabalhos ainda não haviam sido finalizados. Deste modo, deve ficar claro que o modelo apresentado neste projeto está sofrendo alterações, o que deverá necessitar novos estudos. 


\section{CAPÍTULO 8 CONSIDERAÇÕES FINAIS}

Neste trabalho procurou-se mostrar a importância das informações geológicas no estudo de avaliação de recursos/reservas minerais. As análises estatística e geoestatística efetuadas, em momento algum deixaram de lado as informações a respeito da geologia e gênese do depósito.

As interpretações geológicas, principalmente baseadas no trabalho de Gaspar (1989), foram correlacionadas aos resultados da análise estatística obtidas neste trabalho. O referido autor concluiu que o corpo carbonatítico atualmente lavrado seria resultado de cinco eventos intrusivos sucessivos, cada qual com as suas características químicas e mineralógicas.

Conforme observado na análise estatística, verificou-se a presença três populações bem definidas de teores de magnésio, sendo que duas delas, denominadas Área Central e Área Norte, apresentaram fortes indícios de serem constituídas por mais de uma população. De fato, comparando-se os limites das áreas delimitadas neste trabalho com os limites das intrusões propostos por Gaspar (1989), apenas a Área Sul corresponderia a um único evento intrusivo (C1). A Área Central corresponderia aos eventos C2 e parte de C3, e a Área Norte aos eventos C4 e C5, mais parte de C3. No limite destas duas áreas ainda ocorreria uma zona de xenólitos de jacupiranguitos, composta por silicatos ferro-magnesianos. Desta forma, no conjunto de dados dos teores de magnésio haveria a presença de amostras referentes a esta zona, agravando as interpretações.

A separação do depósito em três áreas, a partir da integração da análise estatística com as informações da geologia do depósito foi de grande importância para o prosseguimento do trabalho, pois a análise geoestatística e a estimativa dos teores foram realizadas para cada área individualmente.

Uma verificação bastante interessante da análise estatística consistiu na baixa correlação entre as duas variáveis estudadas, tanto na análise global dos dados, quanto na análise por regiões. Enquanto a distribuição dos teores de $\mathrm{MgO}$ apresentou variações ao longo do depósito, definindo minérios calcíticos, dolomíticos e magnesianos, a distribuição do $\mathrm{P}_{2} \mathrm{O}_{5}$ mostrou-se mais homogênea, caracterizada pela 
distribuição praticamente normal de seus teores. Este fato estaria ligado à mineralogia da rocha, onde os minerais carbonáticos possuem variações composicionais (calcita ou dolomita), enquanto que a apatita constitui-se em um mineral acessório no carbonatito, encontrando-se disseminado por todo o depósito.

Da mesma forma que na análise estatística, a análise geoestatística procurou aliai as infomações sobre a gênese do depósito. Verificou-se que os semivariogramas obtidos para o plano horizontal apresentaram as maiores variabilidades em relação aos semivariogramas obtidos no plano vertical.

A maior continuidade espacial dos dados no plano vertical para a variável $\mathrm{P}_{2} \mathrm{O}_{5}$ confirma a disposição das apatitas, encontradas, preferencialmente, ao longo da foliação verticalizada do carbonatito. Nas Áreas Central e Norte, foram considerados que os semivariogramas calculados no plano horizontal não apresentaram estruturas, não sendo ajustado nenhum modelo a eles.

O comportamento do magnésio apresentou algumas diferenças entres as áreas estudadas. A Área Sul apresentou anisotropia geométrica, com a direção horizontal apresentando maior continuidade. Por se tratar de um corpo geoquimicamente mais homogêneo, sendo constituido essencialmente por calcita, esta maior continuidade lateral pode ser melhor entendida. Em relação às outras áreas, que apresentaram as mais altas variabilidades, ocorre a presença de xenólitos da rocha encaixante dentro do corpo de minério. Nestas zonas também é possível observar bordas de reação entre os corpos. Os xenólitos, juntamente com os produtos das zonas de reação, são constituidos por silicatos ferro-magnesianos, tais como piroxênios, olivinas e flogopitas. Qualquer contaminação do carbonatito por estes materiais acarretaria, nas análises químicas, em teores mais elevados de magnésio, conforme observado nos histogramas das Áreas Central e Norte, onde os valores máximos de MgO são elevados. A partir disso, entende-se a razão das altas variabilidades encontradas nessas áreas.

$\mathrm{Na}$ estimativa de teores, realizou-se a krigagem até a cota limite de -250 metros, devido à falta de informação nos níveis mais inferiores do depósito. Mesmo neste nível, poucos furos continham informações que poderiam ser utilizadas na estimativa. Tentando evitar o enviesamento da estimativa, ou em outras palavras, tentando evitar que blocos fossem estimados apenas com informações de um único furo, os blocos de krigagem foram estimados com um mínimo de cinco amostras, o que garantiu a krigagem somente em áreas com um nivel considerável de informação. 
Nesta estimativa nota-se que a variável MgO apresentou efeito proporcional. Este efeito somente ocorre em casos de distribuições assimétricas positivas, conforme observado na análise estatística da variável MgO. A variável $\mathrm{P}_{2} \mathrm{O}_{5}$, que apresentou distribuição praticamente simétrica, não apresentou este efeito proporcional.

Em relação ao modelo geológico gerado, a sua extrapolação para os niveis inferiores precisaria ser confirmada com novos furos, à medida do avanço da mina. Ainda assim, o modelo gerado apresenta-se condizente com o observado em campo, amarrado ao conhecimento da gênese do depósito.

Um ponto que deve ficar claro é o fato da Bunge Fertilizantes adotar subdivisões diferentes para os carbonatitos, a partir dos teores de magnésio. A subdivisão adotada neste trabalho foi feita a partir da análise estatística, onde se observaram populações de dados concentradas em regiões delimitáveis. Entretanto, a rocha foi denominada simplesmente carbonatito, não levando em consideração diferenças mineralógicas ou tipológicas do corpo. Um estudo pormenorizado poderia ser realizado para uma melhor caracterização do depósito, evoluindo assim, para uma melhor compreensão da variabilidade dos corpos.

Neste trabalho percebe-se a importância de uma análise estatística dos dados antes do início da análise geoestatística. O simples cálculo de distribuição de freqüências garantiu a divisão do depósito, possibilitando um estudo diferenciado para cada área.

Fica claro ao final deste trabalho que as técnicas geoestatísticas devem sempre ter o suporte geológico. Os resultados de cada análise realizada devem ser interpretados de acordo com a geologia do depósito. Um melhor entendimento da gênese do corpo, com as suas sucessivas fases de intrusão, características químicas, mineralógicas, feições estruturais, seria de grande auxílio quando da fase de avaliação de recursos/reservas minerais.

$O$ fato de existirem análises químicas somente para os elementos $\mathrm{P}_{2} \mathrm{O}_{5}$ e $\mathrm{MgO}$ limita a interpretação dos resultados da amostragem e identificação dos tipos litológicos. Análises de outros elementos, tais como potássio, cálcio e sílica auxiliariam a separar as zonas carbonatíticas das zonas de reação com as rochas encaixantes e com a zona de xenólitos. Por situar-se entre as Áreas Central e Norte, estas zonas contaminantes apresentaram sua influência nas análises destas duas áreas. 
Para o caso das apatitas, um fato a ser considerado estaria na gênese destes minerais. Neste trabalho discutiu-se sobre a maior continuidade espacial dos dados de $\mathrm{P}_{2} \mathrm{O}_{5}$. As apatitas ocorrem, preferencialmente, acompanhando a foliação verticalizada da rocha, Não foi objeto deste trabalho realizar um estudo petrográfico ou genético, de modo a se analisar as fases de formação dos minerais. Entretanto, deveria ser verificada a ocorrência de mais de uma geração de apatitas. Os eventos intrusivos que geraram o corpo carbonatítico poderiam gerar apatitas tardias, que não possuiriam nenhuma relação com as apatitas formadas nas fases inicias do magmatismo. Deste modo, a estimativa de teores poderia estar sendo realizada para gerações de apatita distintas, que necessitariam de estudos distintos.

Ao final deste trabalho percebe-se que a geoestatística não pode ser utilizada de maneira puramente intuitiva, mas sim tendo o acompanhamento de profissionais responsáveis pela geração dos dados. A geoestatística é uma ferramenta muito poderosa, mas pode produzir resultados fictícios quando não utiliza bons dados ou quando descarta o acompanhamento de profissionais conhecedores dos depósitos aos quais é aplicada. 


\section{REFERÊNCIAS BIBLIOGRÁFICAS}

ALGARTE, J. P. - 1972. A influência dos arqueamentos cratônicos no condicionamento das alcalinas nos Estados de São Paulo e Paraná. In: Congr. Bras. Geol., XXVI, Belém, 1972. Anais... Belém, SBG, v.1, p.65-69.

AMARAL, G. - 1978. Potassium-argon age studies on the Jacupiranga alkaline district, State of São Paulo, Brazil. In: First Int. Symp. Carbonatites, 1. Poços de Caldas, 1978. Proceedings... Poços de Caldas. p.297-302.

ALMEIDA, F. F. M. - 1977. Condicionamento tectônico do magmatismo alcalino mesozóico do Sul do Brasil e Paraguai Oriental. An. Acad. Bras. Ci., 43:835836.

ALVES, P. R. P. C. (1999) -Estudos de Caracterização Tecnológica no Minério Apatítico do Complexo Alcalino de Jacupiranga, SP. 59p. Monografia de Trabalho de Formatura, Instituto de Geociências, Universidade de São Paulo.

CLARK, I. - 1979. The semivariogram - part I. Engineering \& Mining Journal, 180(7):90$94 \mathrm{p}$.

DAVIS, J. C. - 1986. Statistics and Data Analysis in Geology. New York, Wiley.

DERBY, O. A. - 1891. On the magnetite ore districts of Jacupiranga and Ipanema, São Paulo, Brazil. Amer. J. Sci., 41:311-321.

DEUTSCH, C. V. - 1996. Correcting for Negative Weights in Ordinary Kriging Computers \& Geosciences, v.22, no 7, p. 765-773. 
FERREIRA, F. J. F. \& ALGARTE, J.P. - 1979. O comportamento aeromagnetométricocintilométrico das principais rochas alcalinas dos Estados de São Paulo e Paraná. In : Simp. Reg. Geol., 2. Rio Claro, 1979. Atas... Rio Claro, v.2, p. 195208.

FROIDEVAUX, R. - 1993. Constrained Kriging as na Estimator of Local Distribution Functions, in Capasso, V., Girone, G. \& Posa, D., eds., Proceedings of the International Workshop on Statistics of Spatial Process : Theory and Applications. Bari, Italy, p. 106-118.

GASPAR, J. C. - 1989. Geologie et mineralogie du complexe carbonatique de Jacupiranga, Brésil. França. 344p. (Tese de Doutoramento. U. E. R. De Sciences Fondamentales et Appliquées, Université d'Orleans).

GASPAR, J. C. \& WYLLIE, P. J. - 1983. Magnetite in the carbonatites from the Jacupiranga Complex, Brazil. Amer. Mineral., 68:195-213.

GERMANN, A., MARKER, A. FRIEDRICH, G. - 1987. The alkaline complex of Jacupiranga, São Paulo, Brazil. Petrology and genetic considerations. Zbl. Geol. Paleont., 1(7/8):807-818.

HARBAUGH, J.W.; DOVETON, J.H.; DAVIS, J.C. - 1977. Probability methods in oil exploration. New York, John Wiley. 269p.

HERZ, N. - 1977. Timing of spreading in the South Atlantic : information from Brazilian alkaline rocks. Bull. Geol. Soc. Amer., 88:101-112.

HOULDING, S. W. - 1994. 3D Geoscience Modeling : Computer techniques for Geological Characterization. Springer, Berlin Heidelberg New York.

ISAAKS, E. H. \& SRIVASTAVA, R. M. - 1989. An Introduction to Applied Geostatistics: Oxford University Press, New York, 561 p. 
JOURNEL, A. G. \& HUIJBREGTS, C. J. - 1978. Mining geoestatistics. London, Academic Press. 600p.

JOURNEL, A. G. \& RAO, S. E. - 1996. Deriving Conditional Distributions from Ordinary Kriging : Stanford Center for Reservoir Forecasting (Report No 9), Stanford, $25 \mathrm{p}$.

KOCH JR, G. S. \& LINK, R. F. - 1971. Statistical Analysis of Geological Data. New York, Dover Publ. V. I, 375p.

LANDIM, P. M. B. - 1985. Introdução a Geoestatística. Laboratório de Geomatemática. Publicação Didática $n^{\circ} 3$. Instituto de Geociências e Ciências Exatas, Campus de Rio Claro. UNESP. 69p.

MELCHER, G. C. - 1954. Nota sobre o distrito alcalino de Jacupiranga, São Paulo. Div. Geol. Min., Notas Prelim., 84p.

MELCHER, G. C. - 1966. O carbonatito de Jacupiranga, São Paulo, Brasil, Boletim da Faculdade de Filosofia, Letras e Ciências Sociais da Univerdidade de São Paulo.

OLEA, R. A. - 1975. Optimum mapping techniques using regionalized variable theory. Kansas, Kansas Geological Survey, 137p. (Series on Spatial Analysis, 2).

OLEA, R. A. - 1991.Geostatistical Glossary and Multilingual Dictionary : Oxford University Press, New York, 175 p.

OLEA, R. A. \& PAWLOWSKY, V. - 1996. Compensating for estimation smoothing in kriging. In: Mathematical Geology, v. 28, n 4, p. 407-417.

POPOFF, C.C. - 1966. Computing reserves of mineral deposits: Principles and conventional methods. Washingtons, Bureau of Mines. 113p. (I.C. 8283). 
ROCHA, M. M. - 1999. Estudo Comparativo entre os Métods Computacionais de Avaliação de Reservas e Controle de Teores da Mina de Capanema, Santa Bárbara, MG. São Paulo, 80p. Dissertação (Mestrado), Instituto de Geociências, Universidade de São Paulo.

RODEN, M. F., MIURTHY, V. R., GASPAR, J. C. - 1985. Sr and Nd isotopic composition of the Jacupiranga carbonatite. J. Geol., 93:212-220.

ROYLE, A. G. - 1979. Why geostatistics? Engeneering \& Mining Journal, 180(5):92101.

SAMESHIMA, R.H. - 1995. O erro geométrico na avaliação de reservas do minério residual de fosfato do Complexo Alcalino de Anitápolis-SC. São Paulo, 105p. Dissertação (Mestrado), Instituto de Geociências, Universidade de São Paulo.

SIDES, E. J. - 1997. Geological Modeling of Mineral Deposits for Prediction in mining. Geologische Rundschau. V.86, 2.

SPIEGEL, M. R. - 1994. Estatística. São Paulo, $3^{\text {a }}$ ed.Macron Books. 580p.

VALLÉE, M. \& CÔTE, D. - 1992. The Guide to Evaluation of Gold Deposit Evaluation and Reserve Inventory Practices. CIM Bull., 85(957):50-61.

WACKERNAGEL, H. - 1995. Multivariate Geostatistics. Springer, p.262.

YAMAMOTO, J. K. \& BETTENCOURT, J. S. - 1992. Avaliação de Reservas. Apostila do curso de pós-graduação. 113p.

YAMAMOTO, J. K. - 1991. Comparação de métodos computacionais para avaliação de reservas : um estudo de caso na Jazida de cobre de Chapada, GO. São Paulo. 175p. (Tese de Doutorado apresentada ao Instituto de Geociências - USP). 
YAMAMOTO, J. K. - 2000a. Métodos Computacionais $/ n$ : YAMAMOTO, J. K. -2000. Avaliação e Classificação de Reservas Minerais. Cap. 6. (Inédito)

YAMAMOTO, J. K. $-2000 \mathrm{~b}$. An Alternative Measure of the Reliability of Ordinary Kriging Estimates In : Mathematical Geology, vol. 32, nº 4, p. 489-509.

YAMAMOTO, J. K. \& BETTENCOURT, J. S. - 1992. Geoestatística Aplicada. Apostila do curso de pós-graduação. 182p.

YAMAMOTO, J. K., BETTENCOURT, J. S., MONTANHEIRO, T. S. - 2000. Análise Estatística In : YAMAMOTO, J. K. - 2000. Avaliação e Classificação de Reservas Minerais. Cap. 3. (Inédito)

YAMAMOTO, J. K. \& ROCHA, M. M. - 2000. Análise Geoestatística Estatística In : YAMAMOTO, J. K. - 2000. Avaliação e Classificação de Reservas Minerais. Cap. 4. (Inédito) 